


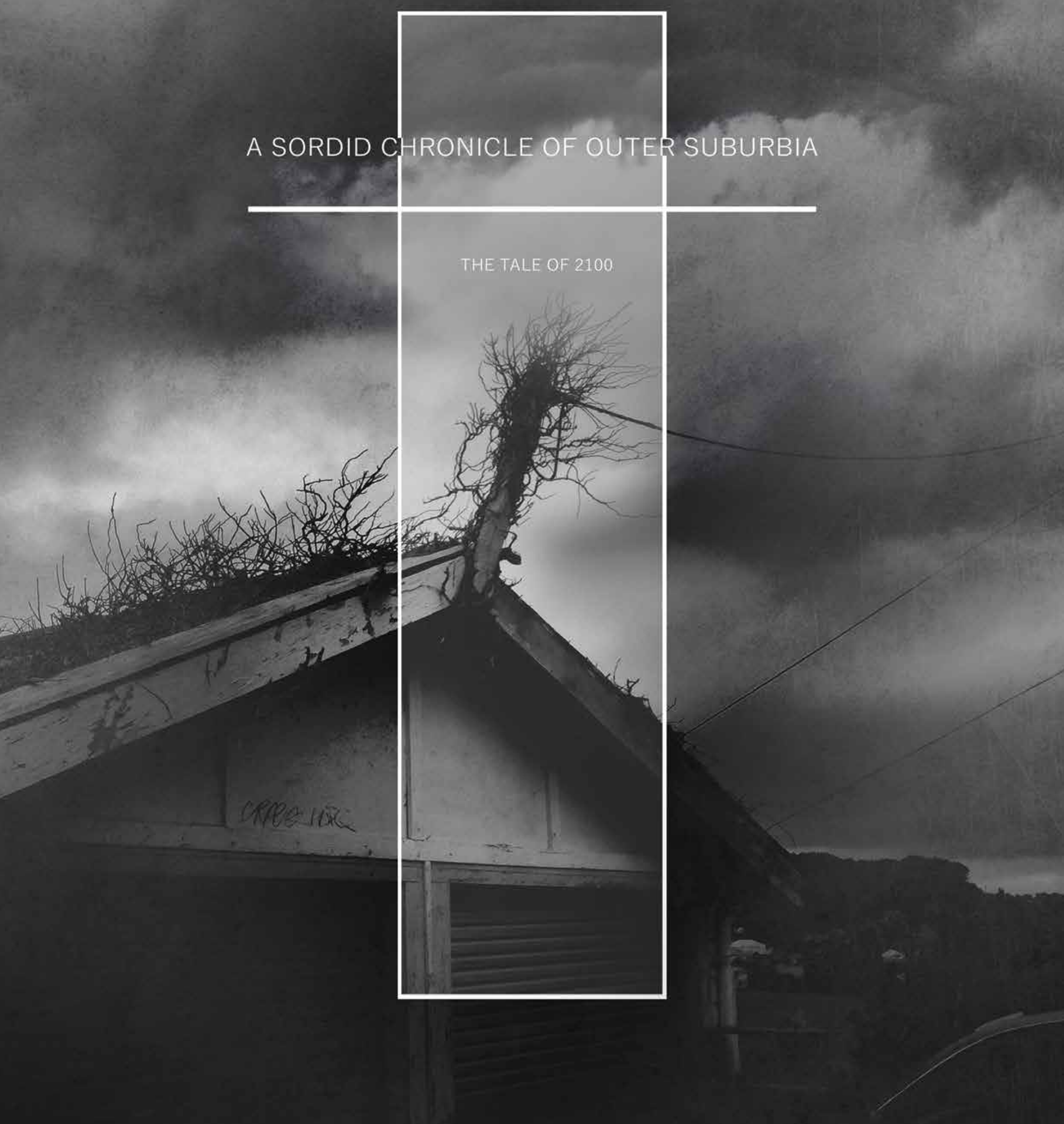





\title{
A Sordid Chronicle of Outer Suburbia
}

The Tale of 2100

\author{
A 120-point thesis submitted to the \\ Victoria University of Wellington \\ in partial fulfilment of the \\ requirements for the degree of \\ Master of Architecture \\ (Professional).
}

Victoria University of Wellington

School of Architecture

2016

By

Ashton Dooley

d 
iv 


\section{Acknowledgements}

I would like to sincerely offer my thanks to all the wonderful people in my life who have accompanied me throughout my architectural endeavours.

To my supervisor Fabricio Chicca, for your continued enthusiasm and astute guidance that has made this year exceed all my expectations.

To my family for their unyielding support, who without which all of this would not be possible. 
$\overline{v i}$ 


\section{Abstract}

A reflection on worldly trends arouses the question as to what new attributes our Earth will manifest in the next 85 years by 2100 . What effects have we wrought in a lifetime of procreation, consumption and production? With the continual expansion of our population, the sprawling and polluting, reports are depicting a negative future as the climate continues to alter. The effects of this change is most critical for those bound by coastal edges as the sea rises to claim what is now usable land. This thesis looks at one such area, Wellington, New Zealand. The city is dictated by the sea and sprawl inland is not a resolute solution.

This thesis proposes that a sea-based kinetic suburb can improve upon the sordid living conditions predicted for 2100 through adaptive and responsive design. By exploring a vision of the year 2100 that has been defined by the implications of excessive suburban sprawl, in alignment with extreme environmental conditions, this thesis proposes how coastal bound communities can survive in anthropogenic aftermath. It argues that with mobile apartment towers suited to the ocean, socialisation and connectivity within a suburban area can be increased whilst still resisting new climatic demands. This research offers informed insight into the future evolution of living in considering both past and present trends; defining a new chapter for suburbia and a typology that is more flexible and convivial. 


\section{Preface}

"There was some other thing that we could not clearly explain. The further we ventured, the more everything looked the same, as if each new street, park or shopping mall was simply another version of our own, made from the same giant assembly kit."

- 'Tales from Outer Suburbia', Shaun Tan, 89.

My passion for art met architecture when reading this book. What stimulated me was those moments where a picture tells a thousand words. I was inspired by the eccentric tales of backyard missiles and hidden courtyards; which got me thinking as to what can and can't be a reality.

Predicting the future is not a science. It comes from beliefs you hold and a reflection on information received. I wanted to create a reality that inspired a proactive response; one that reflects the seriousness of the data and facts pertaining to our future Earth's wellbeing. 


\section{Contents}

$\begin{array}{ll}\text { Acknowledgements } & v \\ \text { Abstract } & v i i \\ \text { Preface } & \text { ix }\end{array}$

CHAPTER 1 : DeSIGN INTENT
Research Question
Project Mission
Justification for Designing to a Worst Case Scenario
- War as an Unforeseeable Variance
- Case Study: Sea Level Rise in Wellington
Site Selection

Chapter 2 : Setting a Scene and NeEd for Design

Climatic Change

13

- Coastal Danger

- Sea Level

- Temperature

- Rainfall and Other

- Summary

Greater Wellington Context

- Sea Level Rise

- Liquefaction

- Wind

- Global Population

- Wellington's Population

- Suburban Sprawl

- Expectancies

Setting the Programme

- A Home

- A Heart

Contemplating The Past

- Plug-In City

- Walking City

Interpreting The Future

- Citadel Skyscraper

- Polar Umbrella

Summary 
The Contemporary Sublime

- The Contemporary Sublime

- Smart Architecture

- Conclusion

Application

Predictions

Application - 2100 Predictions

Summary

Horokiwi 2100

Facilities 


\section{Chapter One}

Design Intent 


\section{Research Question}

The primary question for this thesis is;

- In considering a chronological investigation of the implications of a disintegration in acceptable living conditions, how can coastally defined locations accommodate and prolong life within an dystopian future?

This raises a supplementary question that is also explored;

- What are the implications of alternative suburban living situations socially, aesthetically and on the environment? 


\section{Project Mission}

This thesis presents a vision of the year 2100 as set by the precursors of modern day. It channels three main dystopian concepts; sordid living conditions, population surplus and land deprivation so as to depict a final effort to preserve life with adaptable architecture. The investigation is informed from analysing pessimistic empirical data; establishing a worst case scenario which will account for contingencies in human actions, ethics and economies from now to 2100. 2100 is far enough in the future that there will be a greater need for climate-adapting architecture, where smarter technologies will help achieve resilience.

The exploration of suburban boundaries and the effects of sordid manipulations of living environments will focus around the intervention of a kinetic suburb that's adaptable to this worst case scenario; consisting of apartment towers and green spaces for those who have lost their homes in the onslaught of worsening weather, or who wish to join a more sociable suburb. The intervention is located where the outer suburbs of Wellington and Lower Hutt are set to collide. Through exploring a vision of Wellington's future, the intervention proposes that we must learn to adapt architecturally to the sea rising.

The aim is to re-establish and improve upon acceptable living conditions forecasted for 2100 . To achieve this three objectives have been set;

1 - Provide a stable and enduring sanctuary in a dismal setting.

2 - Adapt to worsening climatic demands and prolong life.

3 - Offer informed clairvoyance into the future evolution of living. 


\title{
Justification for Designing to a Worst Case Scenario
}

\author{
"Let us expect the worst, and then we shall not be \\ disappointed."
}

- Sherwood, 176.

We need to prepare ourselves for the worst case scenario because, as time has told, predictions are flimsy. While we can prepare to some degree for the scenarios dictated by climatic reports, we know the future is non-linear, where an unexpected event can offset a planned and thorough timeline.

Climatic reports offer percentiles of likeliness rather than offering one definitive answer, with the final results of each simulations being displayed in 5, 50 and 95 percentiles. The 95th percentile states that $95 \%$ of the time, the level is below this amount. The remaining $5 \%$ of the time, the level is above that amount (Dijker). This thesis takes the data in the 95th percentile to understand a worst case scenario. This is because if any other percentile was designed for and the 95 th percentile is realised, then the outcome may not survive the pressure of the climatic difference.

The value in exploring extremely pessimistic conditions comes from the truth that some variables cannot be modelled. Reactions by humans to inevitable changes in our societies, technologies, ethics and economies impose ambiguity, and simply cannot be accounted for. Examples of societies that could not predict their downfall are explained in 'Collapse' by Jared Diamond; such as the Easter Islander's who experienced eventual deforestation, which then instigated a population crash from starvation as the entire island relied on wood for materials/food production; and the Mayans, who after having all their land occupied and thus nowhere to relocate to in droughts, were believed to have engaged in warfare over resources to inevitably destroy life.

\section{War as an Unforeseeable Variance}

The biggest influence that cannot be accounted for in models is war. The World Wars undeniably altered our way of thinking and sparked technological advancement. With record fatalities 
from terrorist activity in 2014 (Fig 1.03) and a devastating series of invasive attacks at the end of 2015, there is no assurance that we are safe from future wars.

A further refinement of nuclear warfare could prove more detrimental to the environment than first thought. Jeffery Masters explains how papers from 2008 suggest that the papers of the 1980s which investigated climatic effects from nuclear war to be optimistic; with temperatures shown to plummet as the dust/debris blocks the sun. A nuclear war would likely deplete the stratospheric ozone layer, decimate ecosystems and fashion mass extinction (Starr).

As the climatic effects of war are considered an unforeseen outlier, they are not modelled in climatic reports. For that reason, designing for the worst case scenario is seen as the most appropriate as it accounts for the most climatic possibilities.

Deaths from terrorism have increased dramatically over the last 15 years. The number of people who have died from terrorist activity has increased ninefold since the year 2000.

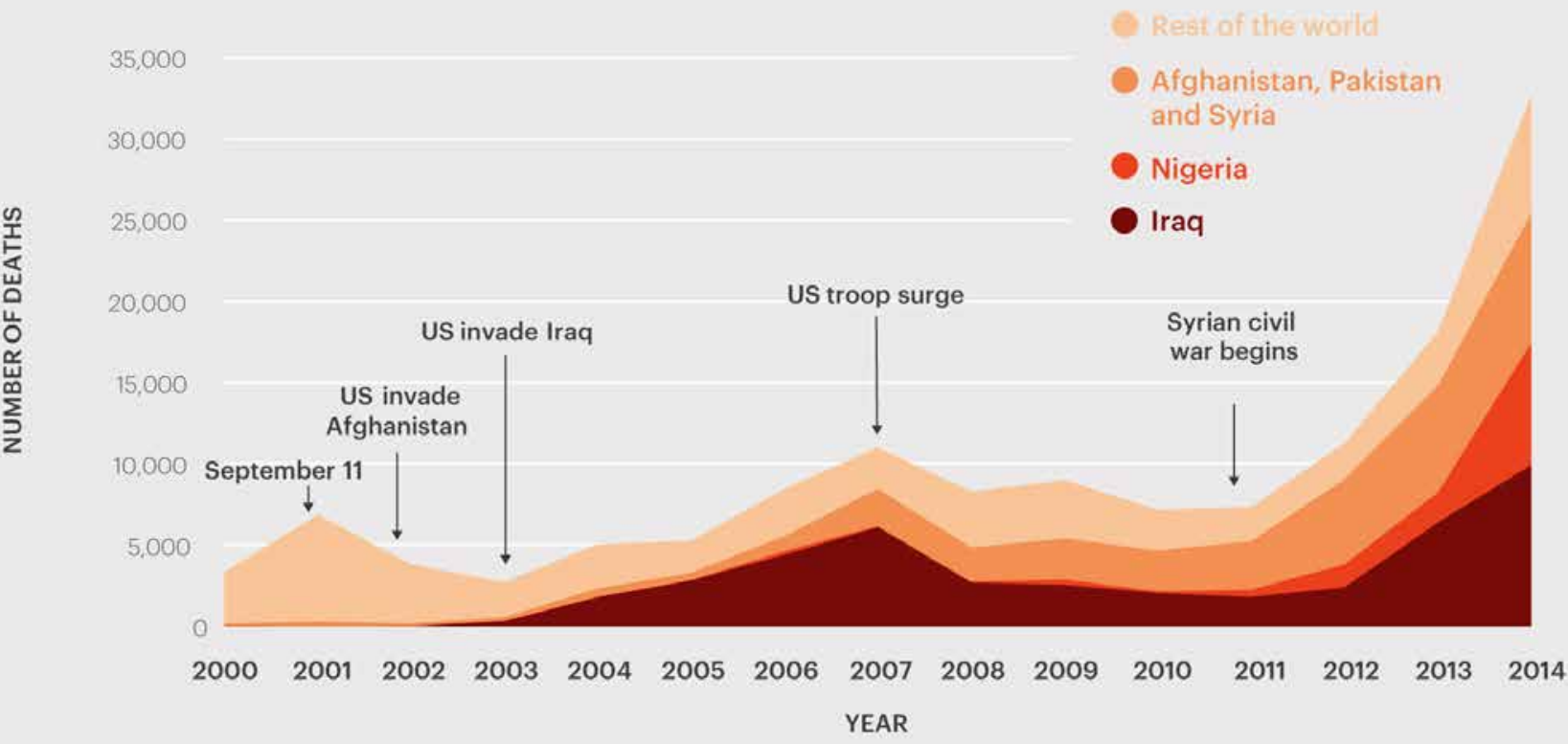




\section{Case Study: Sea Level Rise in Wellington}

A 2012 New Zealand study by Evans, Milfont and Lawrence on sea level rise (SLR) in the greater region of Wellington presented different intensities to different residents and asked for their opinions on associated issues. They showed groups either the predictions for 2050 or 2100, and SLR in 'moderate' or 'extreme' cases.

When exposed to the extreme conditions, the participants were found to show increased levels of support for adapting to climate change and for implementing adaptation options discussed within the survey.

This subject-appropriate case study proves that the worst case scenario would elicit a greater response and support for adaptive architecture. It shows that visually presenting futuristic interpretations is vital for symptoms of dystopia to be planned for now and to provoke some form of action. 


\section{Site Selection}

The setting for this investigation and research is to be New Zealand. The specific site is where Wellington and Lower Hutt are expected to collide; around the suburb of Horokiwi.

A proposed coastal site like this is imperative to the vision as coastal cities are prone to climate change effects through rising sea levels and more severe storms (Anderson, Balk, McGranahan 17). This suggests they will be first to act in response. Wellington is defined by water and the terrain dictates the path of sprawling. It has a restricted amount of viable land available for development, offering a relatable situation applicable to many other coastal environments.

Additionally, this site under a extremely pessimistic lens would still offer a chance for life to prevail. Liu and Allan examined $30+$ climatic change experiments to confirm that drier regions are set to get dryer and wetter regions get wetter preceding 2100. This alludes to monsoonal rains for particular areas of the world in a worst case scenario. These violently wetter areas would not be logical for a sea-based intervention for human survival.
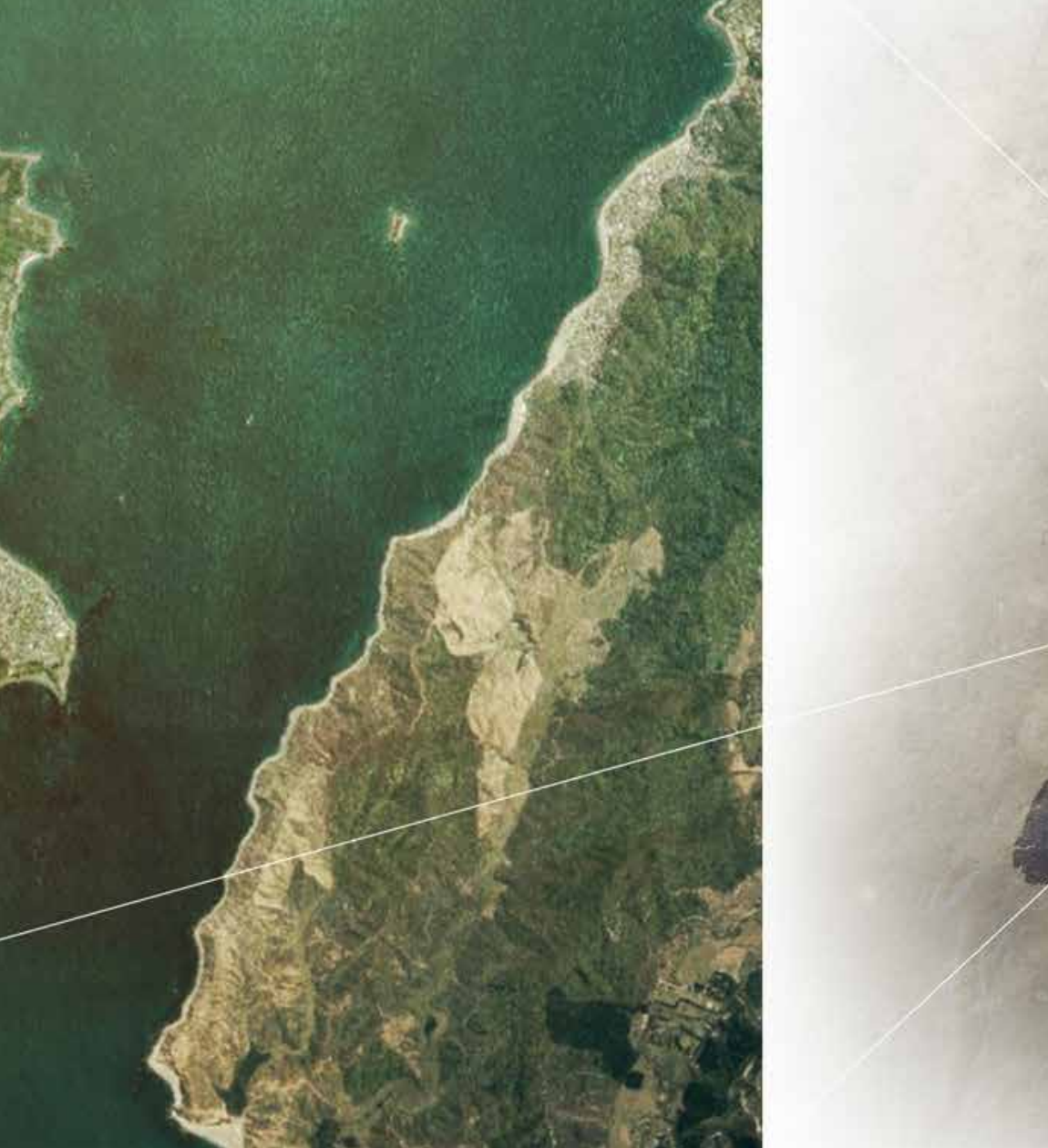


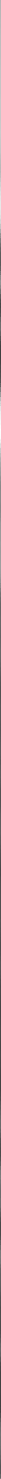




\section{Chapter Two}

Setting a Scene and Need for

Design 
This chapter establishes the worst case scenario for 2100 through research. It looks at what the climate is suppose to be like with a negative perspective, both globally and locally. Through exploring this information, the need for an adaptive response is emphasised. 


\section{Climatic Change}

Coastal Danger

The low-elevation coastal zone (LECZ) is characterised as a contiguous area with the coast that is also less than $10 \mathrm{~m}$ above sea level (Anderson, Balk, McGranahan 17). These areas are highly populated because of the appeal in resources the sea and coastal environments can offer. Logistically colonising by the seas for marine and transport opportunities, aesthetic value and recreation lay as the foundation for the growth of many major cities (Neumann et al.).

The density of the LECZ population from 2000 was documented to reach beyond five times the average global mean in a report by Vafeidis Neumann (et al.). This shows that many people are going to be at risk as density intensifies as we go closer to the shoreline. The same report estimated that the LECZ population will reach nearly $1.4 \mathrm{~b}$ in the worst case scenario by 2100 , more than doubling from 2000.

\section{Sea Level}

Low probability but high impact scenarios (worst case scenarios) are used by many nations to evaluate the extent to prepare for potential coastal adaptation. However this impact (the upper limit of SLR) is not a common agreement. Various sea level effecting factors, like glaciers and continental contribution, are taken into account in different simulations to produce an array of possibilities. This is where the percentiles of likeliness are provided to cover the variety of potential outcomes. 
The 2014 Fifth Assessment Report from the Intergovernmental Panel on Climate Change (IPCC) has SLR for 2100 reaching a maximum of $0.8 \mathrm{~m}$ in a worst case scenario. Although this document is extremely credible for involving over 800 scientific authors in its data exegesis, it was not the highest value anticipated. The following list shows various reports and the highest level considered for SLR planning. From this series of extremes, a $2 \mathrm{~m}$ rise is the value projected for Wellington, with an additional $1 \mathrm{~m}$ storm surge allowance.

- 1.1m - 2008 Delta Commission (Vellinga, P et al.).

- 0.8m - 2014 Fifth Assessment Report from IPCC (Church, J et al.).

- 1.4m - 2009 Scientific Committee on Antarctic Research (Turner, J et al.).

- 1.6m - 2012 Arctic Monitoring and Assessment Programme.

- 1.5m - 2011 US Army Corps of Engineers.

- 2.0m - 2012 US National Climate Assessment (Parris, A et al.).

- 1.9m - 2009 United Kingdom Climate Impacts Programme (Lowe, J et al.).
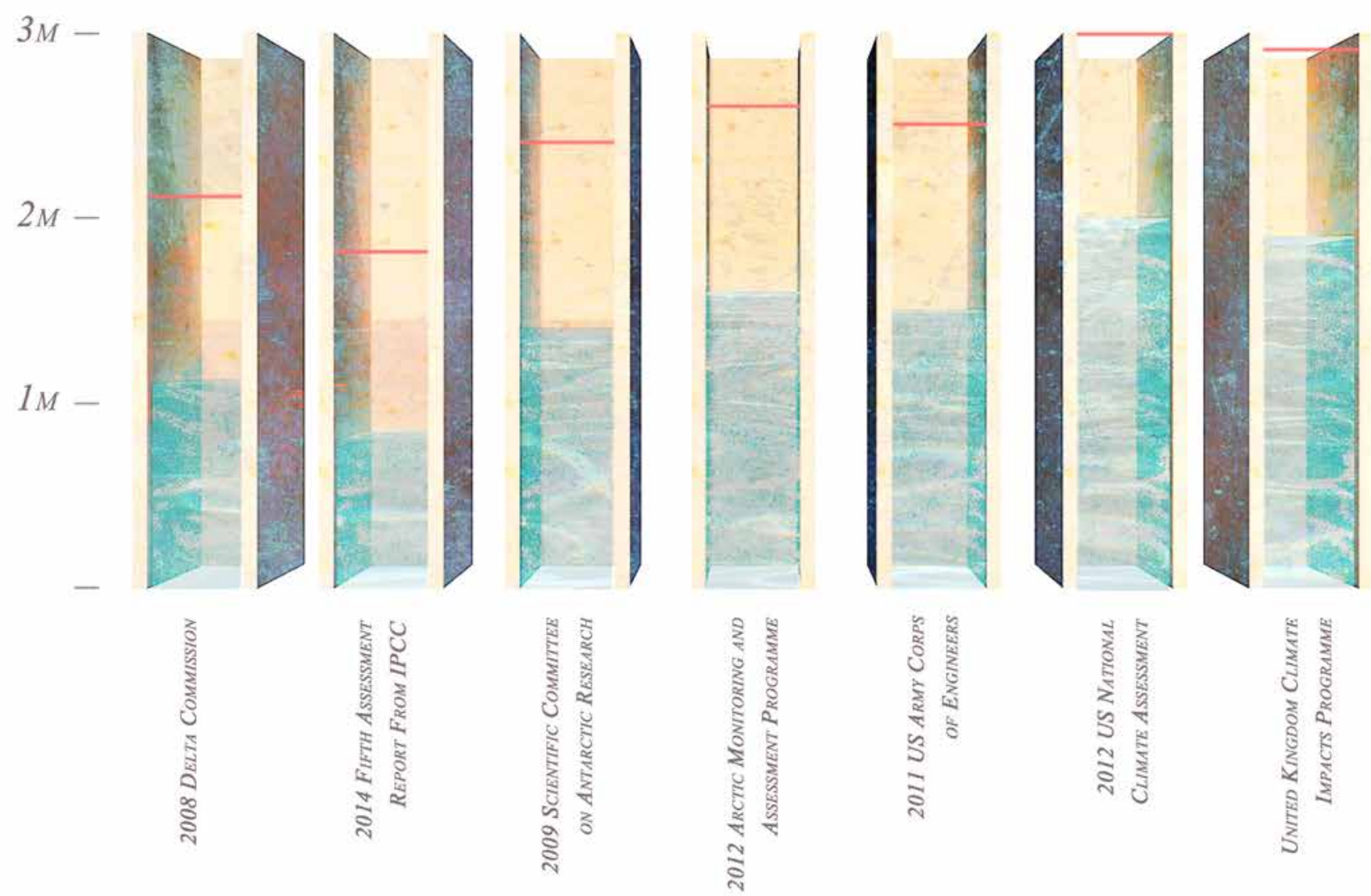


\section{Temperature}

Unlike SLR which is monitored by many, the IPCC reports are the go-to credible source for temperature data and predictions. The global average predicted for the year 2100 from the 5 th IPCC report is $4^{\circ}$. The worst case scenario produced a rise of $4.8^{\circ}$ and thus will be considered (Stocker et al. 23).

Although there are New Zealand specific interpretations of the IPCC's 4th assessment from back in 2007, the maximum of $5.1^{\circ}$ (Wratt, Mullan) in this case is seen as outdated.

\section{Rainfall and Other}

The atmosphere can retain $8 \%$ more moisture with each degree of warming (Renwick et al. 5) and so with this $4.8^{\circ}$ rise established, extreme rainfalls can be projected to increase by $38 \%$ across the country. In relation to the rain's magnitude, tempestuous storms, flooding and cyclones are to be more common - but due to data not being New Zealand specific, predictions of their frequency are unknown.

\section{Summary}

This data establishes a climate to be considered by the intervention. The SLR is the most tangible and important notion to design for, leaving increasing storms and temperatures as a consideration to bear in mind for the Wellington context. 


\section{Greater Wellington}

\section{Context}

\section{$\underline{\text { Environment }}$}

\section{Sea Level Rise}

Wellington's City Council (WCC) recognises that climate change and SLR is imminent and has undertaken research into the impact socially, environmentally and economically. Tonkin \& Taylor Ltd provided a report for the WCC in 2013 outlining all these impacts. The report looks at solutions and weighs up the risks/benefits for each situation.

The map within this report portrayed various levels of SLR where the areas affected worst were the Central Business District (CBD), Kilbirbne and Miramar. It also showed the primary connection route for all modes of transport in and out of the city (SH2) being claimed by the ocean. These facts are portrayed in Fig 2.03.

Sea walls were modelled within a $1.5 \mathrm{~m}$ rise scenario and showed that the water could be restrained to an extent. However this is only a temporary fix and coupled with the effects of liquefaction would mean the $\mathrm{CBD}$ shoreline is unsafe for occupants and future developments. 


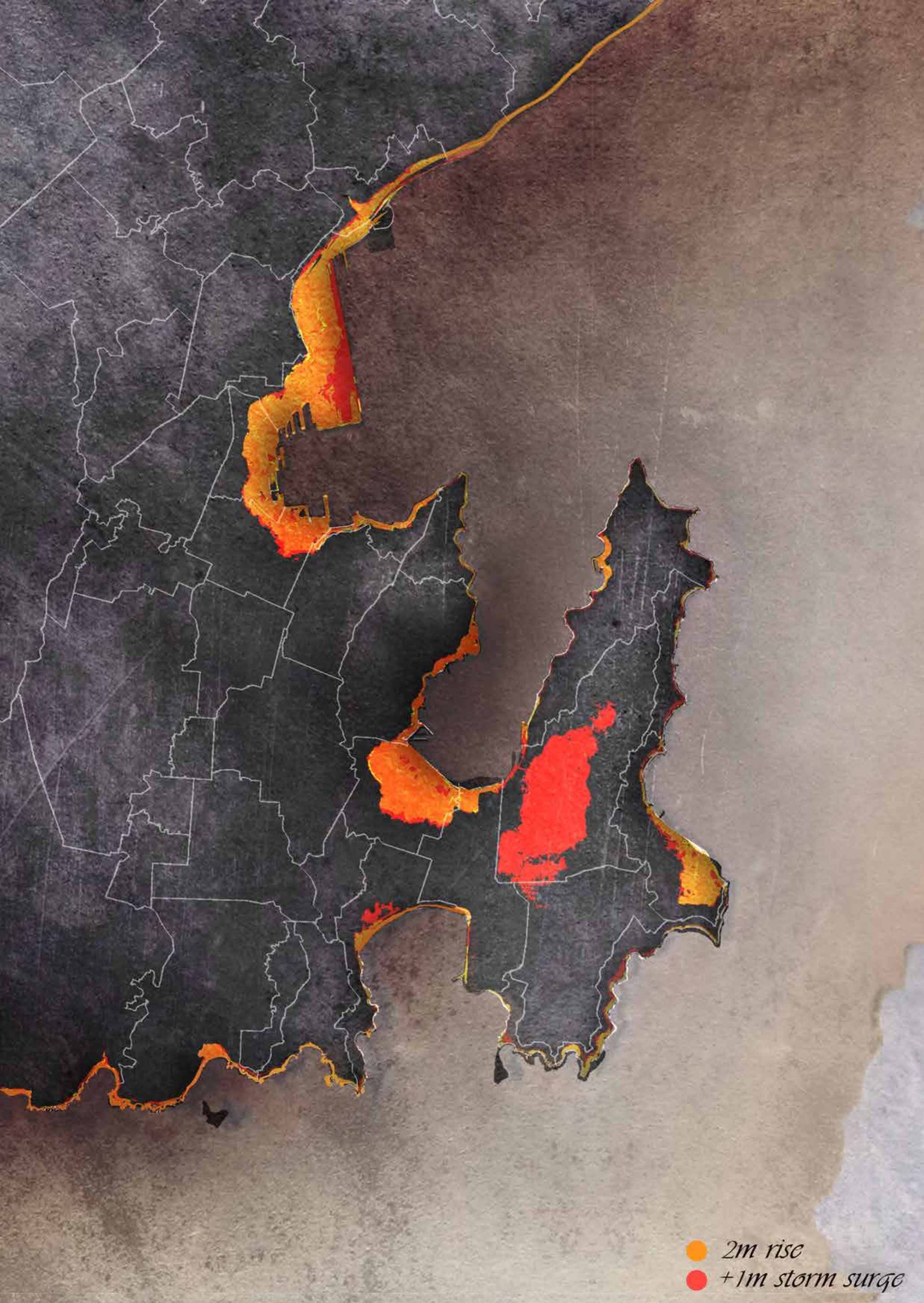




\section{Liquefaction}

Liquefaction is a condition that can be exacerbated from the increase in ground water levels that are correlated to SLR (Tonkin \& Taylor Ltd, 8). Liquefaction occurs during earthquakes where the composition of the soil's sand and water is re-arranged. This makes areas weaker; where sinking and moving effects infrastructure. Fig 2.04 shows Wellington's waterfront (built on reclaimed land) as highly susceptible, meaning that a large quake after the seas have risen could leave this area condemned. This could call for a housing crisis in a worst case scenario.

\section{Wind}

With temperatures reaching the highest levels around the Equator, there will be low pressure in contrast to the high pressure of the poles. As wind moves from high to low, the position of New Zealand makes them susceptible to the Roaring Forties (or westerly winds) that will increase in ferocity with an expanding difference in pressures. The Cook Straight (flanking Wellington) funnels this wind through a small gap and velocity increases. Wellington can, for this reason, be predicted to experience more frequent winds and storms. This is problematic when already in 2015 the areas in red in Fig 2.05 are considered 'high wind zones' for building compliance. 
Eiguefaction ¿̌ones

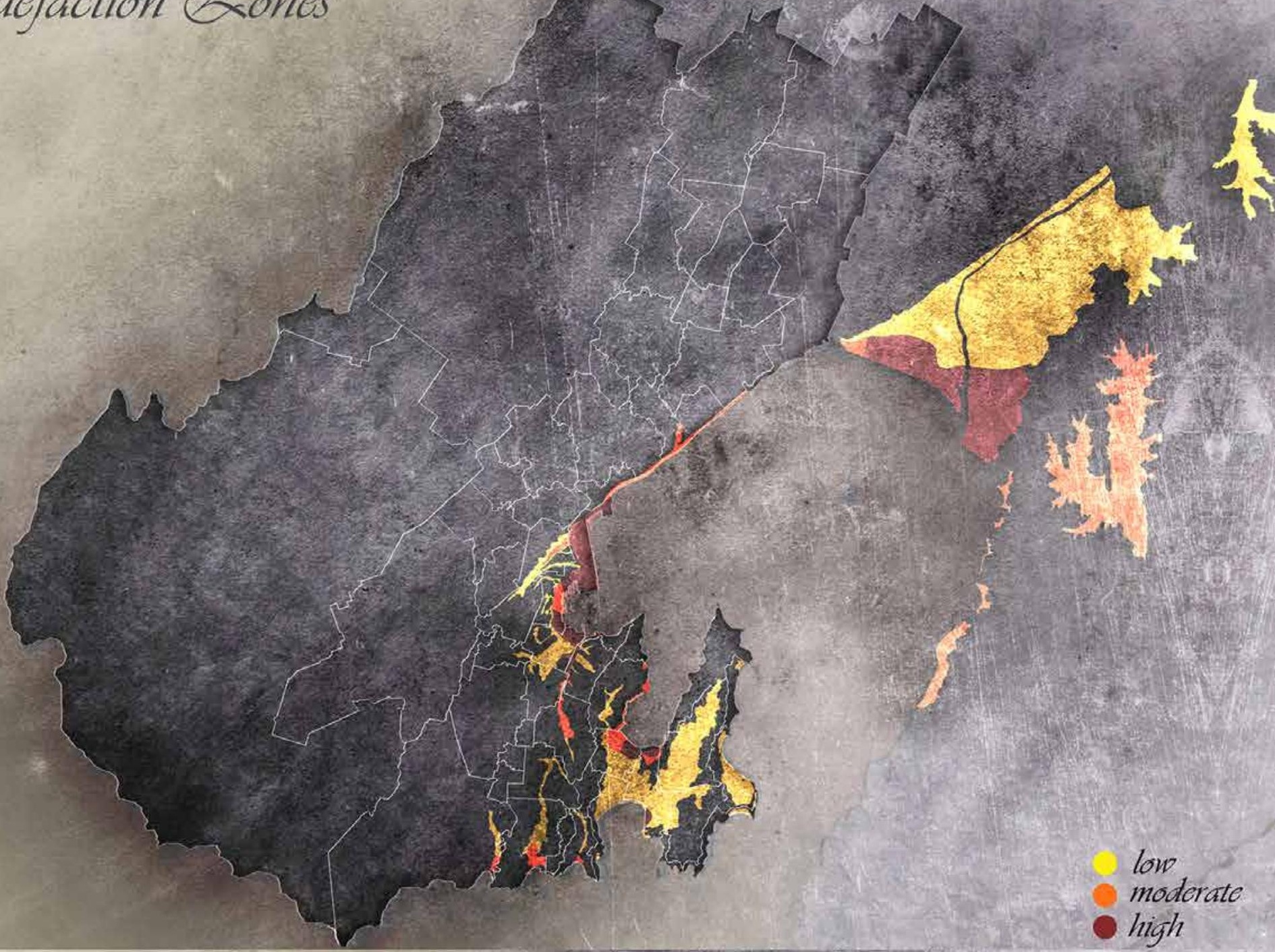

Dind ๔̌ones
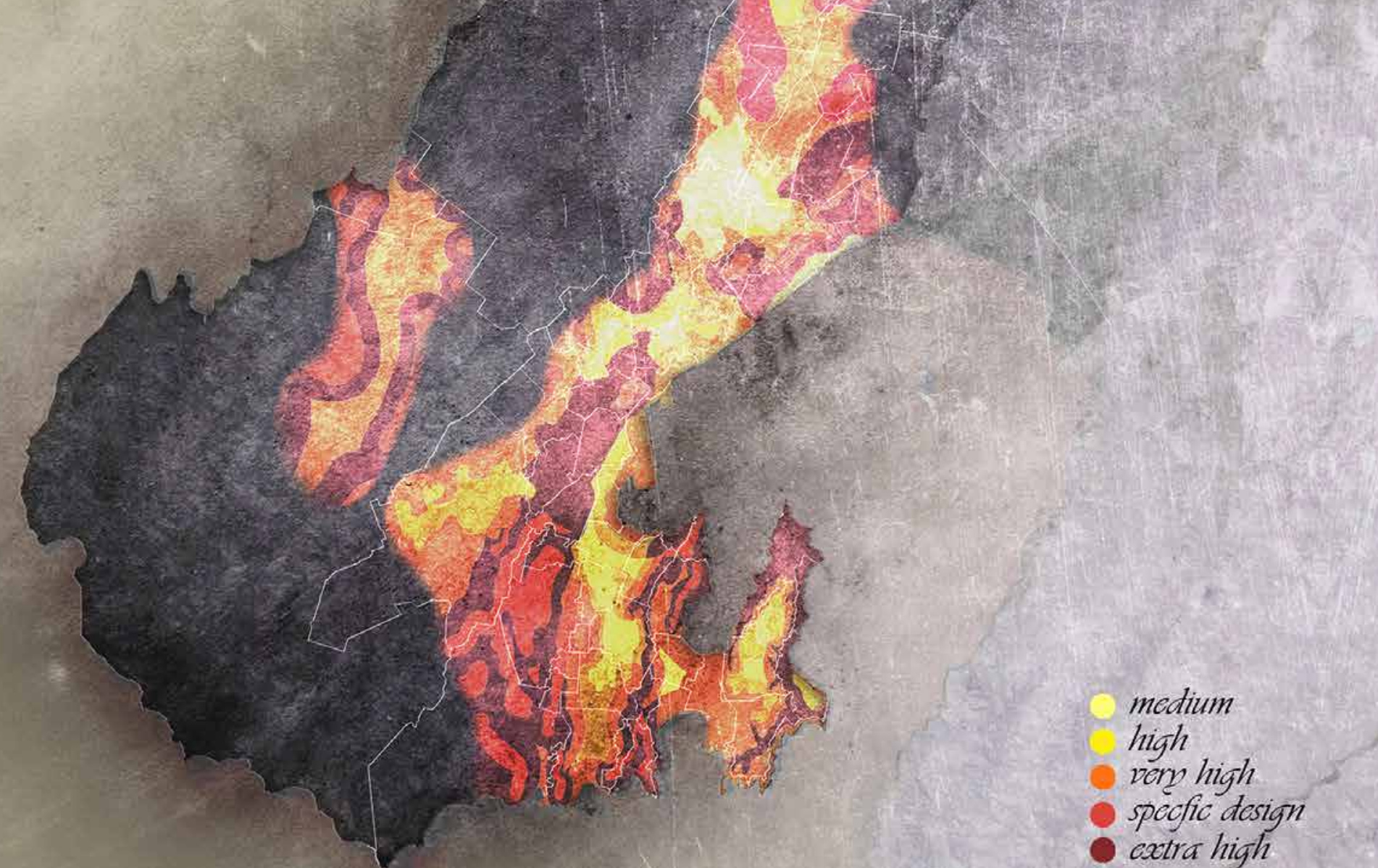


\section{Populace and Typology}

\section{Global Population}

UN World Population Prospect for 2015 reports a continual population growth to the year 2100. This encompasses not simply an overall increase but continental differentiation like Africa increasing immensely, Asia remaining fairly constant and Europe slightly declining (Fig 2.06). It also reports that the estimate for stabilisation or an overall decline in the population to occur late in the century is around $23 \%$.

What this data indicates is that while Oceania are not high contributors to the world's population, particular continental overpopulation has the potential to shift where people live as densities reach unlivable limits. This fact helps establish a scenario for Wellington in 2100 where it appears a great place to move to for overseas populations.

For the purpose of this thesis it is summarised than Wellington's population, like the rest of the world's, will increase. This will be due to the country's localised growth and additional immigrants. The following paragraphs investigate purely a localised growth for Wellington, based off information from Forecast.id NZ to provide a rough estimate of houses that will be needed for 2100. Non-inclusive of unpredictable immigration numbers, this information helps provide justification for sea-based architecture as a unrealised liveable space.

\section{Wellington's Population}

Forecast.id NZ states the population as 200,420 as of 2013 and expects it to reach 246,693 by 2043; an increase of $23 \%$ in 30 years. From the increasing increments this website provided, the predicted number of people in Wellington for 2103 is 401,857 (Fig 2.10, page 23); a 200\% increase in 100 years. This information is crossed with dwelling expectancies to figure out how many new dwellings the Horokiwi and Newlands suburbs can expect. 


\section{(1)evelopment forecast}

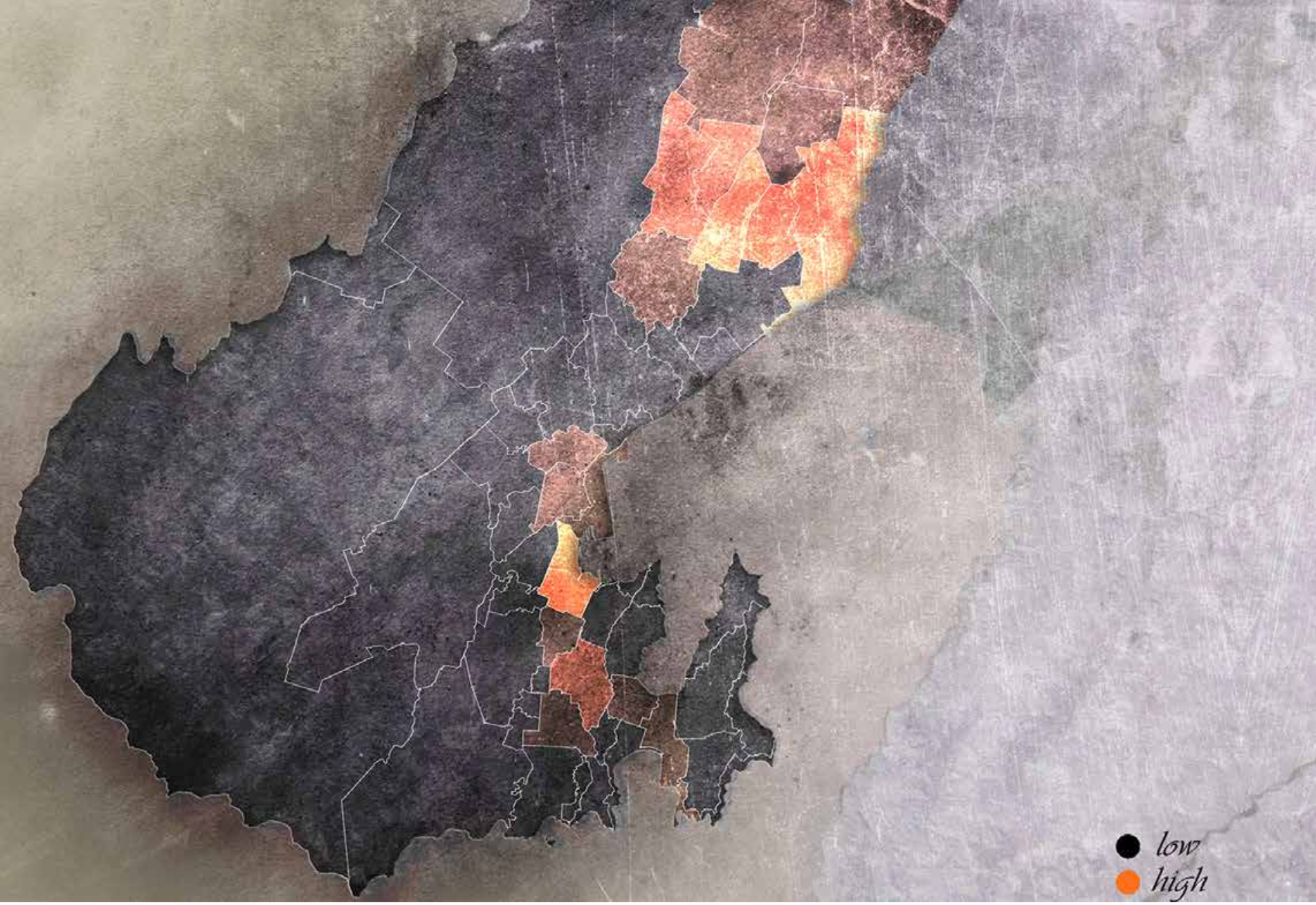

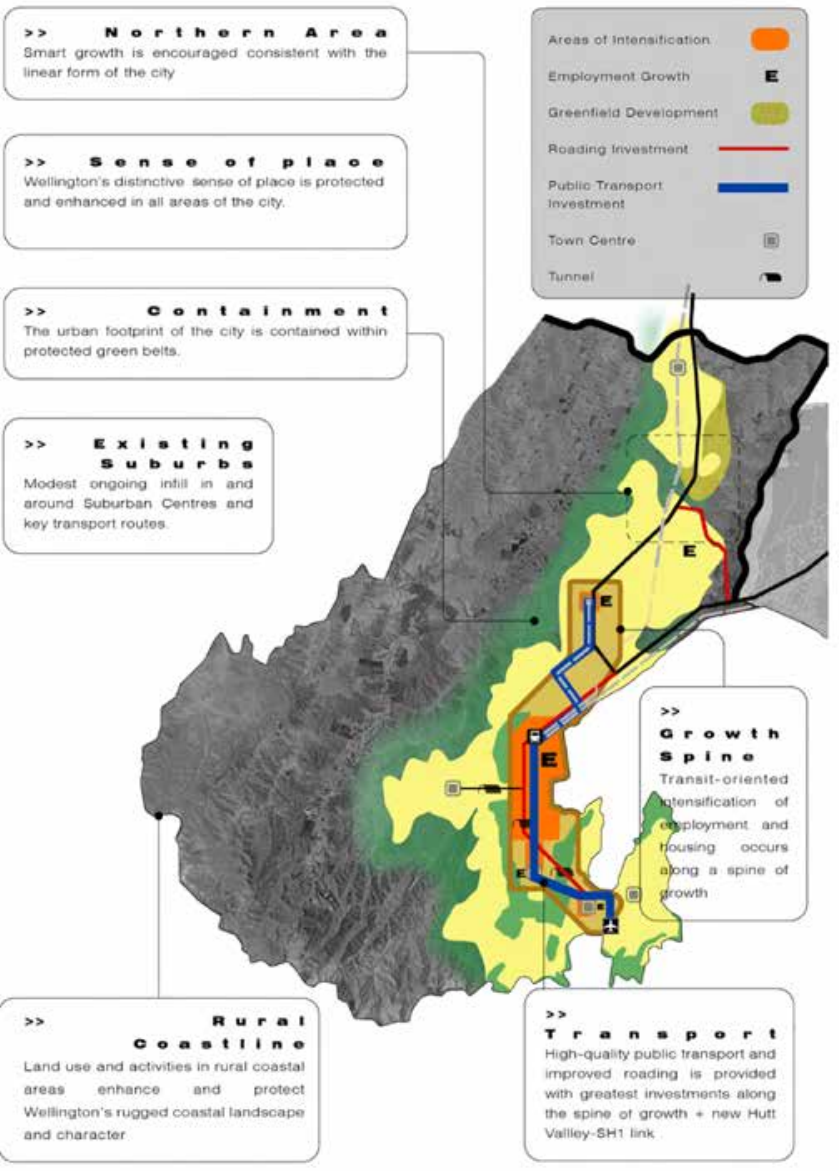

\section{Suburban Sprawl}

The WCC put forth a 50 year growth plan map (Fig 2.08) back in 2006 depicting where Wellington is forecasted to grow as a logical progression. This map shows developments extending out into Horokiwi and Newlands.

Crossing this map with the forecast for dwellings from Forecast.id NZ (mapped in Fig 2.07) proves that these areas will grow rapidly. The forecasts have Newlands (which is nearly completely utilised already) increasing dwelling numbers in 2043 by $19.6 \%$, and Horokiwi by $67.3 \%$. This is the highest of any area forecasted other than the $\mathrm{CBD}$.

With respect to the potential destabilisation of the $\mathrm{CBD}$, it is unlikely that there will be continual development of apartmentstyle housing in this area because New Zealand's legislation generally aims to avoid, remedy or mitigate risks from natural hazards with a precautionary approach (Tonkin \& Taylor Ltd, 34). Moving to more stable ground for developments leaves Horokiwi as a prime candidate in light of this. 


\section{Expectancies}

Taking the information on new dwellings and crossing it with the estimated population for Wellington, the number of dwellings expected to be built in Horokiwi and Newlands was estimated for 2103 (data started from 2013). Fig 2.10 shows these numbers, where the number of dwellings in these two areas alone is estimated to nearly double; easily merging with Lower Hutt with the addition of their growth.

Newlands as of 2013 has 2742 dwellings, which is outlined in Fig 2.08. The solid blocks then show the area consumed by the predicted amount of new dwellings (three times as much) for Newlands and Horokiwi. With the growth of other suburbs as well, a collision is imminent. These suburbs have some of the lowest land prices in Wellington, meaning once the inner city is full, the development of these areas is viable regardless of their distance from the $\mathrm{CBD}$.

With developments occurring out in these suburbs, the aforementioned connection between State Highways is expected. The construction of this connection is believed to pass through the Horokiwi quarry upon its closure as developments inevitably fill the suburb. The number of houses estimated helps set the scene for the 2100 site's appearance. An analysis and visual prediction for this site are excogitated later (Chapter Five).

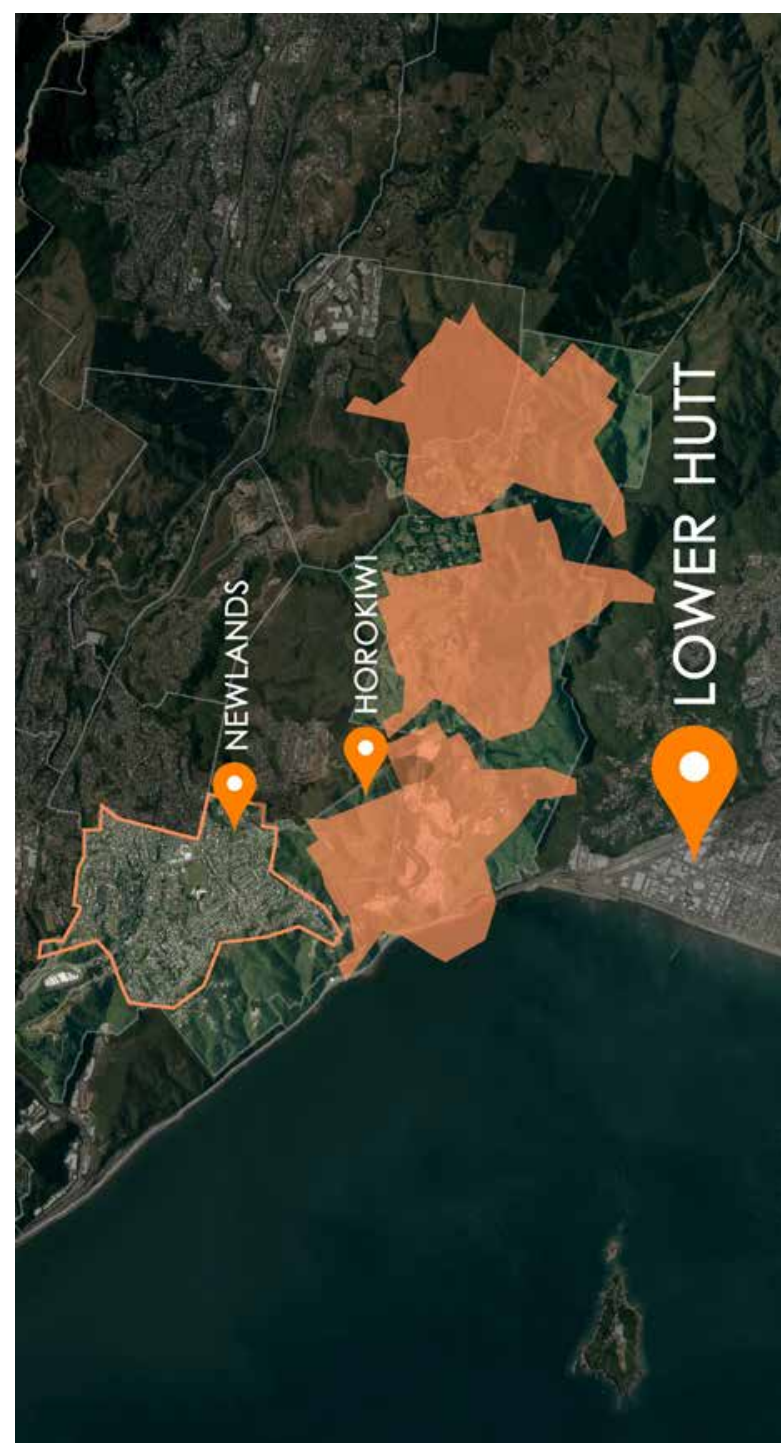

Fig 2. 09. Depiction Map of Newland's Predicted Growth. 


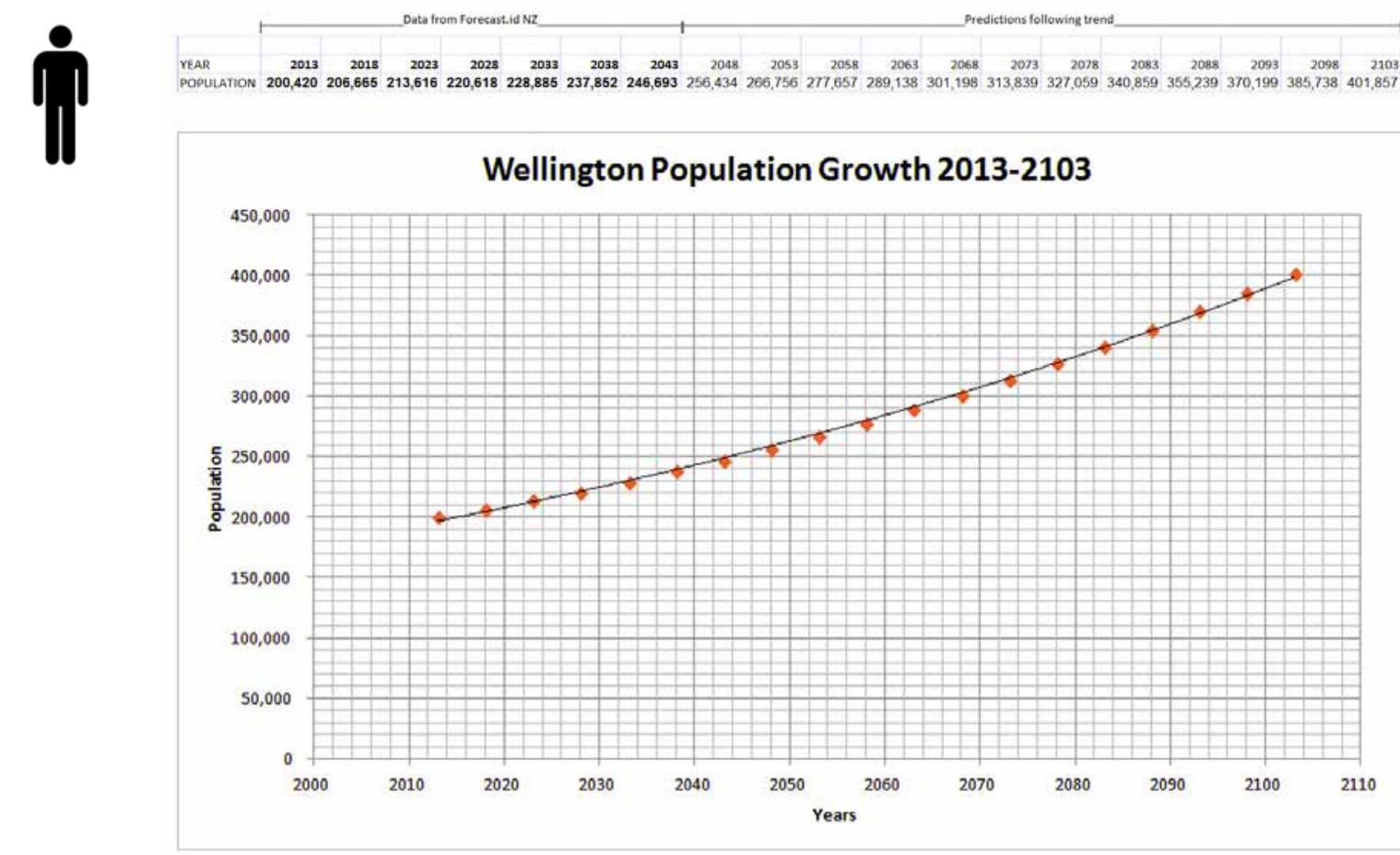

Fig 2. 10

Graph of

Wellington's

Population Growth.

Infomation on population for Wellington (from Forecast.id NZ)

Poluation growth 2013 and 2043

Houses built between 2013 and 2043

People per Household

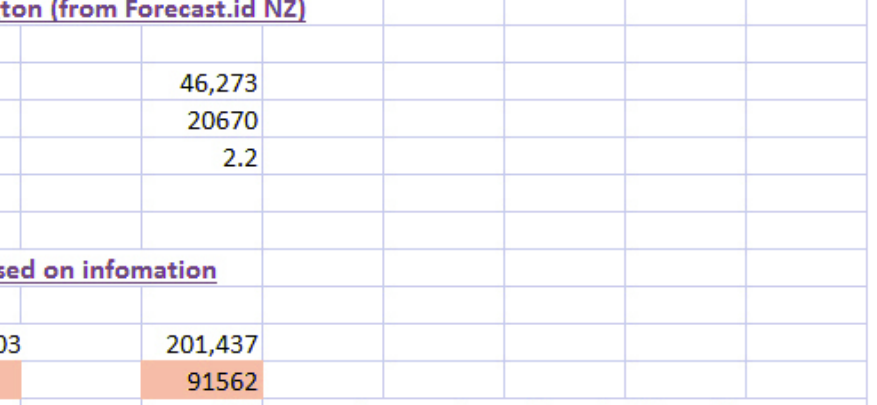

Houses built between 2013 and 2103

2.2 < assuming people per household remains constant

People per Household

Infomation on dwellings built for Wellington (from Forecast.id NZ)

Horokiwi dwellings built 2013 to 2043

Newlands dwellings built 2013 to 2043

$1386<$ making up $3.5 \%$ of all dwellings

$538<$ making up $3.3 \%$ of all dwellings

Predictions for dwellings built in 2103 based on infomation

Horokiwi dwellings built 2013 to 2103

Newlands dwellings built 2013 to 2103

Total

$5311<$ making up $5.8 \%$ of all dwellings

$3571<$ making up $3.9 \%$ of all dwellings

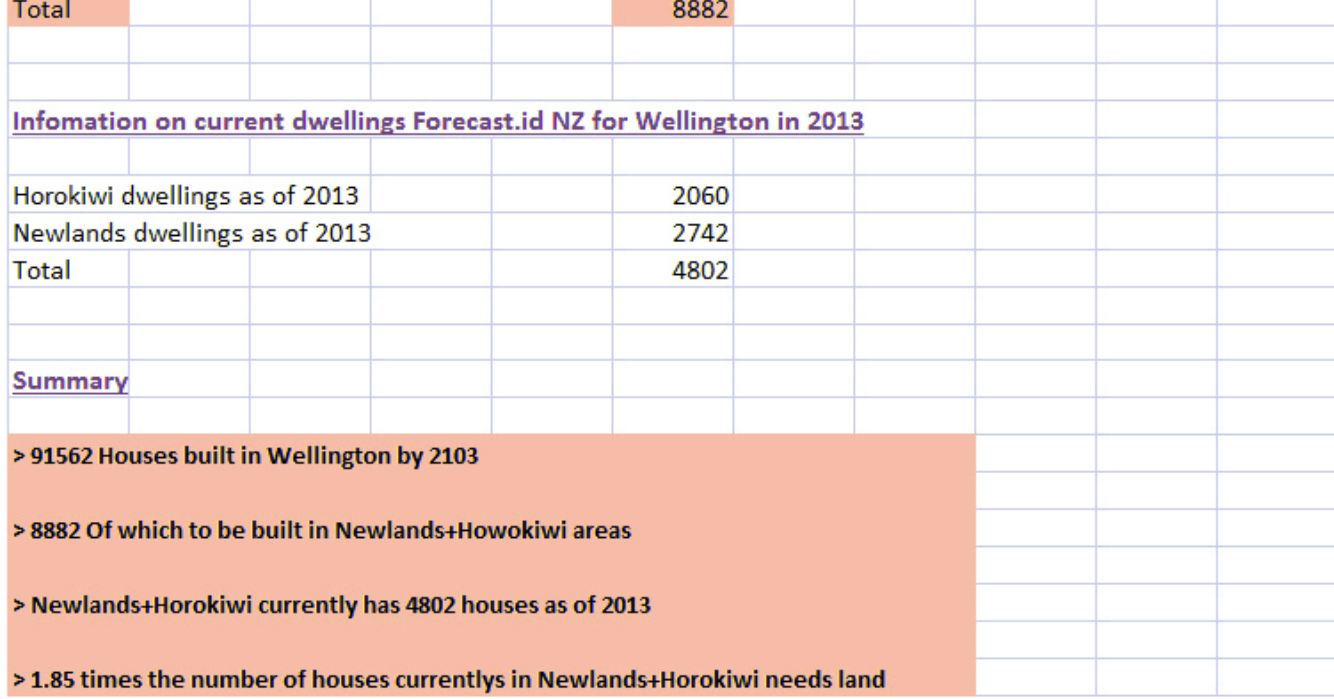

Fig 2. 11.

Analysis of

Wellington's

Population Growth and New Dwellings. 


\title{
Setting the Programme
}

\begin{abstract}
A Home
According to this investigation's calculations, Wellington needs a plethora of new places to house its increasing population. While the $\mathrm{CBD}$ will definitely house the majority of these people in apartments, these places will eventually be subject to SLR and liquefaction risk. When Wellington finally reaches Lower Hutt, new tactics for developments are going to have to be considered as the mountainous terrain and coastal borders are normally problematic. This invites the programme of the intervention to consider sea-based accommodation for residents wishing to live in a more climatically adaptive setting.
\end{abstract}

\section{A Heart}

There is an opportunity to create an intervention that is more than simply enduring. Designs like the Citadel Skyscraper (Chapter Three) lack proper consideration of socialisation and as a result may not be pleasant to live in. What is needed is a dynamic suburb that facilitates connectivity and interaction. The weather in 2100 must have the occasional pleasant day, so making sure the intervention can best make use of these situations to liven spirits is a must.

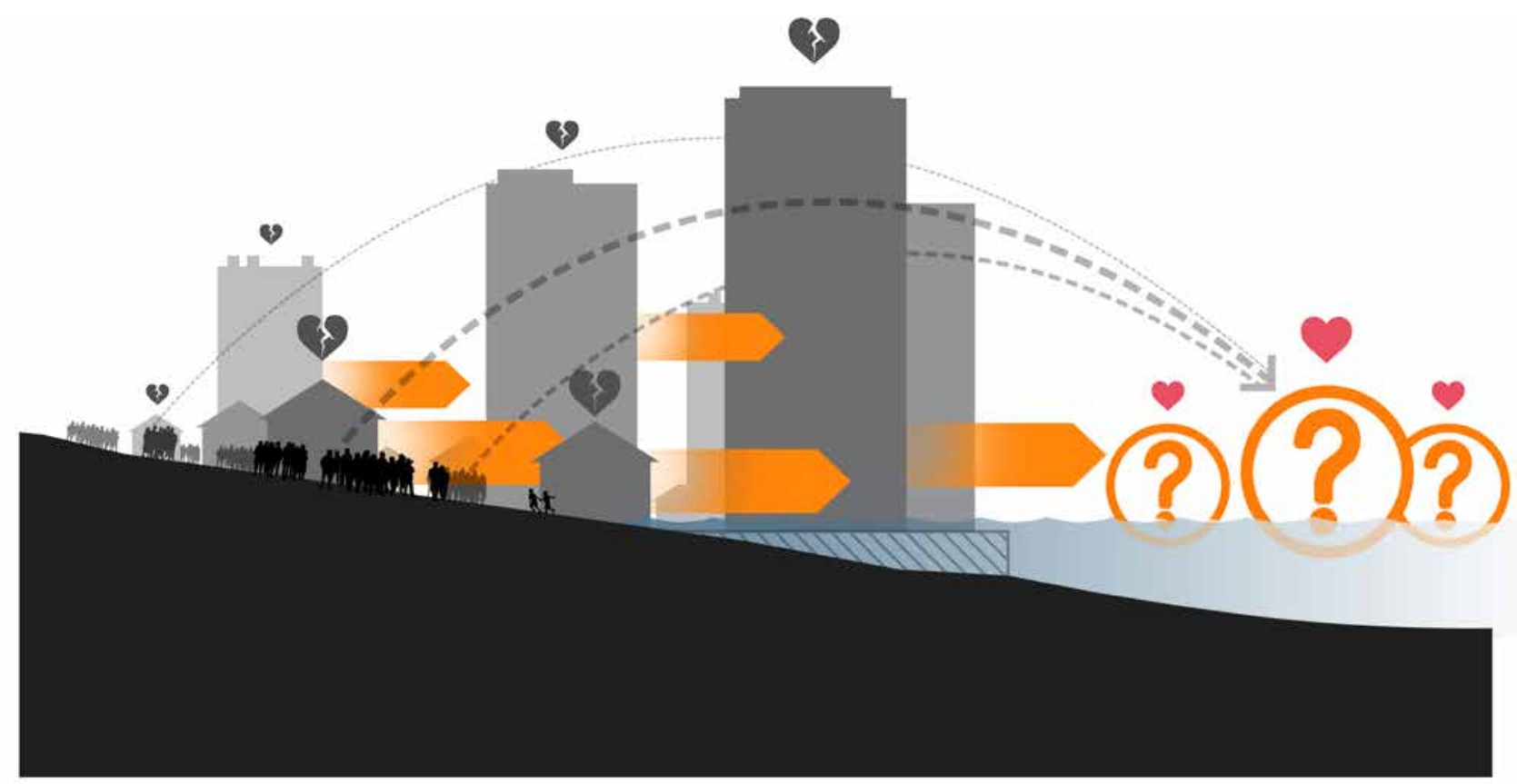




\section{Chapter Three}

Precedents 
This chapter analyses a series of precedents set both in the past and future. Two precedents are evaluated to understand the complexity of past predictions and the extent to which they could be realised today. The later two are driven by genuine issues and therefore reveal unique problem-solving approaches for future pioneering proposals. 


\section{Contemplating The Past}

\section{Plug-In City - Peter Cook, 1964}

Plug-in City was a project that was developed by the avantgarde architectural group known as Archigram between 1962 and 1964. The project aims to expand on the gregarious quality of a city by offering a dynamic environment with clustered living that has been planned for obsolescence and reuse. A reinterpretation of transport shapes the project with cars being docked in silos, structural tubes as service paths and travelators assisting the burden of public transport. The re-appropriation and inter-changeability are the greatest properties of this design. Educational facilities can be replaced by housing and complexes can grow with additional rooms a crane's lift away. The kinetic, almost lively nature of the architecture blends well with current modes of living with ready-fix solutions and fastpaced lifestyles.

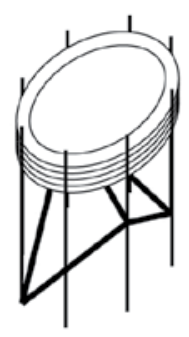

Pilons, silo decks and lift tubes established

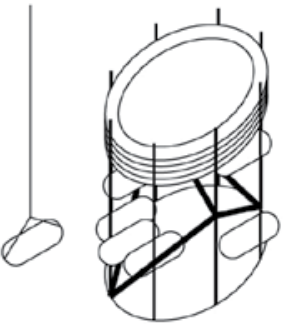

Education rooms of $U$ niverstiy plugged in

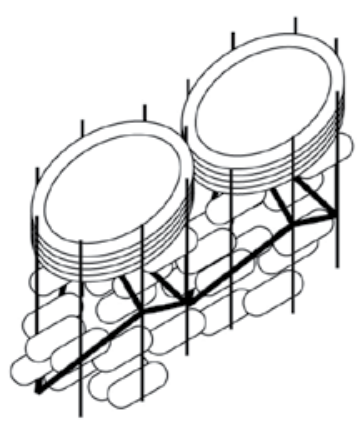

Period operating at maximum capacity

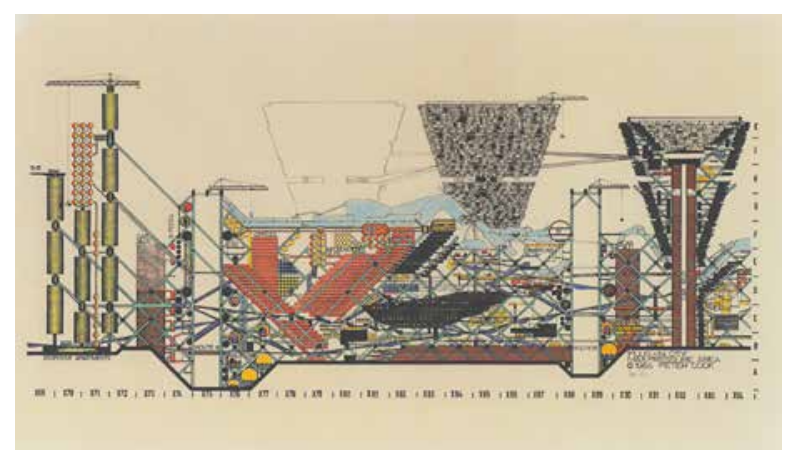

Fig 3. 02. Plug-In City.
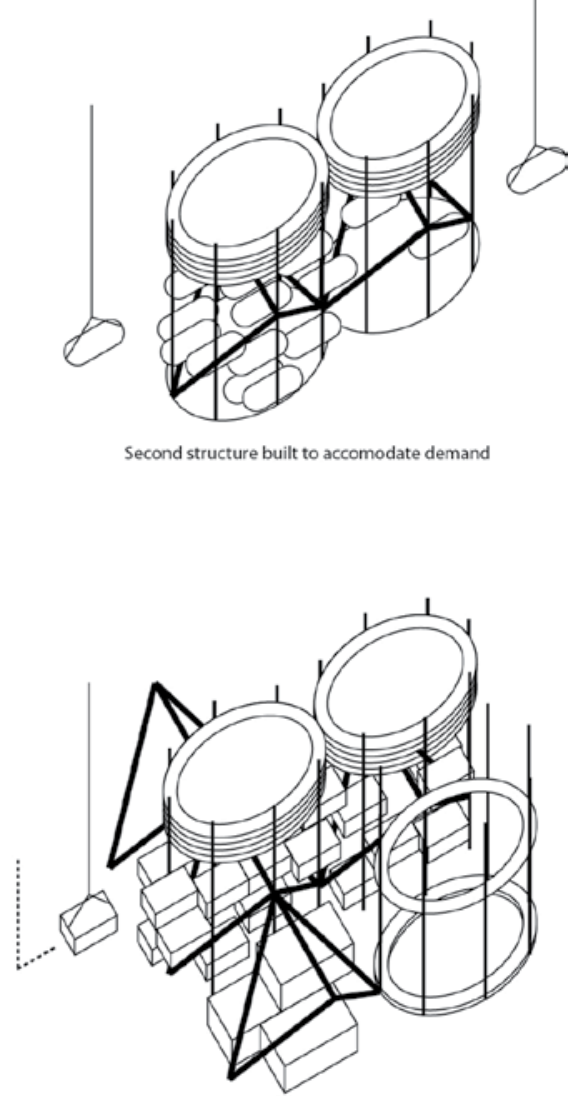

Node established and assembly of other facilites follows

Fig 3. 03. Diagram of City's Development and Repurposing Ideology.

- Objective 1 - City is enduring because of its re-appropriation factor.

- Objective 2 - The turnover when an area becomes obsolescence ensures maximum efficiency of the community so that it remains stable in that manner to house or provide local amenities.

- Objective 3 - As of its time, it provides predictions on clustered living and city-wide connections. 


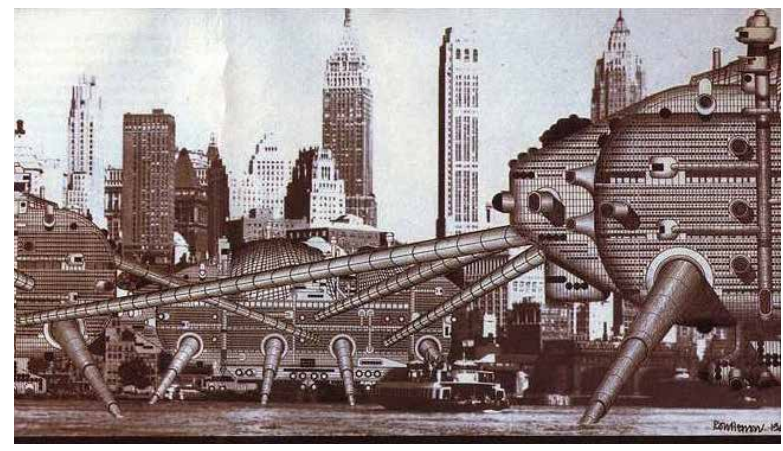

Fig 3. 04. Walking City.

\section{Walking City - Ron Herron, 1964}

Walking City proposes a nomadic urban civilisation that is not tied to a single location. The super-structures have the ability to traverse both land and sea in search of resources and aid certain areas with required manufacturing capabilities. They also can amalgamate to form metropolises to later disperse if power needs to be shifted or relocated. The proposition of a society where ties are broken and boundaries are blurred underscores an anticipated belief in the technological capabilities of the future. The integration of this project, alongside other cities proposed by the Archigram group, predicts a sharing of information and resources within a network that is flexible and ever-changing. Walking City alludes to land ownership being revoked for places to grow resources; the flexibility of the city allows for you to live in multiple locations and not be bound to one spot.
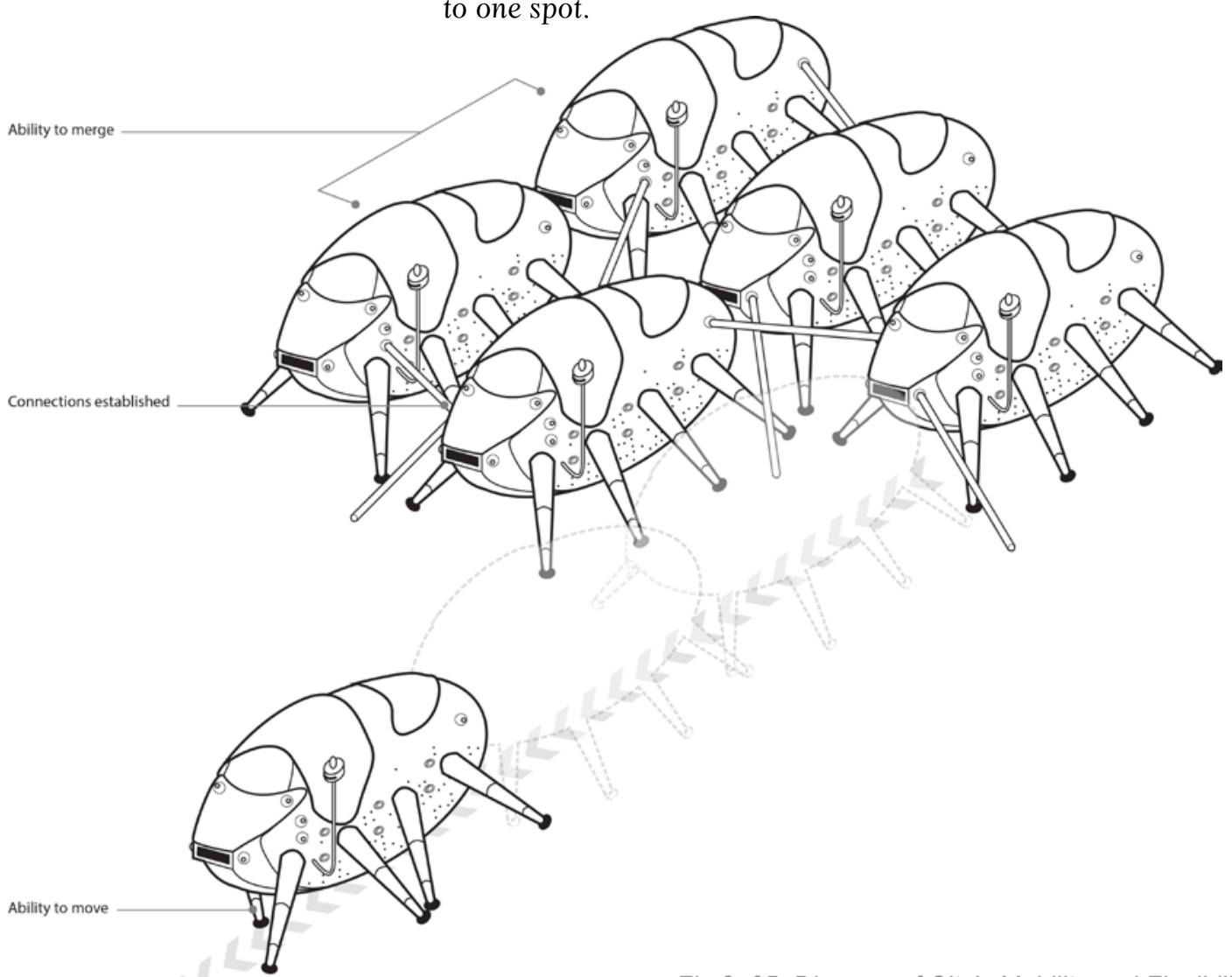

Fig 3. 05. Diagram of City's Mobility and Flexibility.

- Objective 1- Amalgamation braces the cities and brings communities closer. The roaming structure reduces the struggle to obtain resources.

- Objective 2- Mobility allows for places of climatic distress to be avoided.

- Objective 3 - A reflection on the fast-paced emerging technologies of its time, the project articulates how greater connectivity and flexibility could be realised. 


\section{Interpreting The Future}

\section{Citadel Skyscraper - Victor Kopeikin \& Pavlo Zabotin, 2012}

This skyscraper is a defensive shield that revolves in a chainlike fashion around Japan to protect its shores. It achieves fortification by incorporating breakwaters and drainage channels to disrupt tidal energy. This precedent has been designed with anticipation of dangerous circumstances such as earthquakes and tsunamis and tests how people can survive solely within these towers. The project additionally aims to relieve overcrowded cities by relocating the residential function to the shores, leaving the centres economically focused (Evolo). Thus the design is primarily residential units;

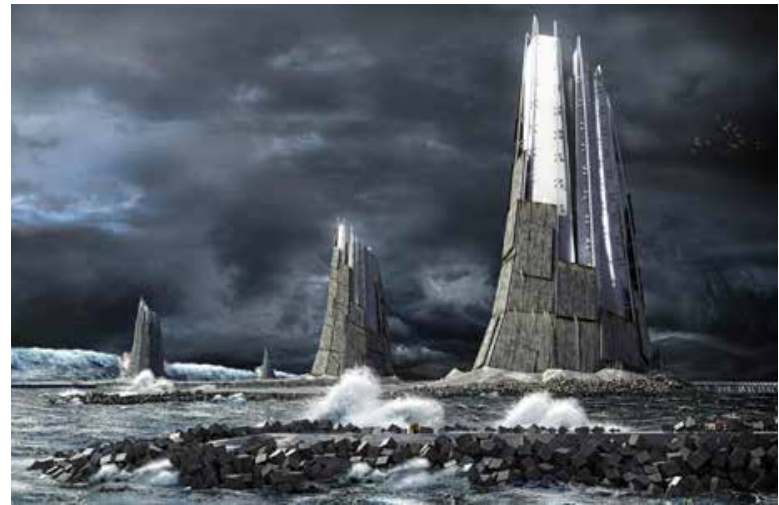

Fig 3. 06. Citadel Skyscraper. proposing new typologies for human life to experience.

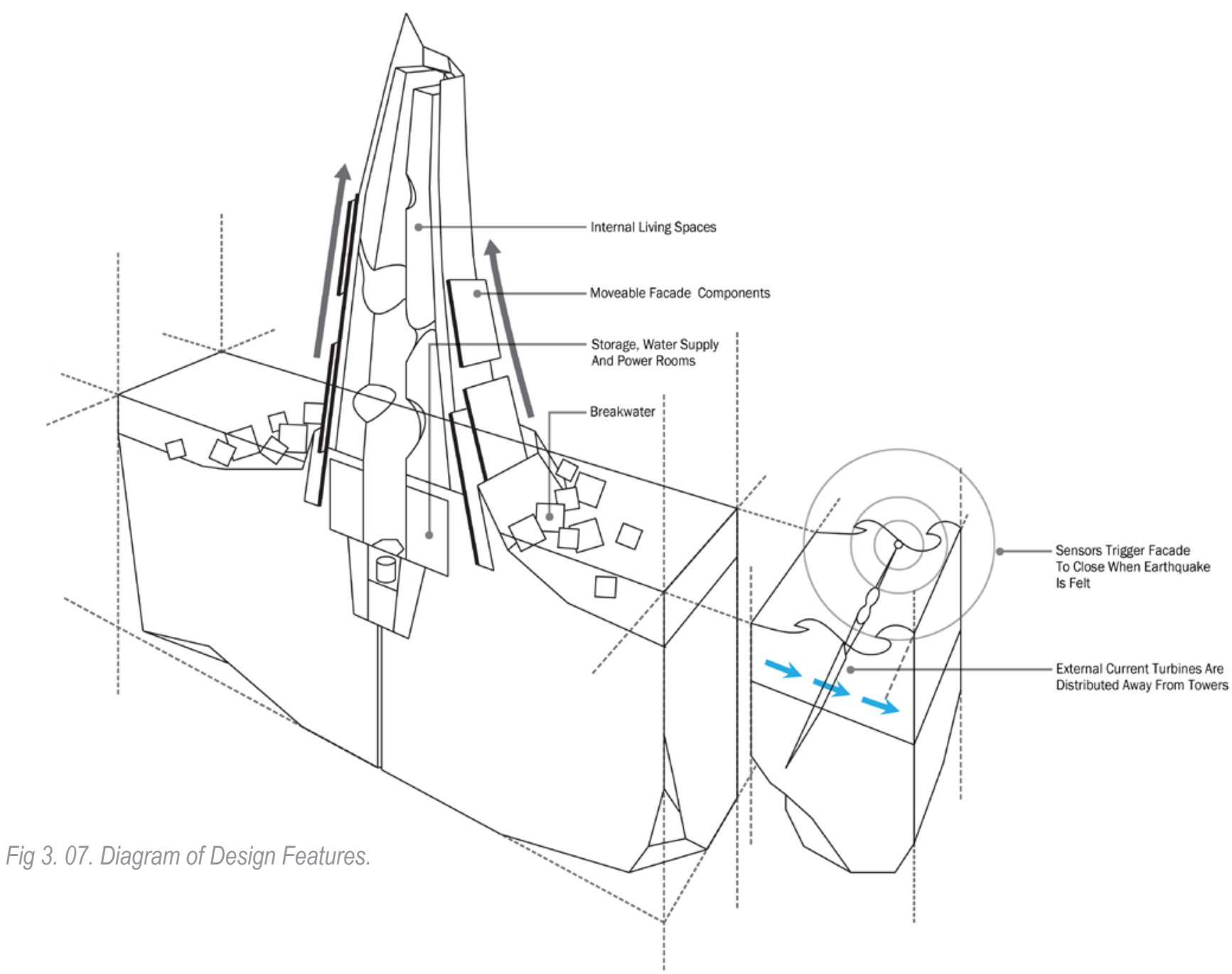

- Objective 1 - It endures the weather with its facade/barrier disruptions. It uses natural energy sources to power.

- Objective 2 - It prolongs life by offering a safe-haven from tsunamis in a seismically active area.

- Objective 3 - It appropriately anticipates overcrowding and offers a solution. 
Polar Umbrella - Derek Pirozzi. 2013

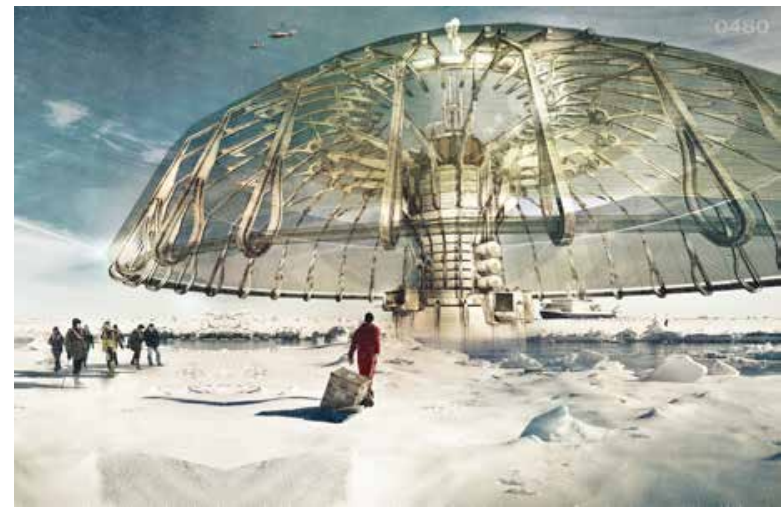

Fig 3. 08. Polar Umbrella.
This umbrella structure has been designed to help re-establish the Arctic layers by reducing heat gains in order to help cool the vulnerable region. The double-jointed system allows for as much of the sun's radiation to be absorbed and therefore shade the ice. It shows how architecture may respond to climatic demands and prolong their effects. As another modular design, it can be replicated in areas most significantly affected. It includes research facilities and dormitories among other programmes. Alongside thermal energy it utilises salinity gradient power (recycling of salt water) (Evolo).

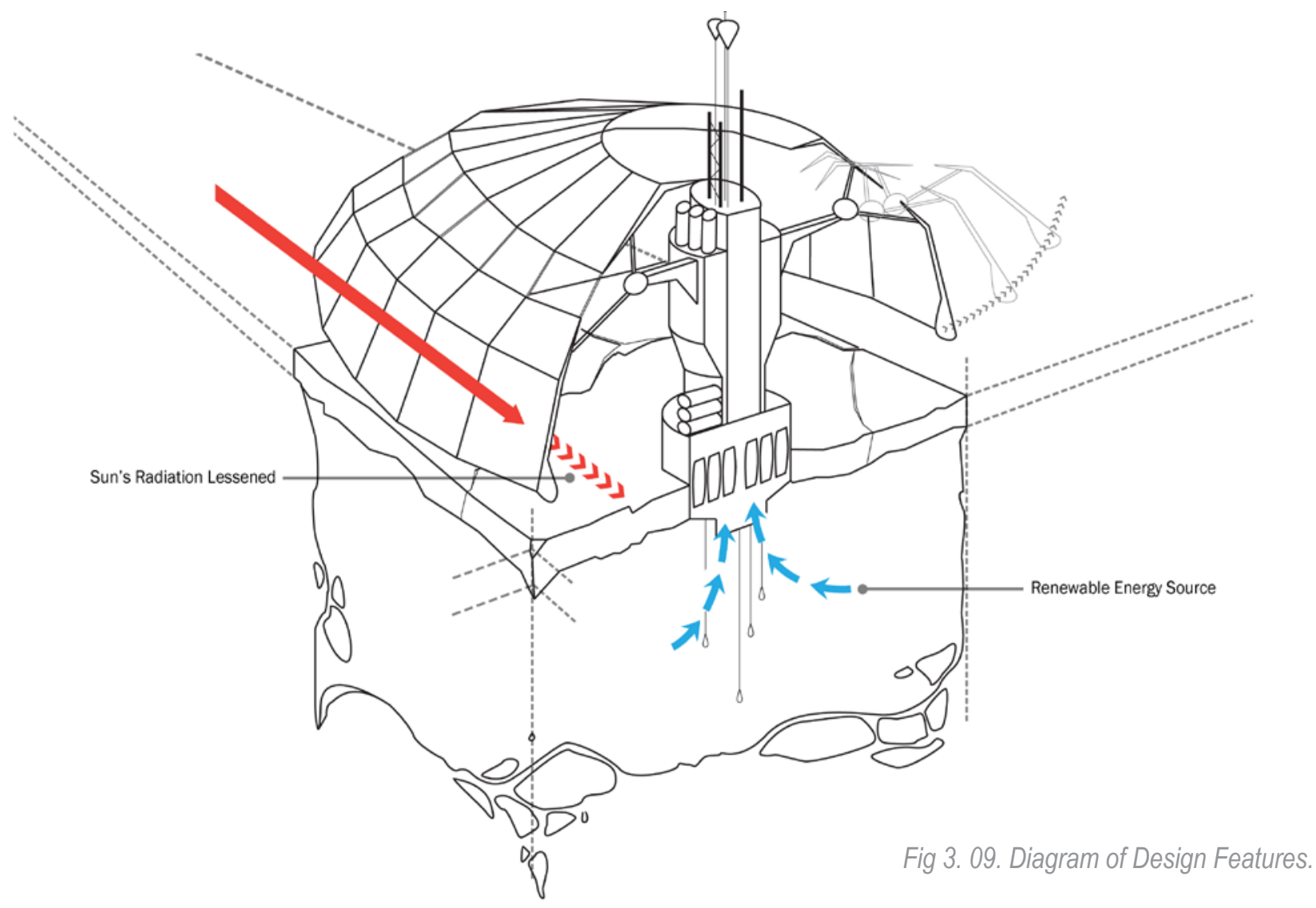

- Objective 1 - It is enduring in its self-efficiency, and offers wildlife rehabilitation.

- Objective 2 - Solar radiation in a pessimistic situation is absorbed to gain energy and prolong melting.

- Objective 3 - While being located in a remote location, provides clairvoyance into how liveable structures will move via smart sensory technology. 


\section{Summary}

Both precedents from the past contain large scale designs that would be able to be built in our current time. This is because technology has been developed and is readily being incorporated into architecture meaning we can build taller and bigger. It is believed that these projects have not been realised however as they are a style of architecture far from what is current and generating them would reshape cities at a cost that is not practicable. Regardless, the content examined holds value. Mobility and configurability are seen as the assets of these projects where they allow for greater interaction and use of space.

Both precedents for the future incorporate a defensive and dynamic design to deal with environmental impacts; deciding upon a shielding strategy for solving their sites' issues. Additionally, both designs have moving parts for protection but are fixated to their locations - unlike the past Archigram proposals. This is because the design approach appears to have differed over the half a century period between precedents. The more modern concepts were designed to endure and be replicated, while the Archigram proposals appear to relocate or replace the architecture when needed. It is believed a middle ground could prove valuable where a prototype could be massproduced to adapt and adjust to a future climate, as opposed to running away. 


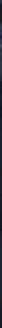
28

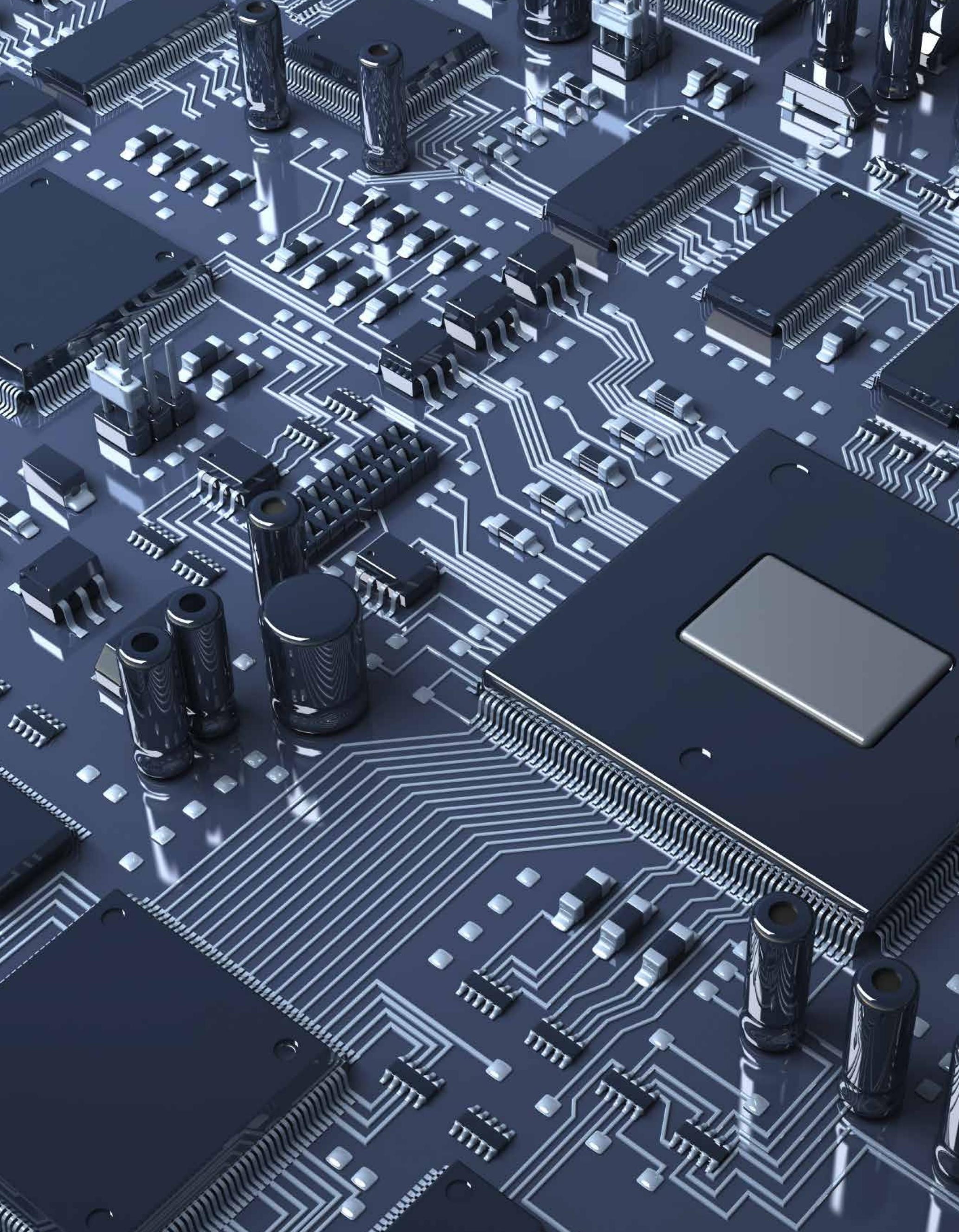




\section{Chapter Four}

Literature Review 
This chapter provides theoretical background on themes that are germane to the established objectives. The themes are explored and at times overlap, revealing appropriate strategies and/or outlooks to achieve each objective.

Technology is analysed to reveal how integrating sublime qualities will promote smart architecture that will remain enduring and resilient. Following this is a history of the predictions from the last century to understand the validity of prophecies and practicable nature of the intervention. The content of this chapter is derived from the precedents within Chapter Three, especially with reverence to the adaptable features and technologies examined. 


\section{The Contemporary Sublime}

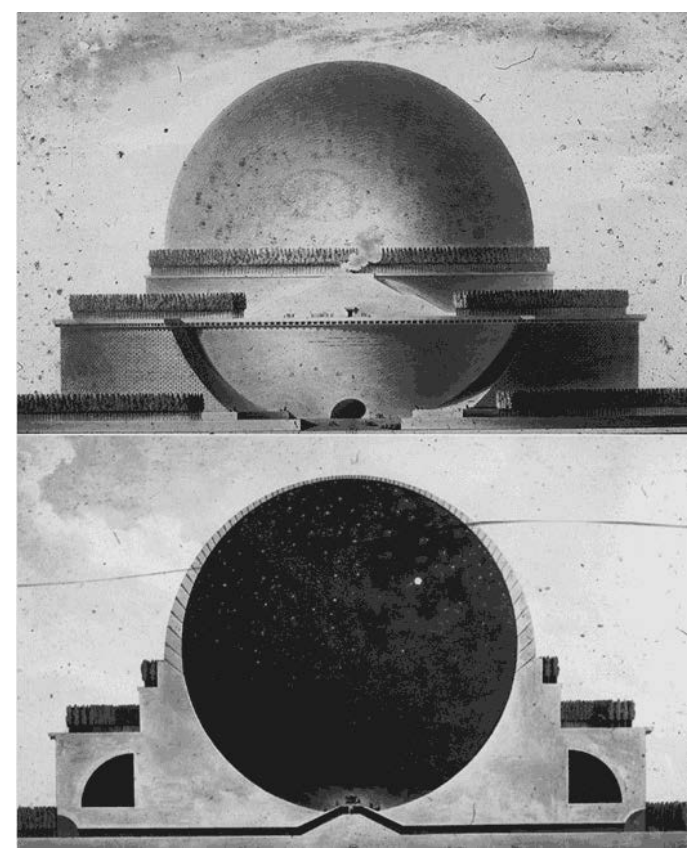

Fig 4. 02. Newton's Cenotaph by Étienne-Louis Boullée.
[1 - Provide a stable and enduring sanctuary in a dismal setting.] [2-Adapt to new climatic demands and prolong life.]

\section{Measuring Nature}

Kant identified two instances of the sublime, the mathematical and the dynamic. The mathematical concerns itself with infinitude and insignificance, like looking up at the night sky, while the dynamic coincides with the forces of nature, like eruptions and their potential devastation. Alongside these phenomena of the sublime, Kant riddled the idea that there should be a point at which nature can be measured. He was aware of nature's sublime tendency, its unpredictability, and longed to find truths that could be elucidated.

This measurable quality was pursued by a few characters like Étienne-Louis Boullée and Claude-Nicolas Ledoux. These people took what had been resolved about the sublime and tried to explain it through measurable dictations; one medium being architecture. Solidifying this line of thinking, Boullée once said, "I have tried to avail myself of all the means put at my disposal by nature and to convey with my architecture the image of grandeur. "(90). This quote rightly justifies the power that is projected in the infamous Newton's Cenotaph, where both the Earth's and Newton's discoveries are celebrated. This celebration eludes to how our line of thinking has progressed to its fixation on containing nature and its sublime presence.

\section{The Contemporary Sublime}

Having control over nature in itself appears as a fantasy restrained to artworks, however it is believed that by developing technology we have been able to put into motion the ideals of work such as Boullée's Newton's Cenotaph and take control over nature's reign. "Modern man is less and less willing to be overpowered by nature; instead, he vigorously takes technological command of nature." This 2014 perception from De Mul is mentioned within his writing as he talks of how our age is succumbing to secularization as we no longer stand ideally by in face of nature's mysteries. Therefore it can be said that the contemporary sublime is technologically bound, due to its immense potential and that it has allowed us to comprehend the original sublime - nature. 
The technological rise allowed us to divulge nature's mysteries, and even relatively correctly predict and analyse its next move; be it a cyclone or global warming's affects. This implies a sense of control lies within technology through the manipulation of the elements and leaves architecture as a measurable medium for expressing the contemporary sublime. Architecture that utilises and adapts to the power of nature's elements suggests more advantageous living, far beyond the limits of our current unresponsive dwellings. Asselin believes that designs that are purely aesthetic will be eclipsed by designs of multi-functional value, ranging from social to environmental. This will be due to issues like water demand creating a necessity for establishing more productive designs (57).

\section{Smart Architecture}

Instances of the contemporary sublime are already being seen in architecture. For example, the Bahrain World Trade Centre - finished in 2008 and standing at $240 \mathrm{~m}$ - is the world's first building to integrate large-scale wind turbines. Supplementary technologies like solar panels help reiterate the building's wish to 'tame' nature for its benefit. The Bahrain World Trade Centre shows the public through its technology that it acknowledges the natural forces presented in its location and has the power to manipulate them for its own benefit.

The incorporation of technological instillations within architecture plays a huge role when appropriately responding to climates. The 2007 Kiefer Technic Showroom utilises dynamic facade shading to allow personalisation internally and externally. The electronically controlled shutters allow for the internal environment to be regulated to the user's needs. The evolution of solar motion technology in a matter of years has allowed this dynamic shading response to no longer require manual control and can now respond to the sun naturally (Construction Specialties Inc.); acting like a living part of the building.

Form also can be technologically calibrated. Returning to the example of the Bahrain World Trade Centre, its sail-like form has been designed to funnel and accelerate wind speeds for its turbines (Fig 4.05). Its tapered form and positioning allows 

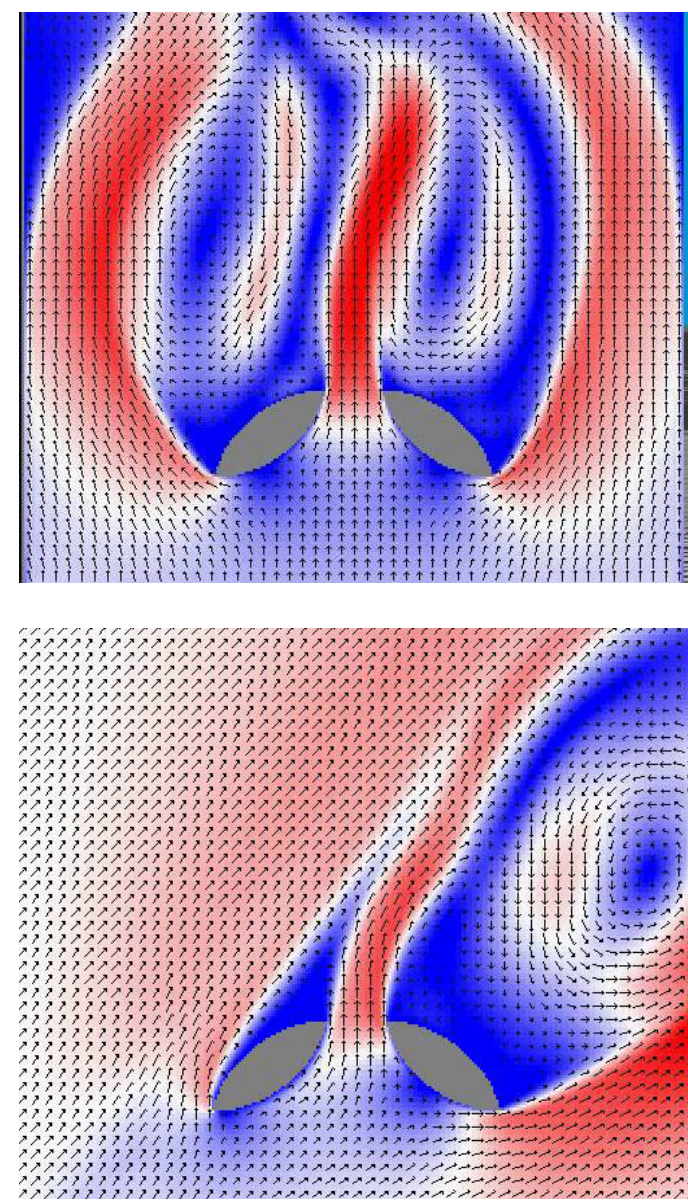

Fig 4. 05. Bahrain World Trade Centre Channelling Wind at $90^{\circ}$ (Top) and $45^{\circ}$ (Bottom) Angle Winds. for wind to be channelled, increasing the turbine's generation. The inbuilt turbines supply up to $15 \%$ of the tower's power needs which equates to light for 300 homes (MetaEfficient).

Adaptability can also be found in materiality. The development of air purifying concrete for example is able to absorb nitrogen oxides; an emission that contributes to acid rain and smog (Quick). Research from 2009 has shown that this type of concrete can remove nitrogen oxide content by $25-45 \%$ over normal concrete (Brouwers). The use of vegetation in green roofs and walls helps a buildings adapt in extreme conditions by reducing temperature extremes through shading and evaporative cooling (Garrison, Horowitz 2).

\section{Conclusion}

The 'taming' of nature through technology illustrates that nature leans to be finite and understood while technology now rules as the contemporary sublime through its limitlessness. Jeremy Gilbert-Rolfe said (about technology) in support of this argument; "... terrifying in the limitless unknowability of its potential, while being entirely a product of knowledge... at once unbounded by the human, and, as knowledge, a trace of the human now out of the latter's control." (128). This view resonates with his beliefs on how the sublime cannot pertain to nature today like it once did as there has been a sense of resolution, while technology is yet to be fully realised. Simon Morley agrees that the sublime now resides with technology when stating "Rather than nature, the incredible power of technology is more likely to supply the raw material for what can be termed a characteristically contemporary sublime." (1).

Technology has immeasurable potential where an exploration within architecture undoubtedly would provide auspicious living environments for occupants. By eliciting control over nature, power can be harnessed and living environments can be more resilient and efficient. A design investigation into the potential benefits of future technological capabilities for adapting to changing climates appears as a positive step forward in architectural exploration. 

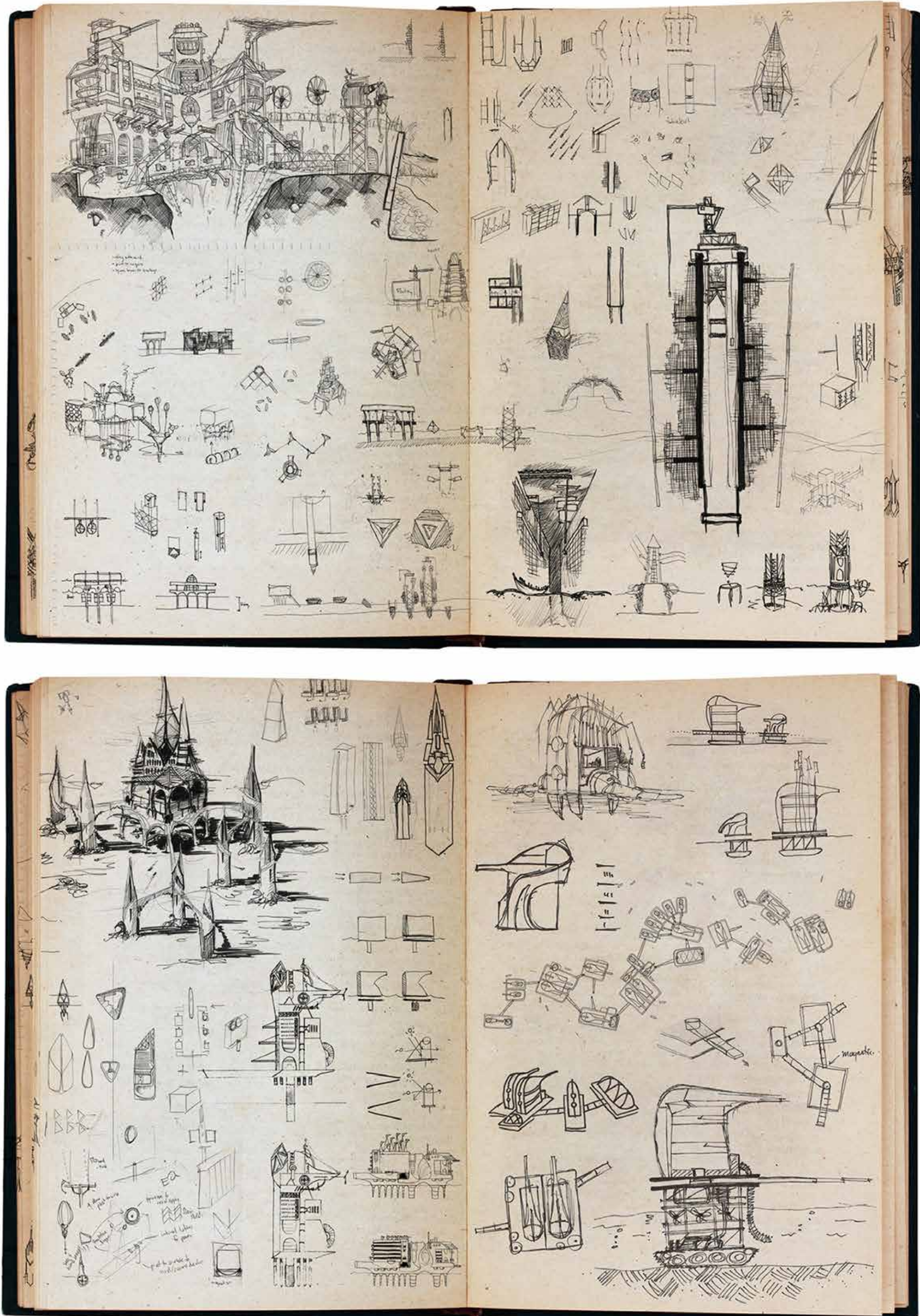


\section{Application}

Fig 4.07 (over page) are collage explorations of nature's power and $a$ vision of how the intervention may appear aesthetically. Fig 4.06 is a series of working sketches which engage with nature to subdue its impact; aerodynamics, turbines, solar design, weather conductors and moving parts were some areas explored. The aim of these sketches was to elicit a design that could adapt to the harsh predicted weathers by absorbing the power or manoeuvring for beneficial gains.

Solar, wind and tidal energies are not harmful to the environment and as such procure no reason to conceive of new sources of energy as they are not outdated. Instead the intervention looks to push the magnitude and application of these technologies within architecture. 


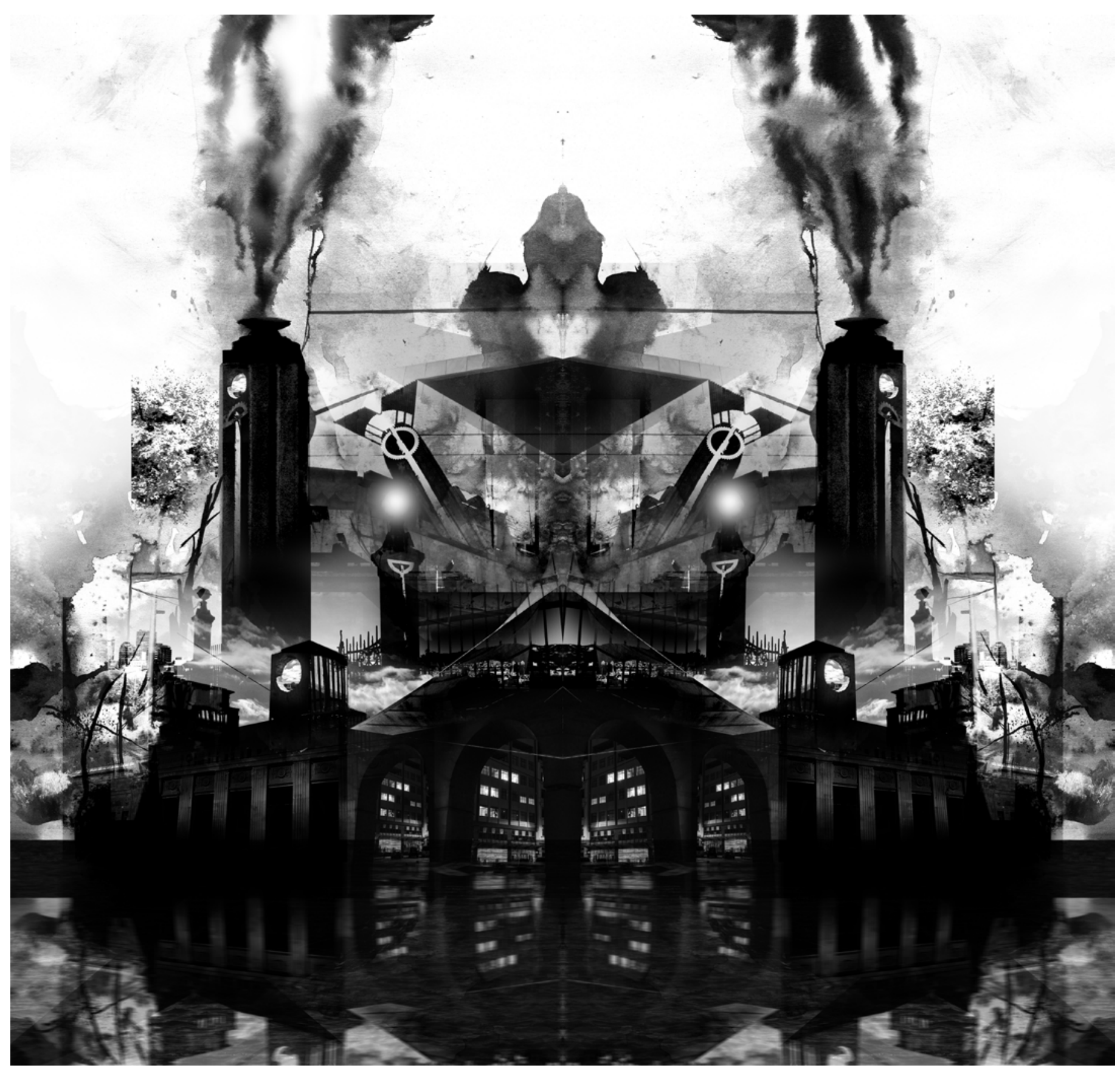

Fig 4. 07. Collage Anticipating 2100. 


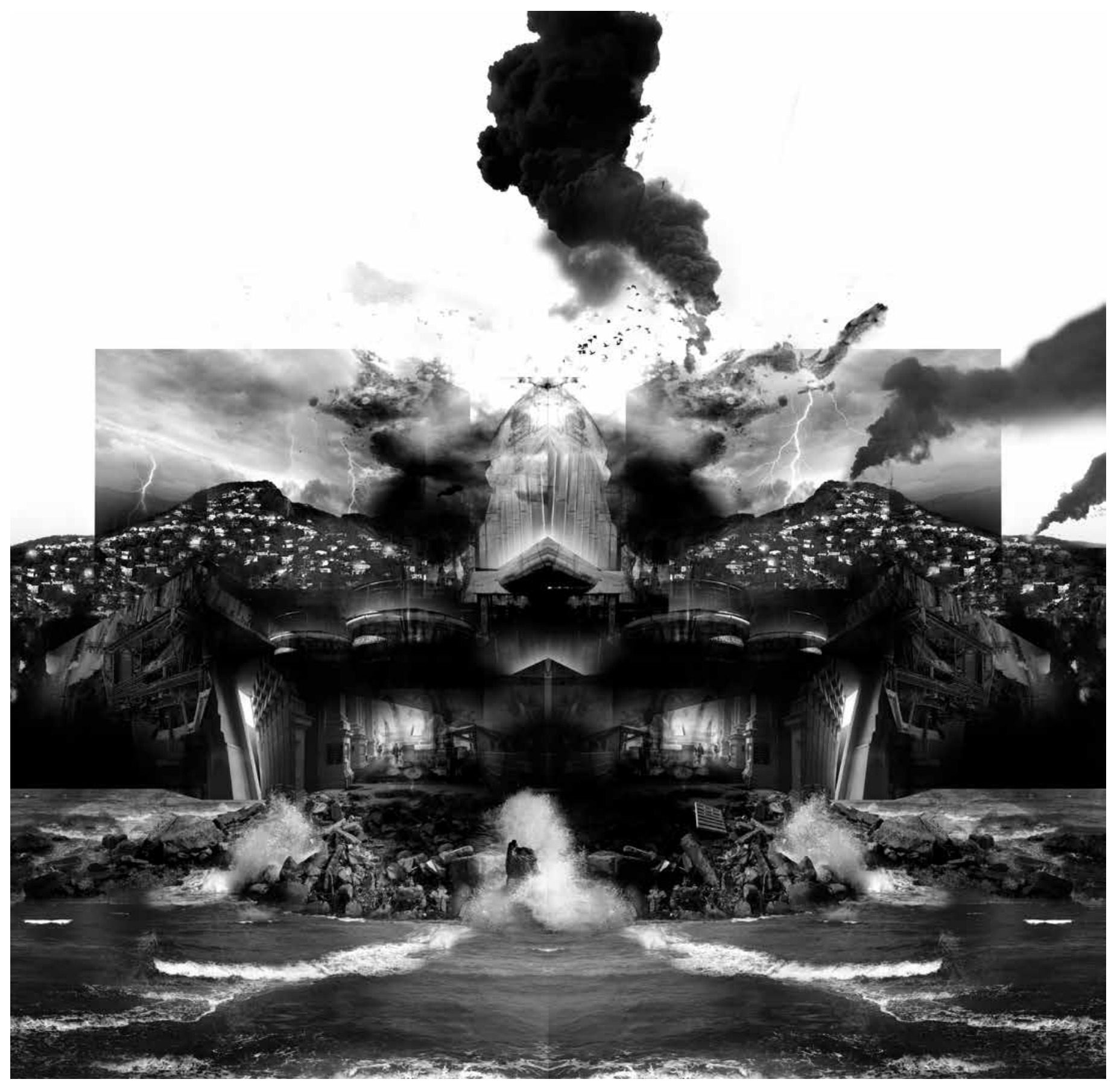

Fig 4. 08. Collage Anticipating 2100. 

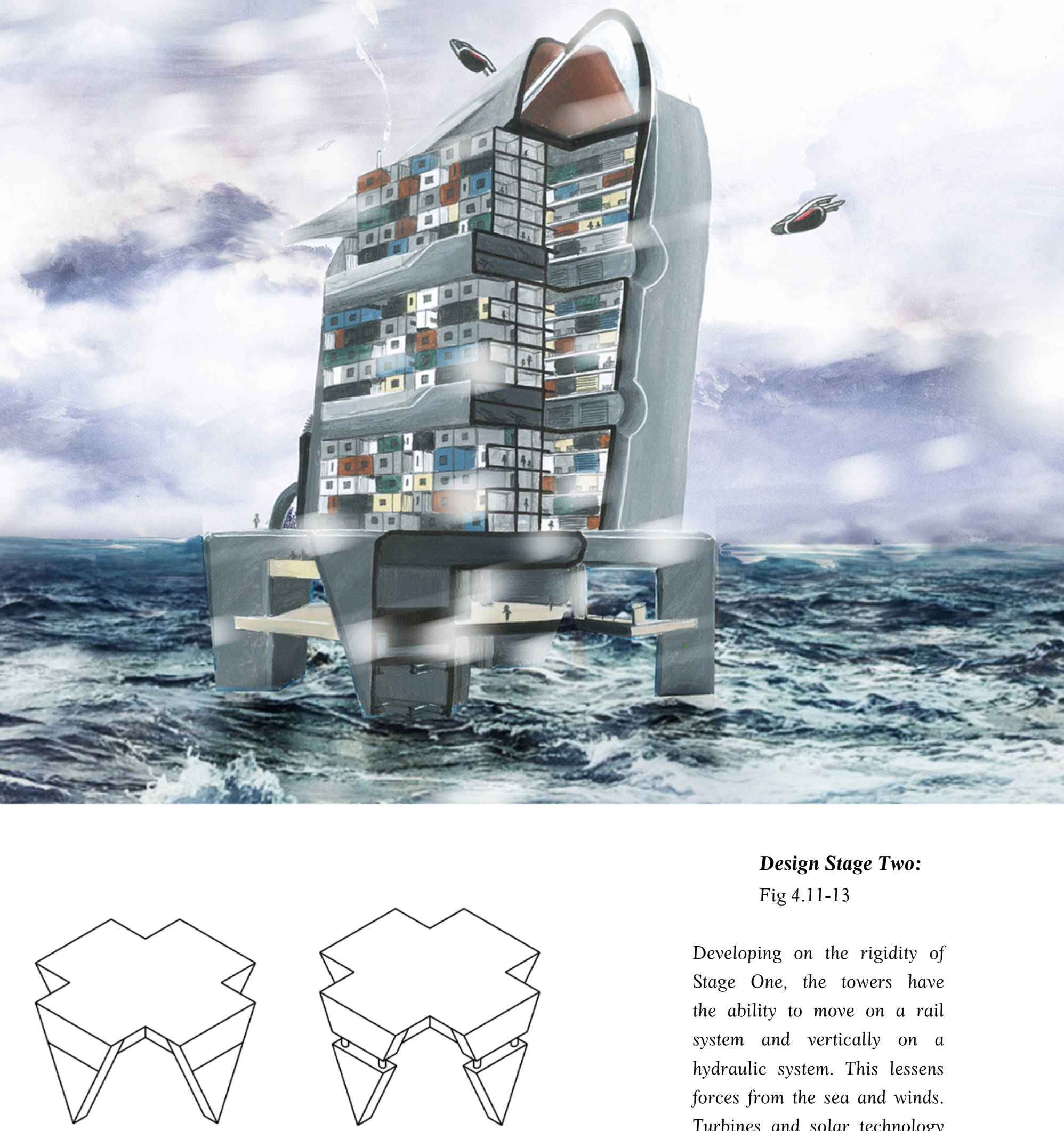

Design Stage Two:

Fig 4.11-13
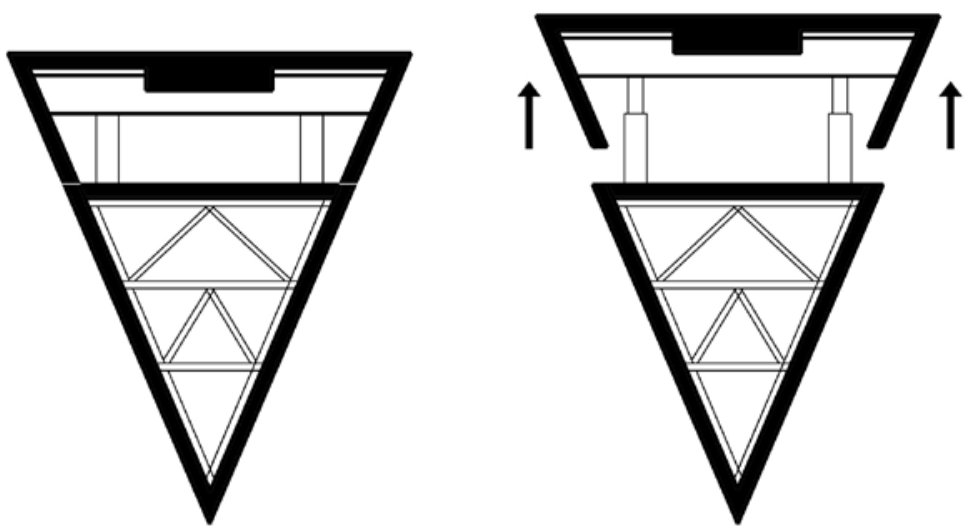

Developing on the rigidity of Stage One, the towers have the ability to move on a rail system and vertically on a hydraulic system. This lessens forces from the sea and winds. Turbines and solar technology was still developed and a more aerodynamic form was refined.

[The final design refines all aspects. Most notably removing rails to allow multidirectional movement and the addition of gravity lasers, lighting conductors and other components to be further explained in Chapter Six.] 


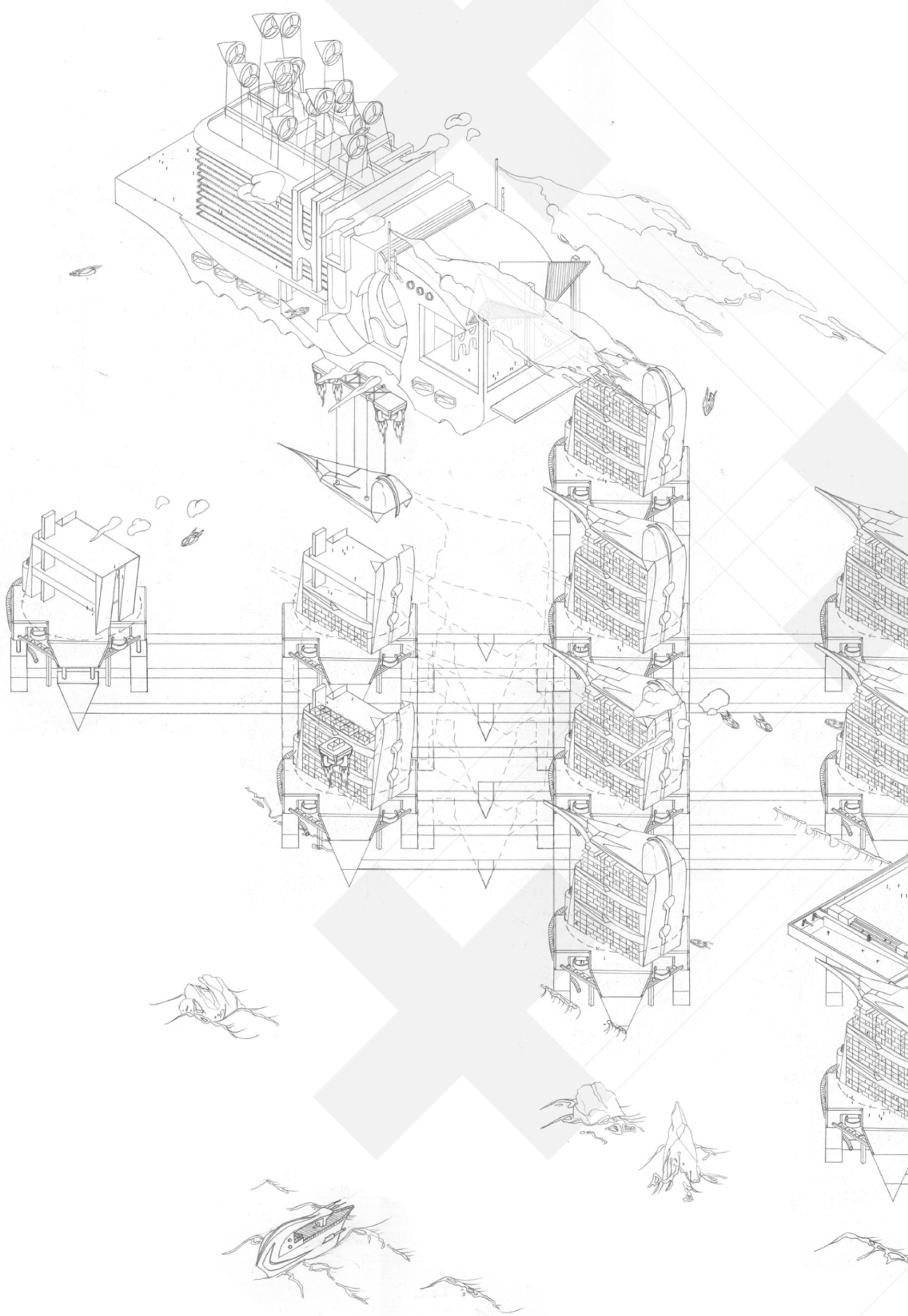

Fig 4. 13. Design Stage Two, Isometric Drawing of Suburb. 


\section{Predictions}

\section{[3-Offer informed clairvoyance into the future evolution of living.]}

The examination of some of the last century's predictions will establish an understanding for producing analogous predictions. Looking to the past is necessary to recognise what percentage of predictions made are likely to come true, how to form logical predictions and if there is some methodology.

What was noted is that the predictions primarily revolved around technology. While technology's evolution plays a huge role in how the 20th century played out, in the predictions analysed there was no talk of two huge worldly impacts, war and climate change. While inklings of climate change can be excused in earlier years as technology's negative connotations did not spark any need to predict a deteriorating atmosphere, it is wondered why predictions of sequential wars after WW1 were not anticipated more.

The later in the century it was, the more confident the authors seemed with their predictions; even though the success rate remained around one-third as an average for all predictions analysed over the century.

1900

John Elfreth Watkins Jr. produced an article What May Happen in the Next Hundred Years offering up some surprisingly accurate predictions. He foresaw that the camera would deliver images around the world, the introduction of colour photography, worldwide connectivity, and air control in houses. The predictions are not excessively wild and are influenced by a pretence that a technological revolution would improve our way of life sometime the next 100 years.

On the other hand he wildly overshot predictions such as removing $\mathrm{C}, X$ and $Q$ from the alphabet, and no cars in large cities. Predictions like these had the capacity to be realised however due to political and/oreconomic viability would nothave been deemed feasible. Additional realistic predictions can be seen throughout the century which also failed to come to fruition. 

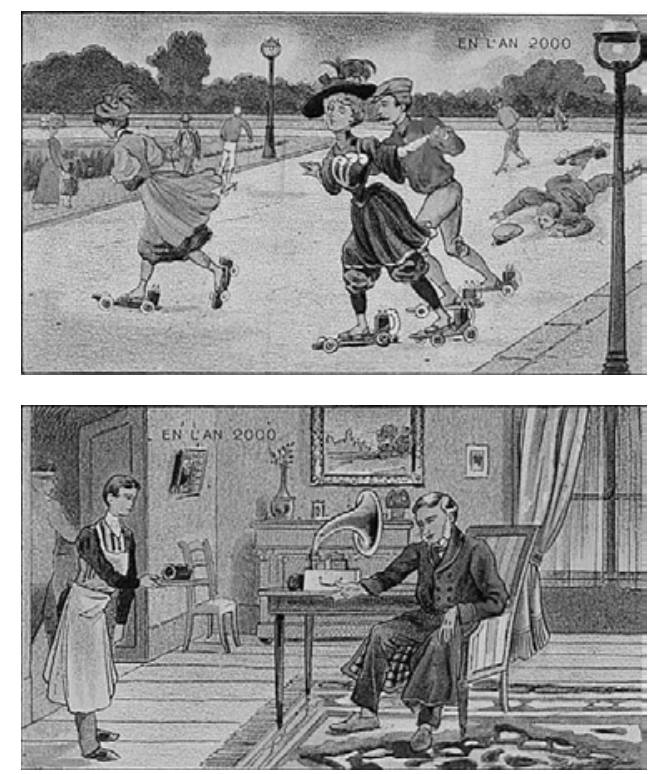

Fig 4. 14. Artist's Visions for the Future.

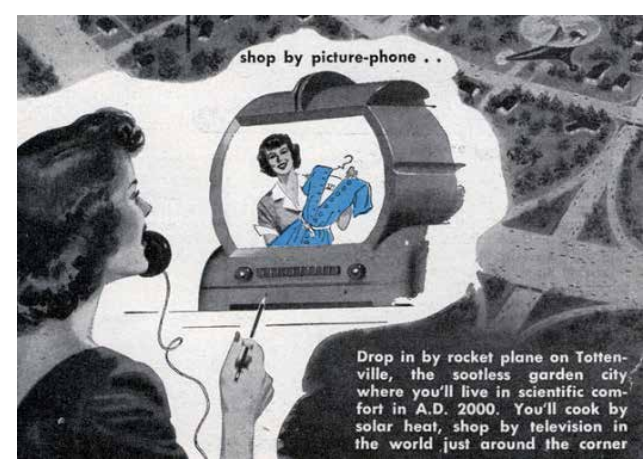

Fig 4. 15. A 1950's Prediction of TV Shopping.

A series of artworks from French artist Villemard are not so accurate - even though some of them may have been for comedic effect. What is important to note is that while they depict the future, the stylisation appears to be stagnant. A prediction of recordable telephone messages is played back on a phonograph (Fig 4.14), not predicating any futuristic form development at all. The same can be said about the fashion. There should be awareness that forms and aesthetics will advance parallel to technology.

\section{0}

The halfway point of the century saw an increase in predictions as technology advanced. In this year an article by Popular Mechanics entitled Miracles You'll See In The Next Fifty Years came out, depicting a family in a futuristic world. The most valid predictions were of what now is the internet, TV shopping (Fig 4.15) and pre-fabricated houses. Storm diversion technology is among the incorrect predictions. This article illustrates the value in predictions that are a logical step in technological progression; in this case, the merging of TVs and phones to predict TV shopping. Diverting an entire storm is a godly task and wishful prediction to make.

\section{2}

Robert Heinlein published a list of predictions where the interesting aspect is what he believes will not come to fruition. Concepts such as time travel, radio transmission of matter, manlike robots, a permanent end to war, and scientific proof of personal survival after death. This acknowledges limitations and that while humans are smart, we are not infinitely powerful. It can be said that some of these still are not likely to happen. 
Arthur Clarke who was considered an important character in science fiction writing of the 20th century, was able to predict the capability of communication. Clarke predicted mobile phones (invented 1973) and telecommuting long before they existed (Saenz). The majority of his other predictions still haven't come to fruition as he left the dates unclear. Considering we are only at the 50 year mark since his predictions were made they still may be fulfilled. There was hopes of living on the moon and a machine capable of material replication - "an invention to end all inventions." (BBC Horizon).

Clarke states about prophets: "If his prediction sounds at all reasonable, you can be quite sure that in 20, or at most 50 years, the progress of science and technology has made him seem ridiculously conservative. On the other hand, if by some miracle a prophet could describe the future exactly as it was going to take place, his predictions would sound so absurd, so far-fetched, that everybody would laugh him to scorn. "This is seen the most useful piece of information taken from this analysis. It clarifies that predictions are not a science, although being heavily informed by it. They are open-ended scenarios susceptible to becoming obsolete because of the next revolutionary invention.

\section{2}

Predictions for the millennium were still happing nearing the end of the century. A Glimpse Of The Year 2000 contained a series of predictions from futurists. The most interesting part is that author Waldemar Kleinfield declared that futurists don't see everything; listing the rise of women in the workforce and the Vietnam War as examples. 


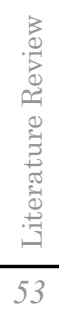



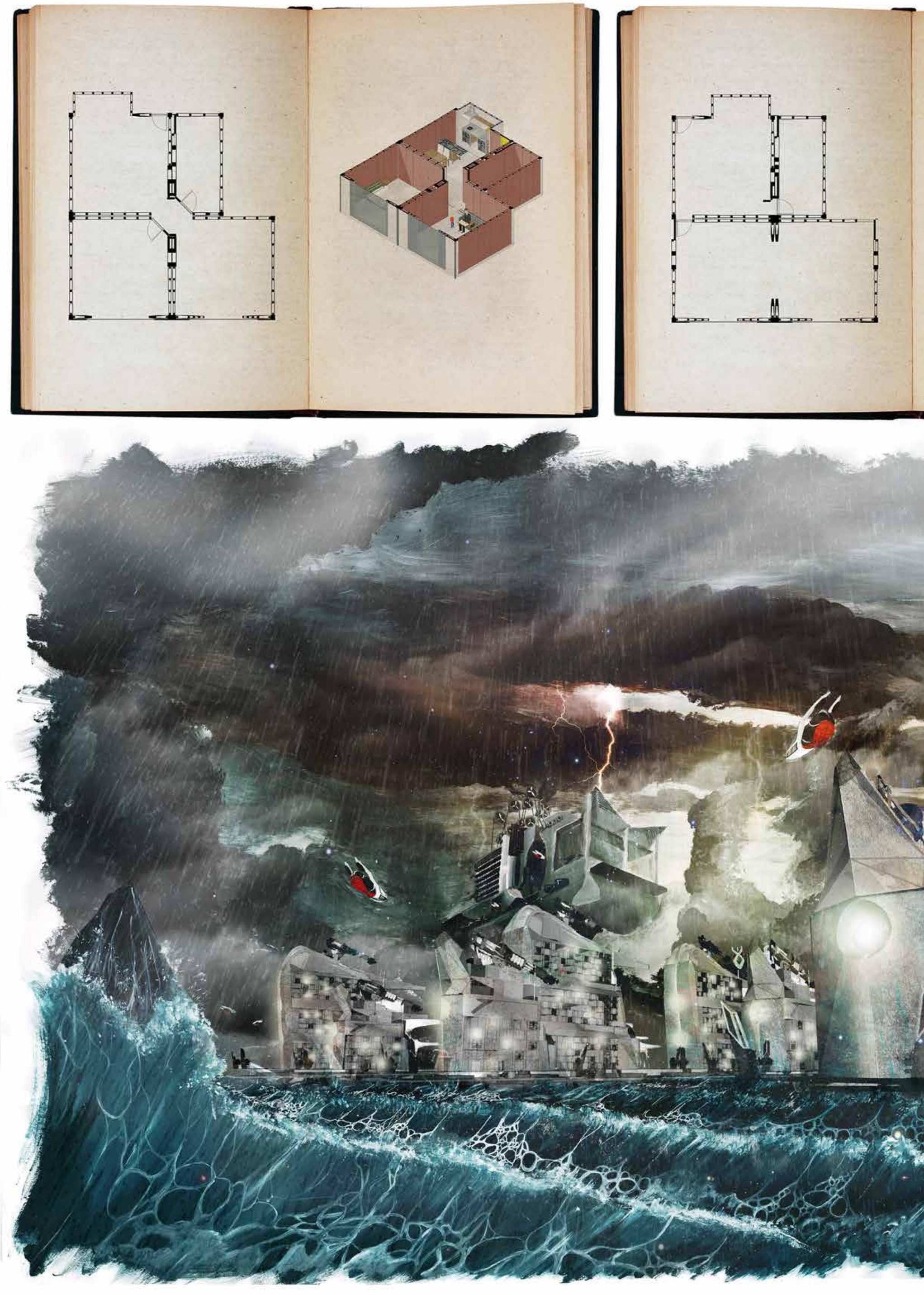


\section{Application: 2100 \\ Predictions}

This thesis involves both site specific and global predictions. The site specific predictions are deemed rational developments for Wellington that will have altered the appearance of Horokiwi come the end of the 85 year period.

The global predictions are more cumbersome and affect ways of living/life quality. These predictions are deemed to be probable outcomes of technological advancement and climate change after considering the evolutionary progression of 1900 to 2000 and forecasted climatic research.

This thesis assumes the following scenario based off the research carried out. It establishes a practicable setting for design.

\section{Site Specific Predictions}

- Sea walls will be built in response to sea levels but act only as a temporary solution.

- A connection between $\mathrm{SH} 1$ and $\mathrm{SH} 2$ will be built (in addition to various other roads) for a greater connectivity in the Wellington hills. The Horokiwi quarry will be closed for said highway and housing opportunities.

- Wellington's sprawl direction will be Nor-Eastern towards Lower Hutt.

- Some (weathered) houses of the 20th century will provide inadequate living conditions.

\section{Globalised Predictions}

- $2 m$ SLR $+1 m$ storm surge allowance, $4.8^{\circ}$ temperature rise and more violent weather extremes.

- Rubbish build-up in suburbs. Including the likes of air pollution and lots used as dumping grounds.

- Noticeably less vegetation due to pollution.

- Advanced natural power generation technologies as fossil

Fig 4. 16-17.

Housing Intervention: 3D Printable with Moving Walls for Customisation.

Exterior in Harsh Weather. fuels peter out.

- An increase in buildings adopting aquatic capabilities.

- Global focus on desalination to combat population thirst.

- 3D printing advancing to a state where printing can be done in a variety of materials/scales.

- Technology around lasers, force fields and gravity alteration developed due to warfare pressure. 


\section{Summary}

Key themes have been analysed to reveal design principles pivotal to achieving the aims and objectives of the thesis. The intervention has been developed coherently from the analysed themes and four precedents to result in something that is resilient, sagacious and still conceivable.

\section{The Contemporary Sublime; How to be resilient}

- The understanding of how to adapt to a changing environment, shaped by an understanding of potential technology and how it can benefit inhabitancy.

\section{Predictions and Precedents; How to be sagacious}

- Providing a scenario and solution that is guided by personal interpretation yet remains believable.

- The understanding what could be, or what is to come, based on knowledge of the past and present. 


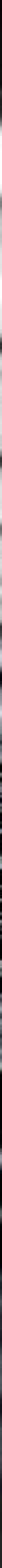




\section{Chapter Six}

Scenario Development 


\section{Horokiwi 2100}

This chapter is a projection of a worst case scenario for the hills of Horokiwi (Fig 5.02). It is representative of the research undertaken so far for a future 95th percentile scenario. It takes into account environmental change alongside population demands to establish a setting for the intervention to be designed into in the subsequent chapter.

Fig 5.03/04 shows the progression to 2100 with a narrative. The sea level, alongside pollution, dwelling numbers and soil degradation is increased to portray sordid conditions and challenge acceptable standards of living. 

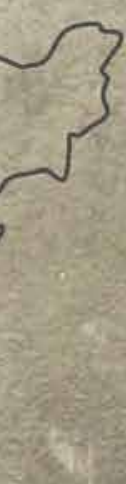


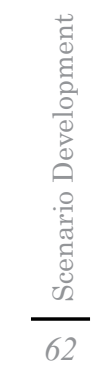

\section{0}
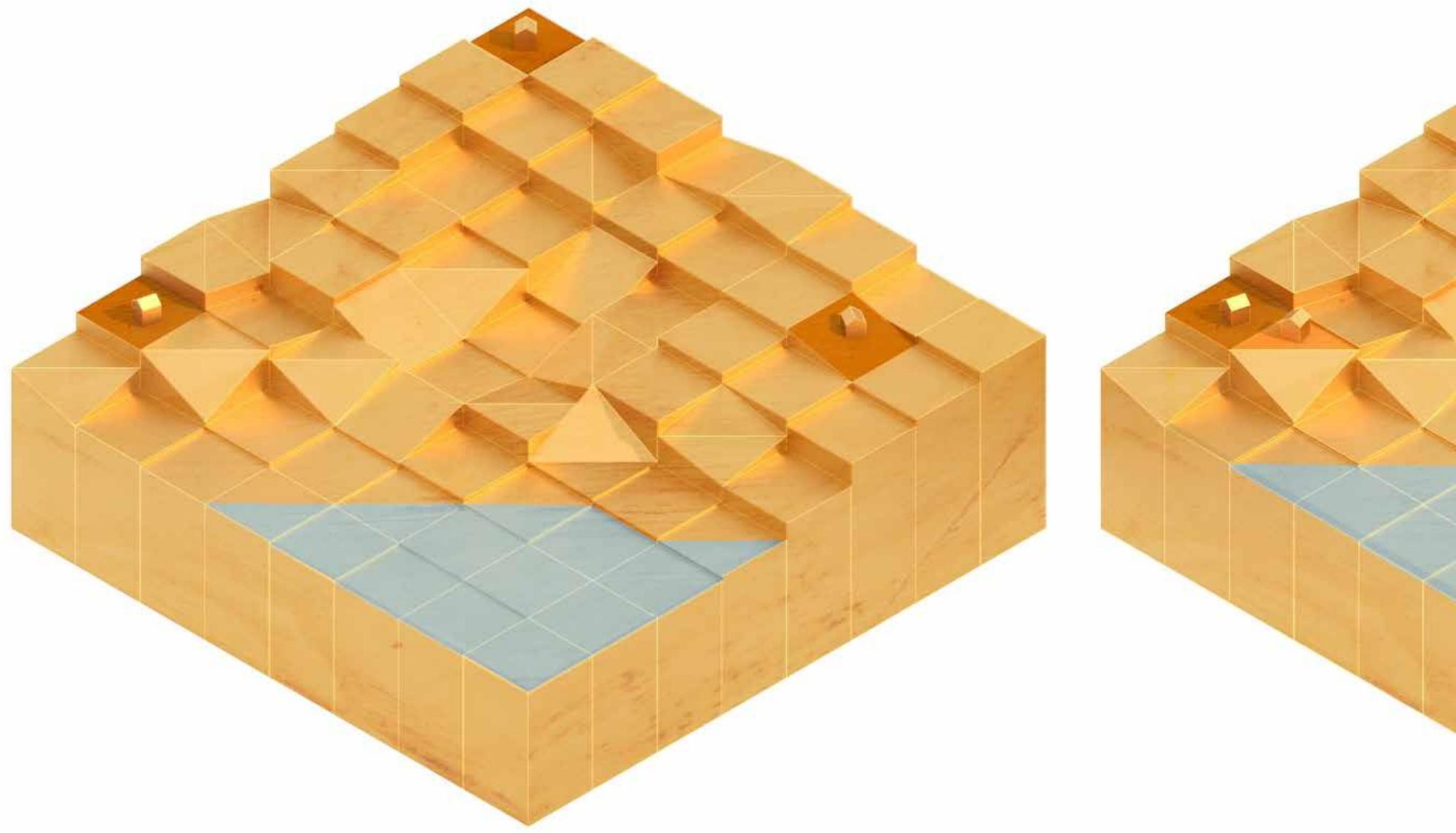

Fig 5. 03. Horokiwi Progression Diagrams 2010 - 2100. 
2040

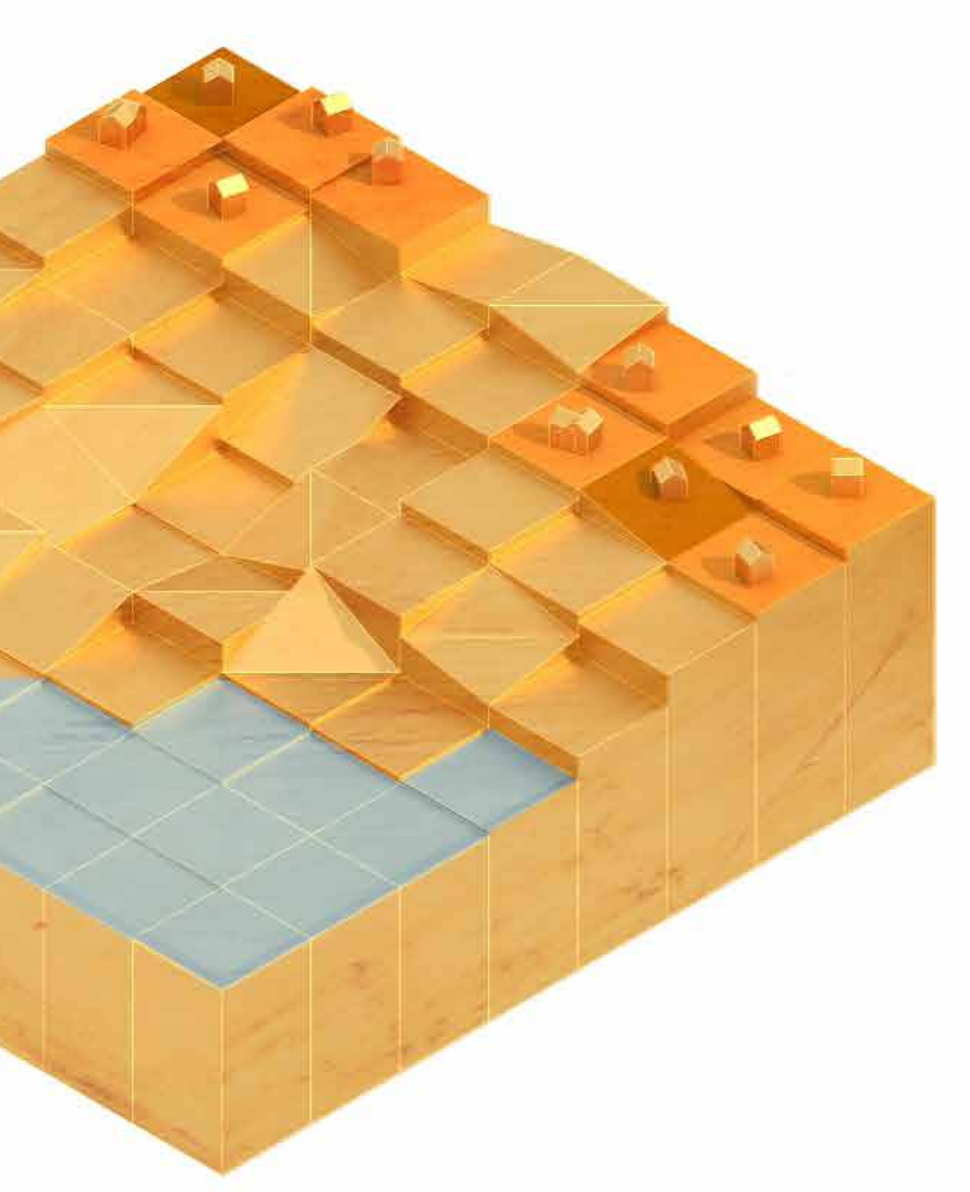

2070

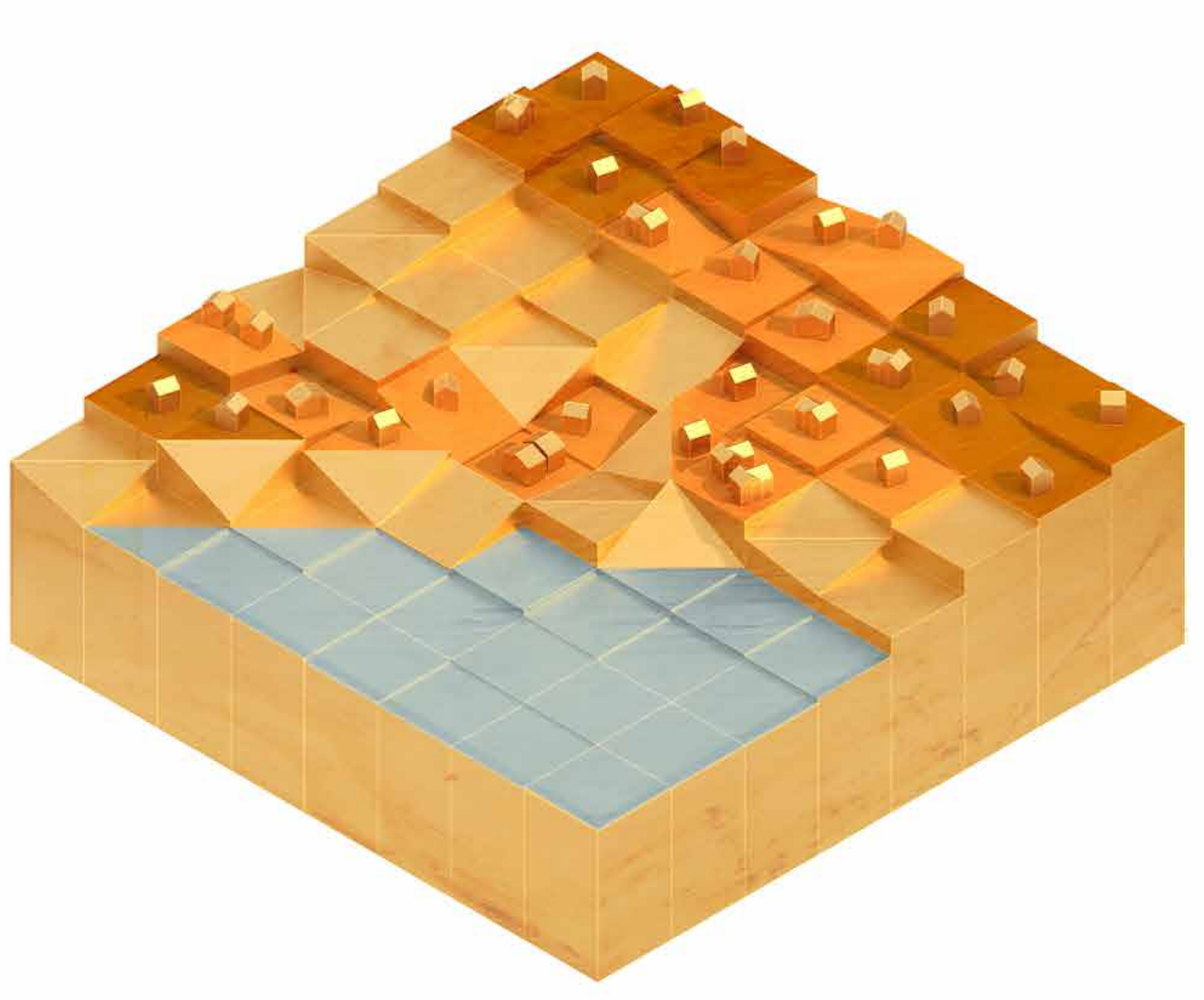

2100

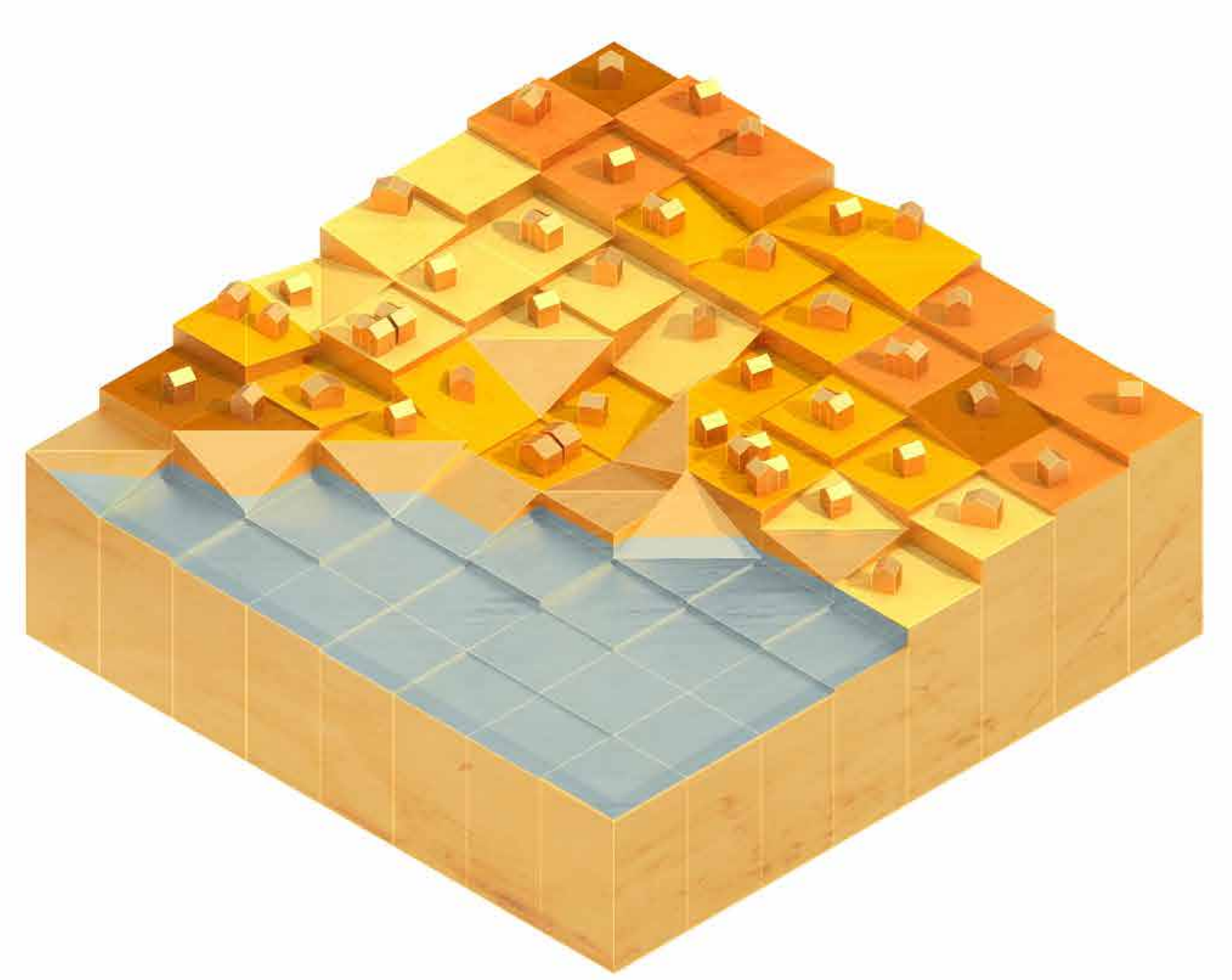




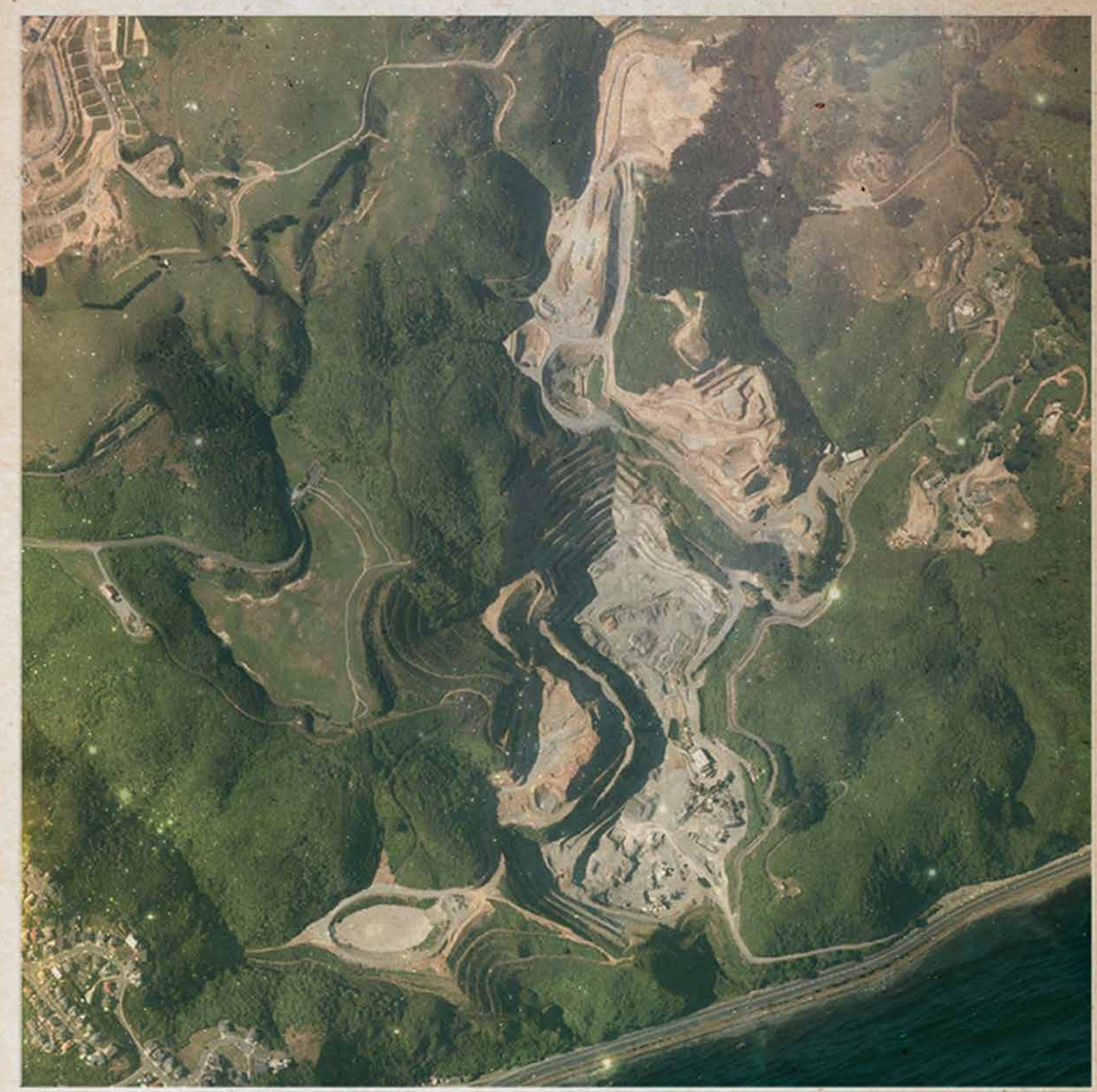

2010 


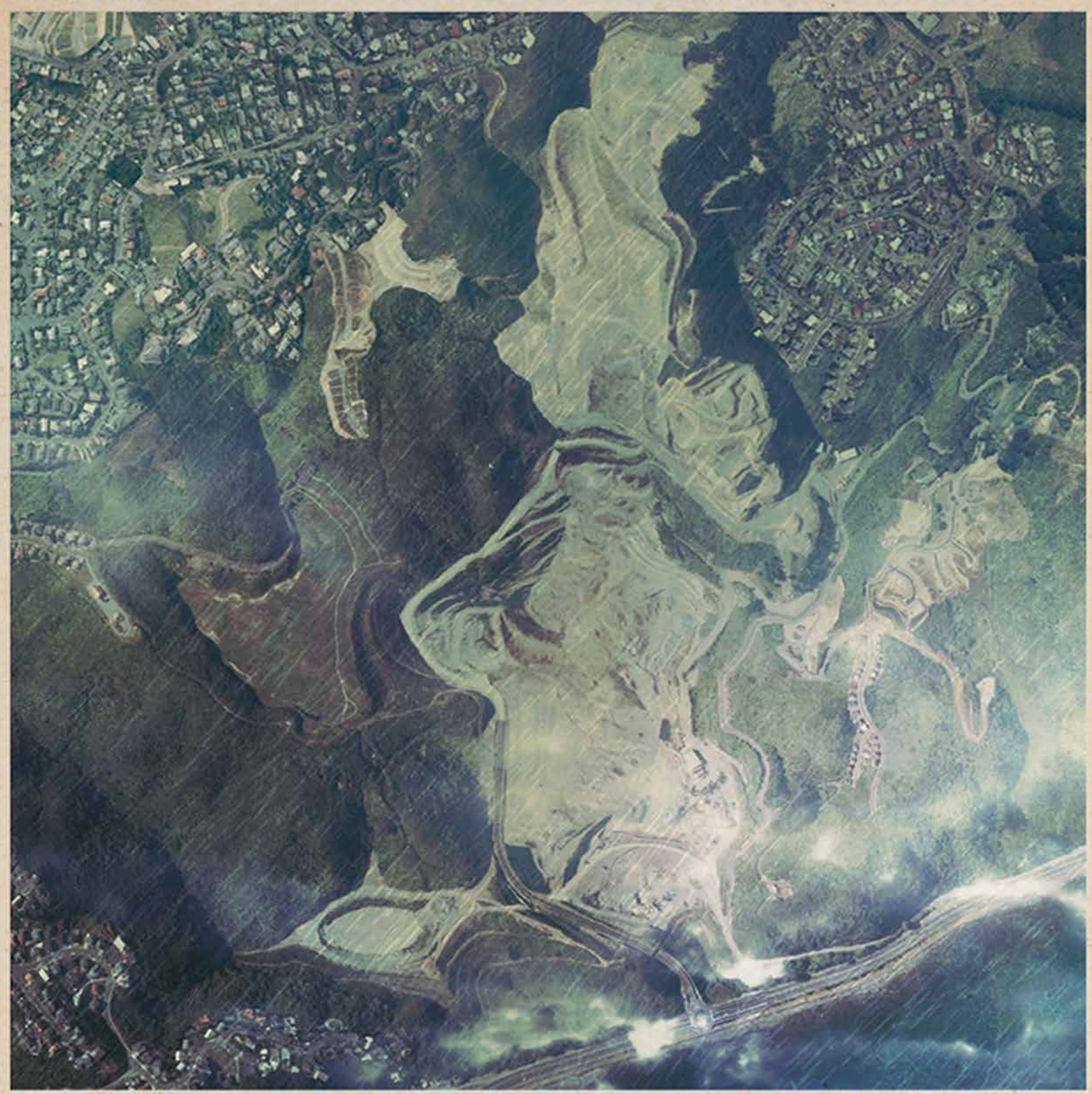

2040 

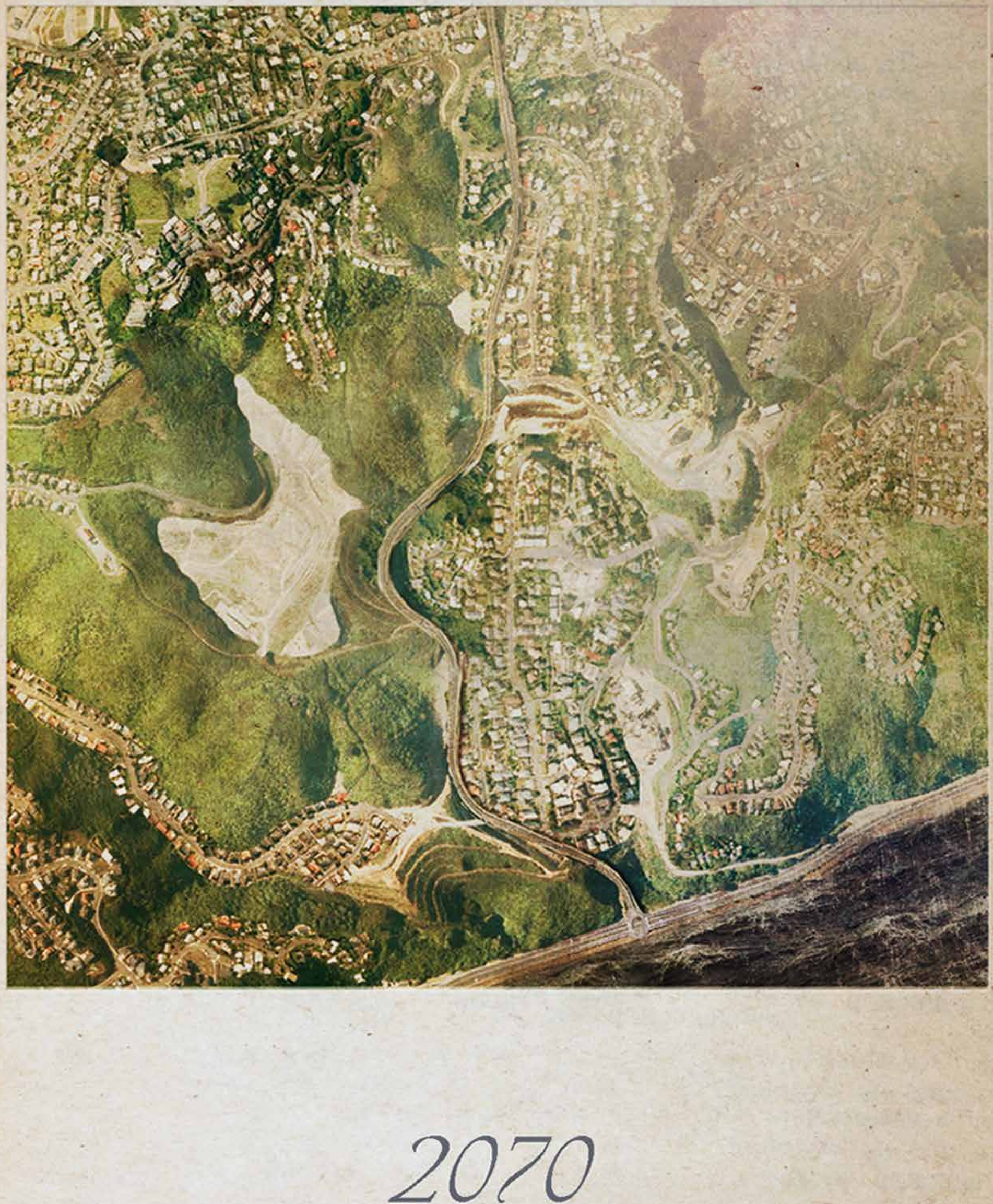

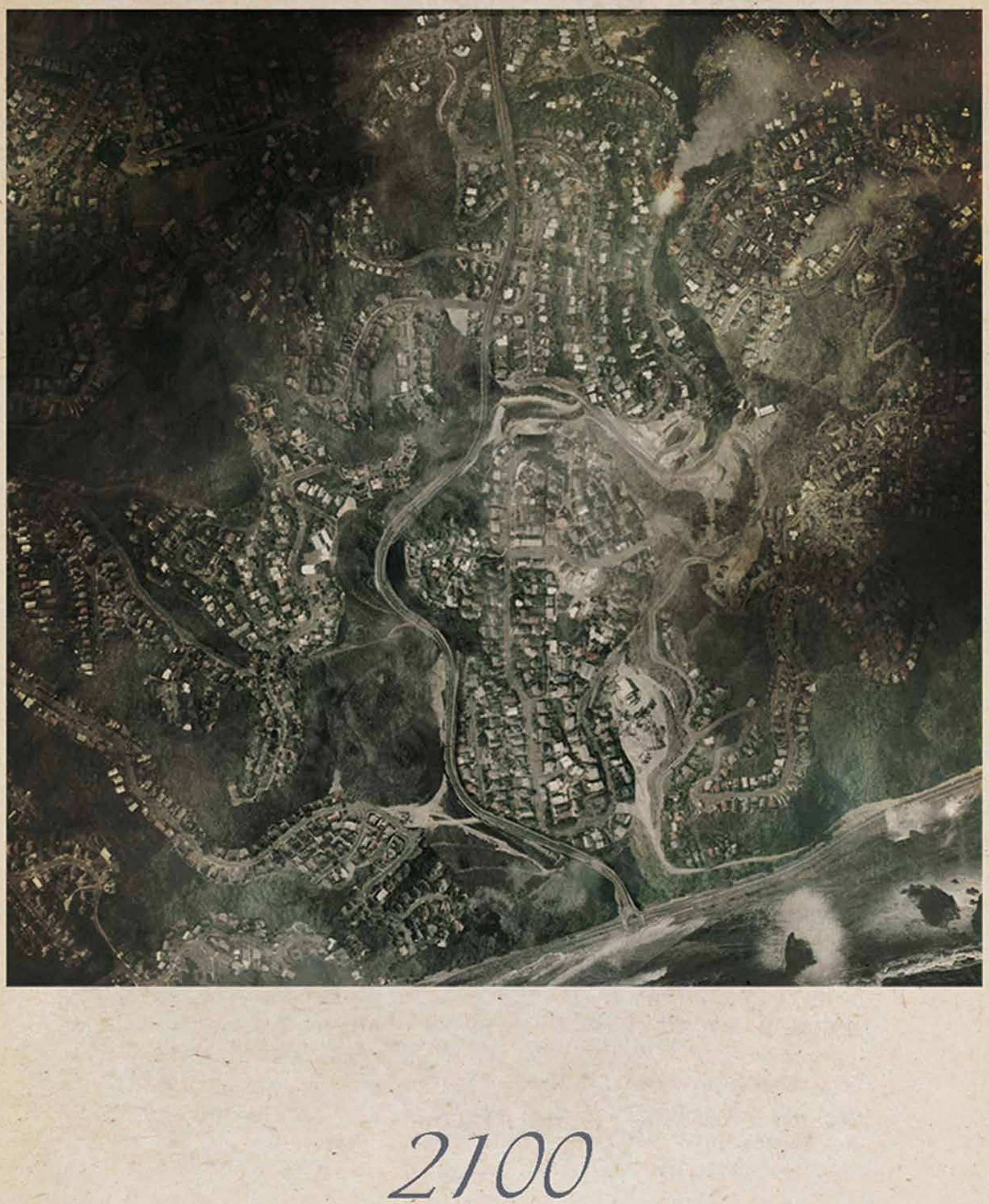


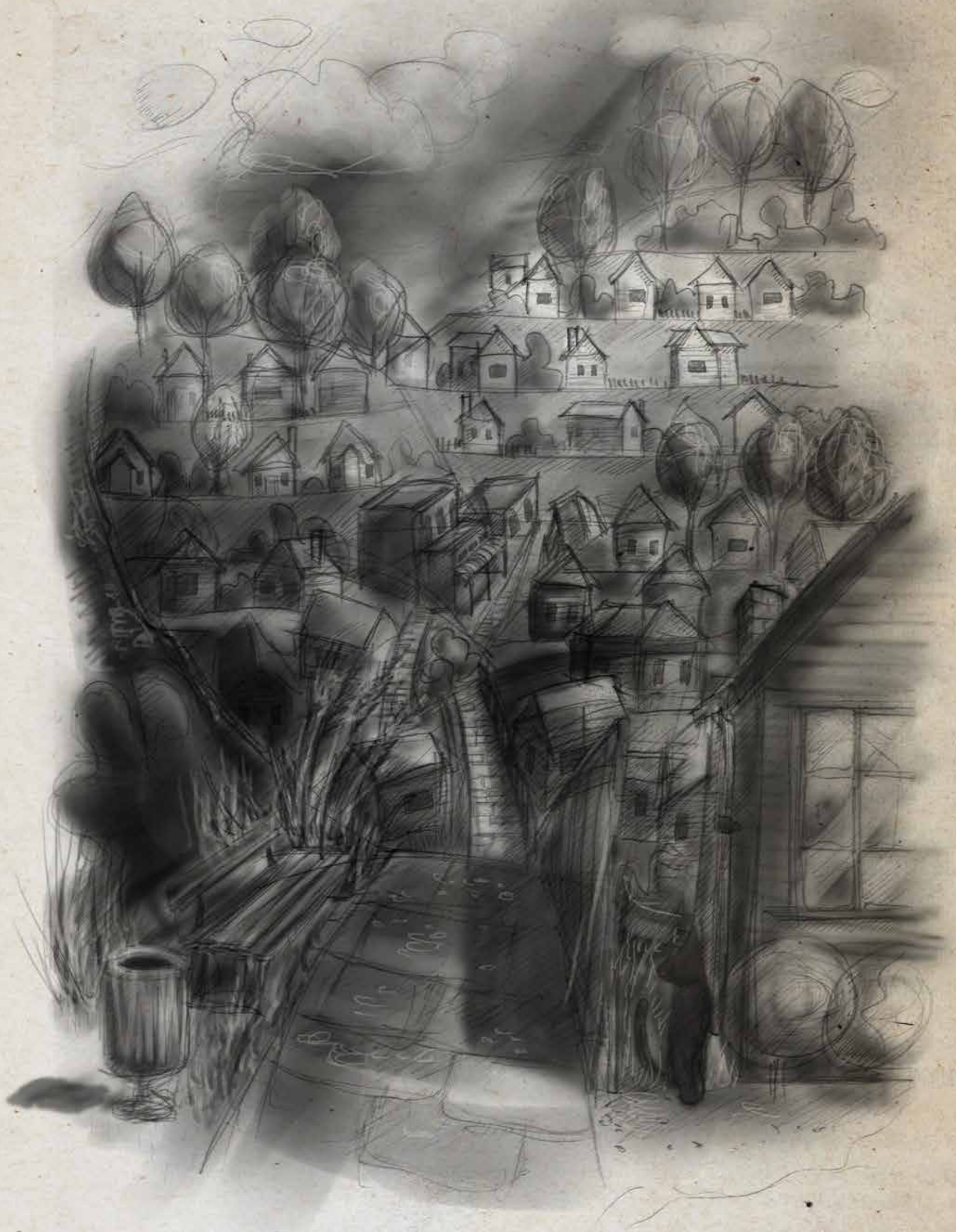




\section{Chapter Five}

Prologue 


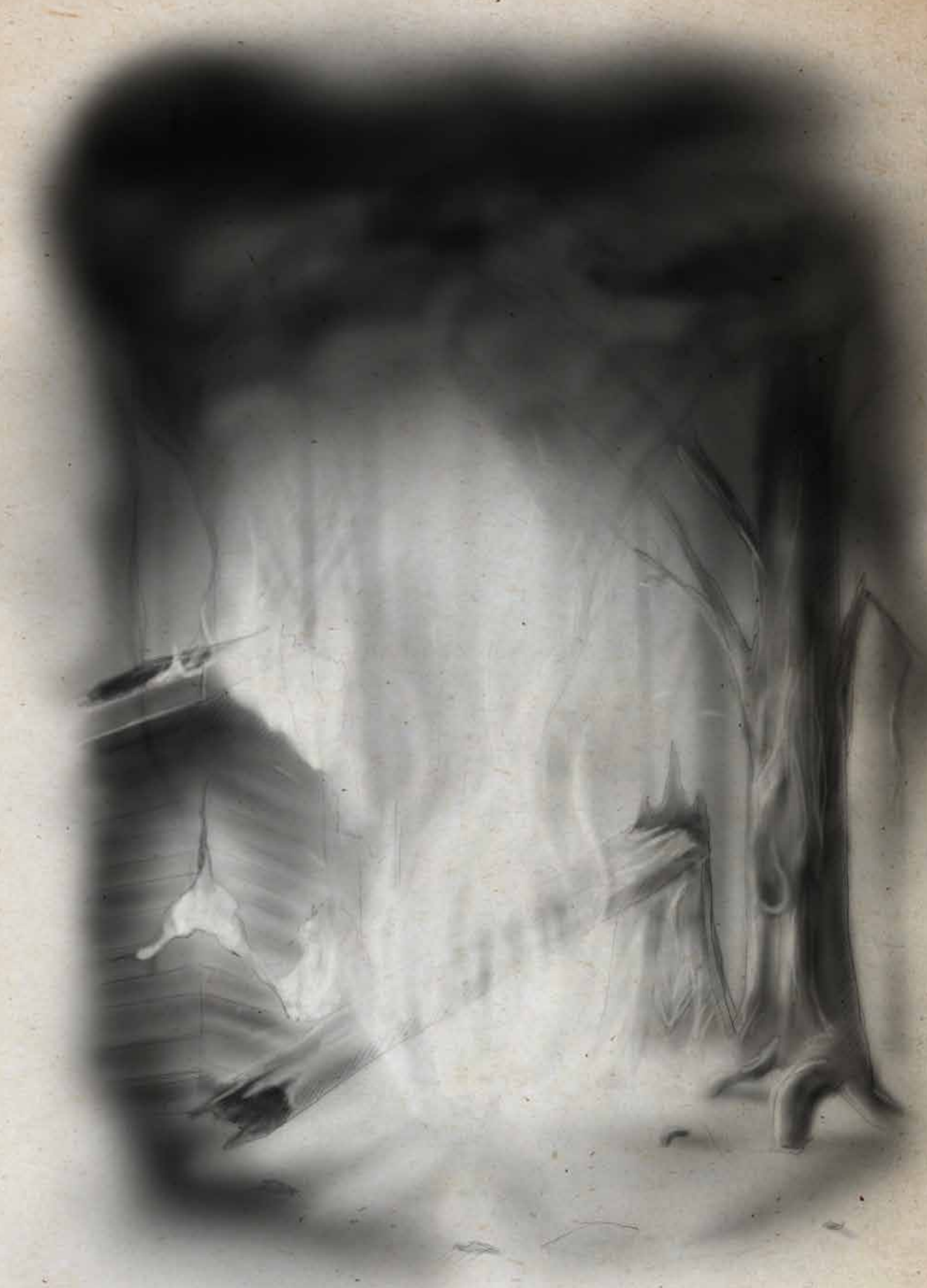

Burdened with a spark, to birth the kindled remains, culled, left ruined by these ravishing flames.

It smoulders, it stains the wretched canvas of oak, consuming all colour in a sable delta of smoke. 


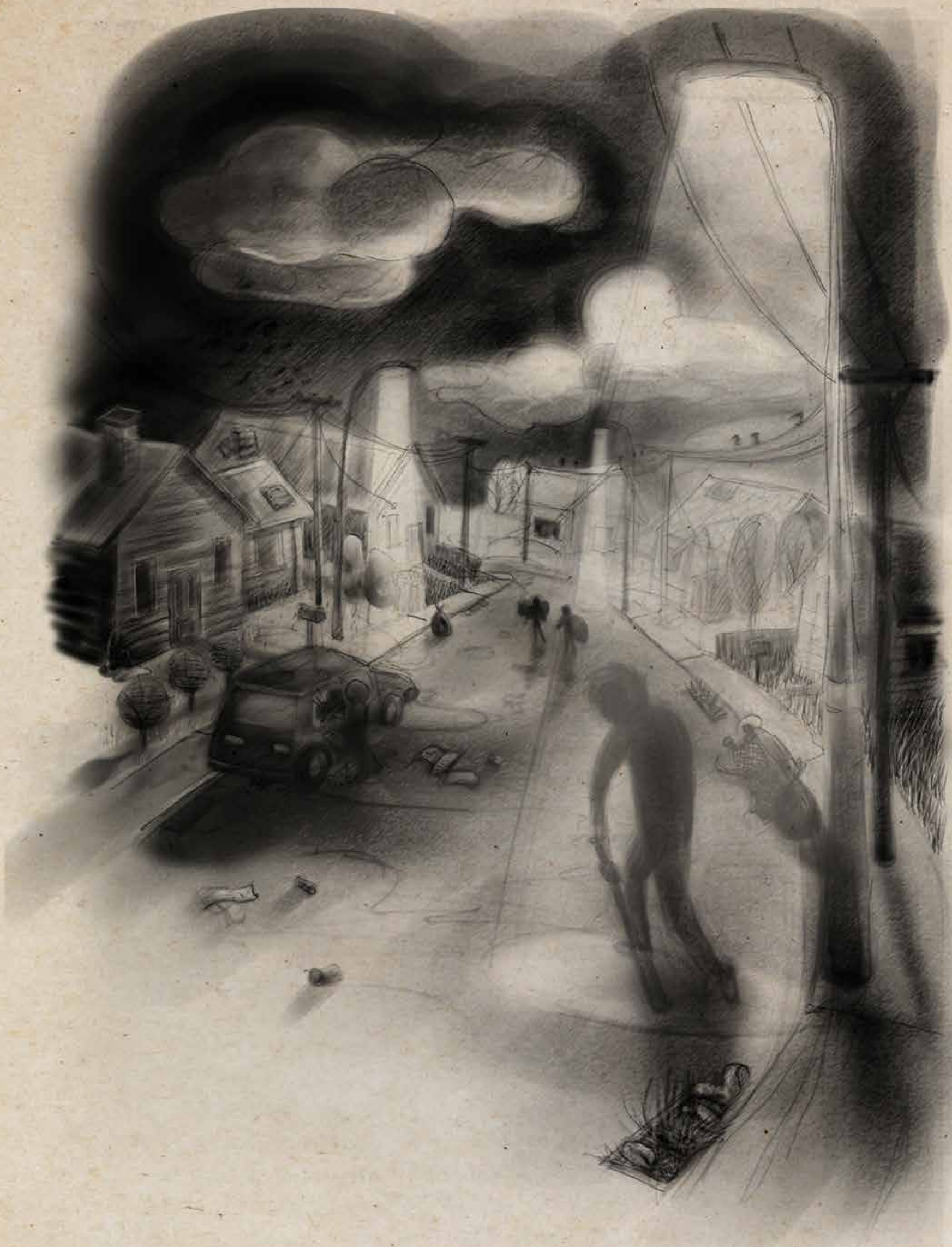

While deep in doldrums the sky weeps to heal,

bathing the ground with a cleansing appeal.

Yet each breath is tainted, a painful melancholy flux

in this disenchanted street of criminal disgust. 


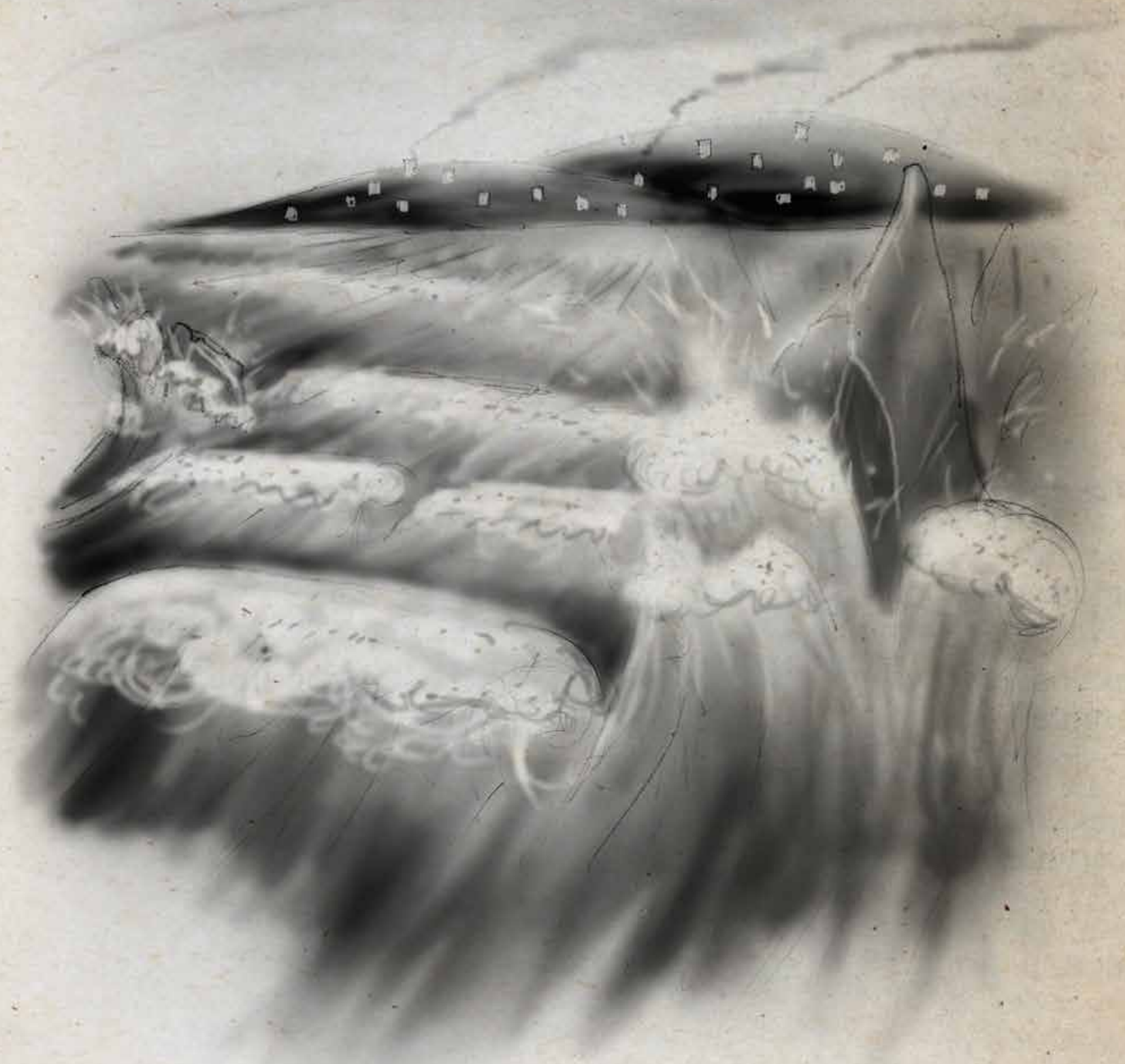

A stone's throw away the ocean picks its fight,

lobbing a fluid punch in the glow of the night.

The outline of a callous wind casts its knockout blow controlling the reins to elicit a dissonant woe. 


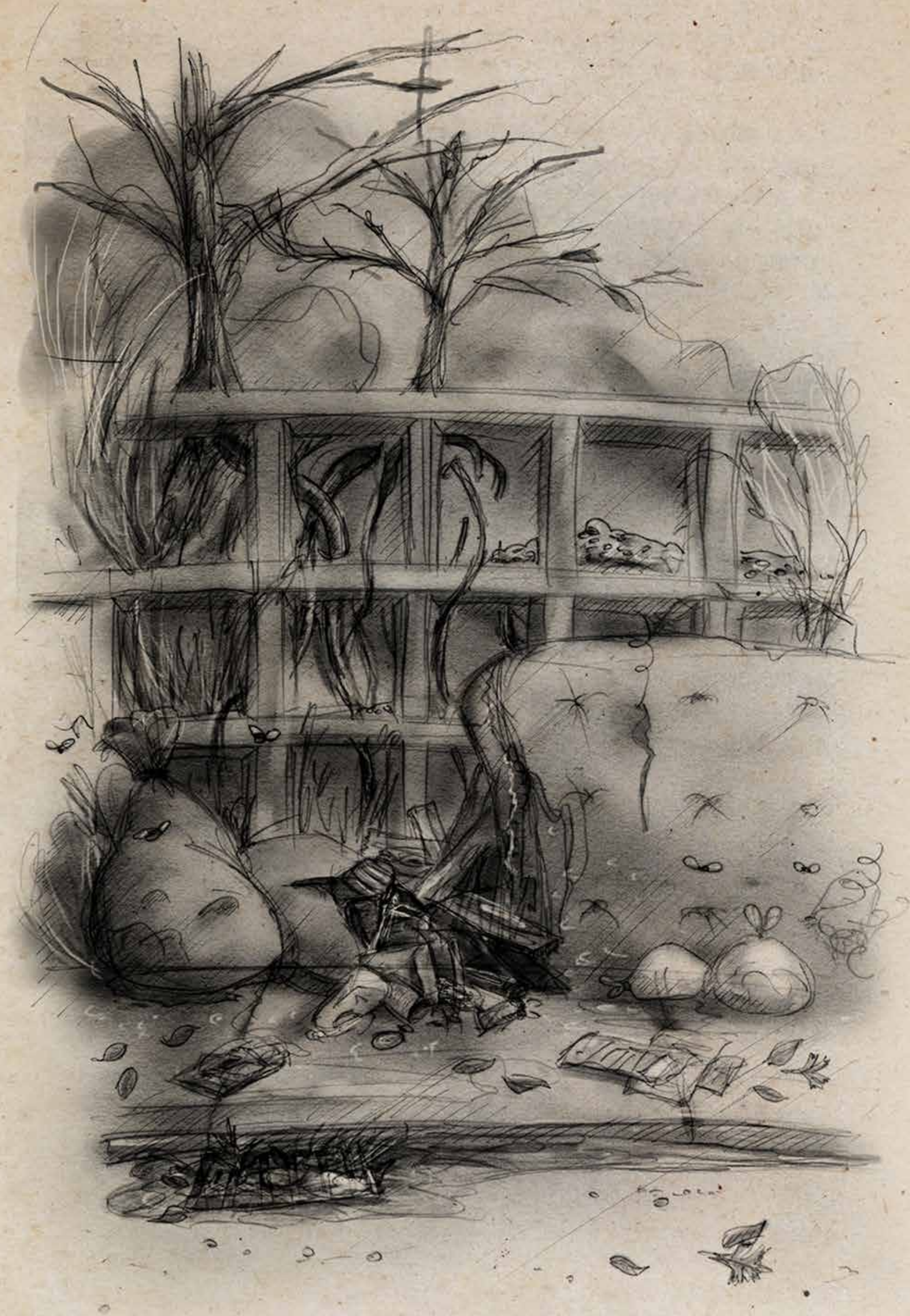

Before the clouds readjust in a fatal submission the morning sun appears to whisper its condition.

Raising the temperature, to disclose its potential blurring those streets once formerly residential. 


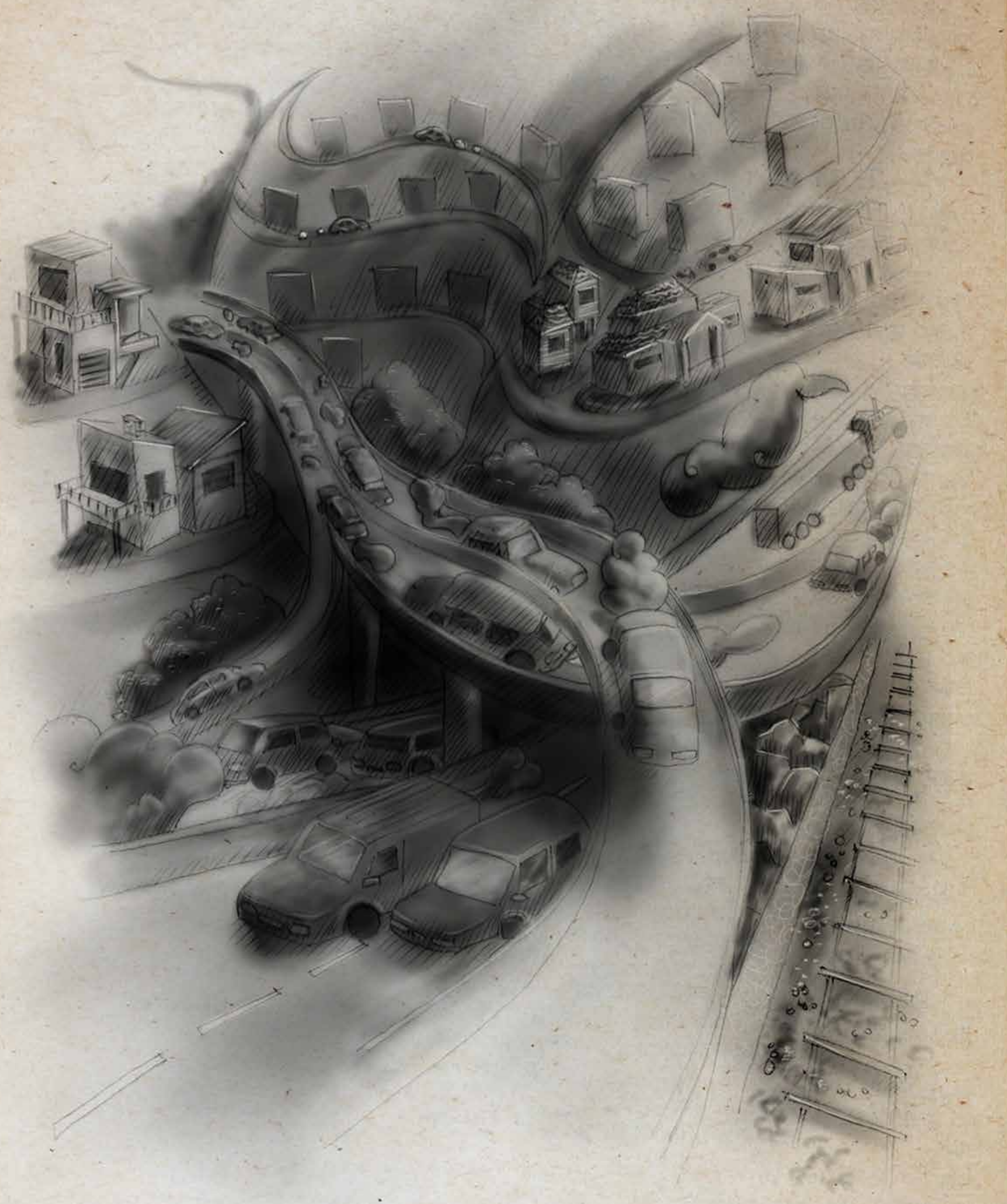

There's silence in the trees, the engines won't sleep.

The sky is distressed, it continues to weep.

From the blame of a fiend, reverence trumped by desire;

that chapter's closed, sealed by the hand of a liar. 


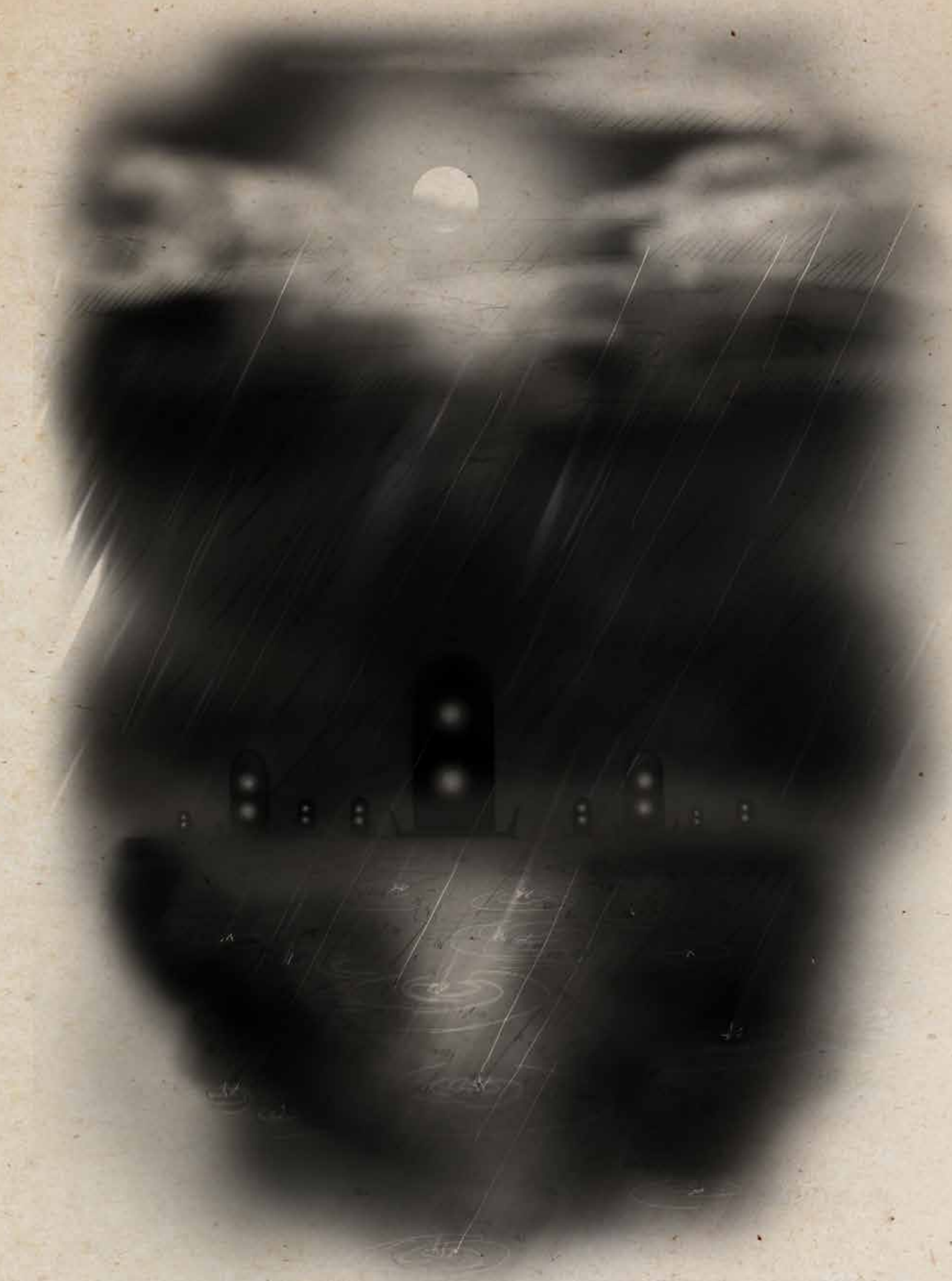

Now turn to endure, rebirth a derelict dwelling, into a home, fit for this elemental shelling.

Brace for the impact, prolong the dismay, forced to witness earth's final day. 

Chapter Seven

Design Intervention 
The land we've been given is in anguish. The forces have just become too strong. This tale is not mine, I don't belong here.

Grandpa's stories of how it was before the shift, before the madness; why is that not my story too?
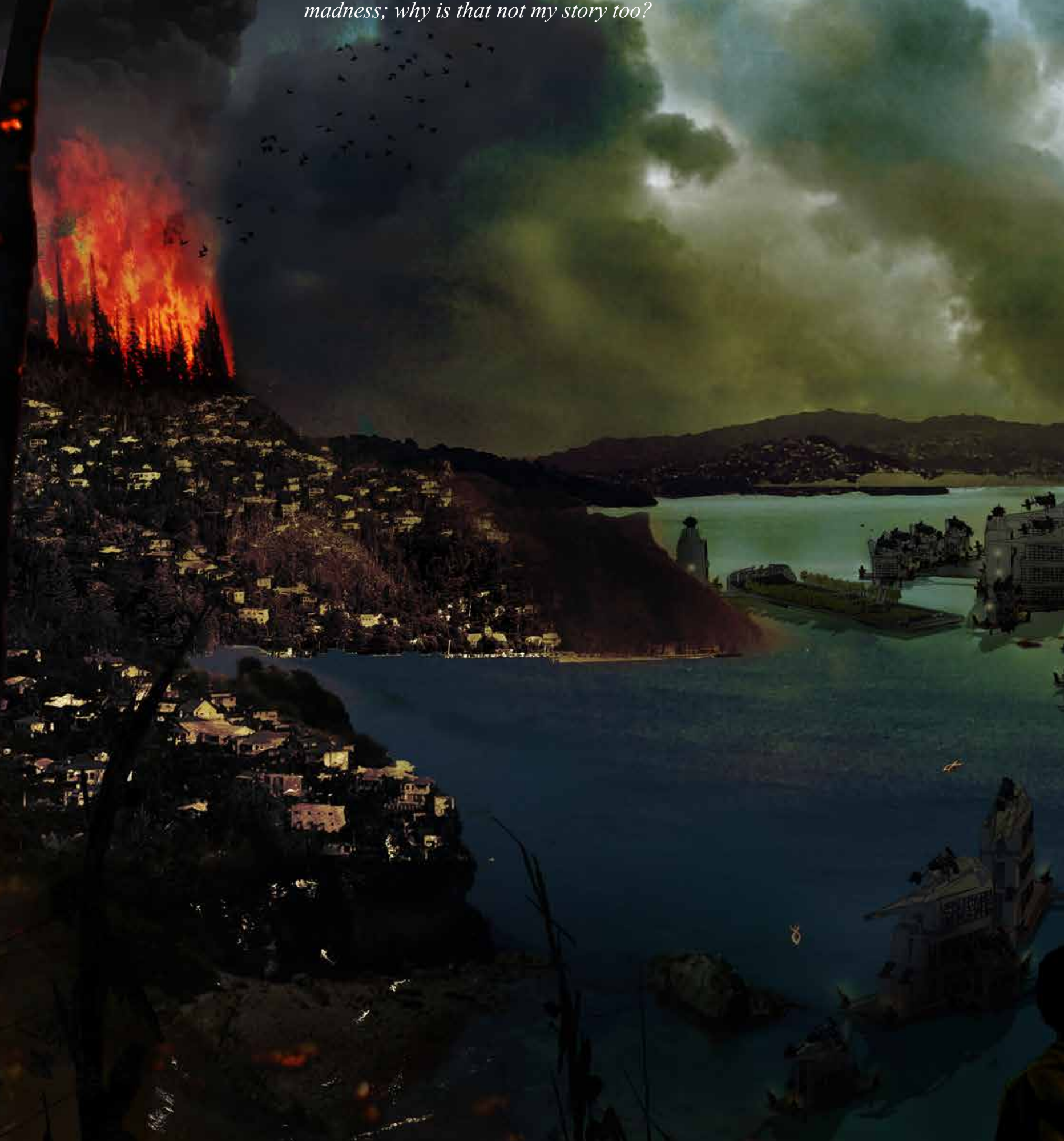


\section{Introduction}

"Architecture can't force people to connect, it can only plan the crossing points, remove barriers, and make the meeting places useful and attractive."

- Denise Scott Brown, 132.

As Fig 7.03 shows, all land near the sea is occupied and the environment ruined. Lower Hutt has been slowly claimed by the sea and many buildings have been rendered useless.

The intervention comes in the form of a kinetic, sea-bound suburbia. It is seen as a way to provide a safe and resilient location for people to relocate to. Hundreds of mobile apartment towers and green spaces will line the coast and be

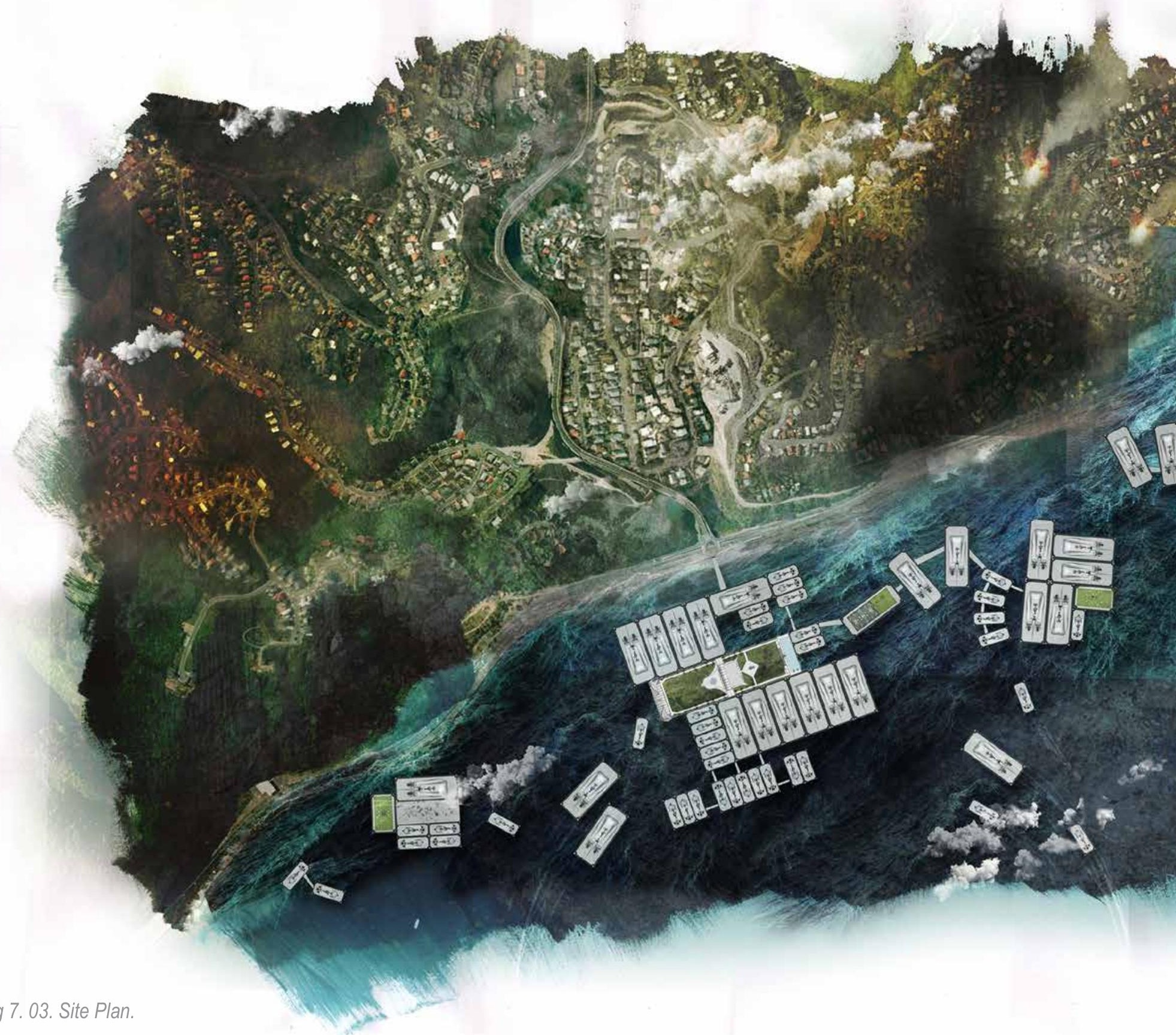


able to adapt to a variety of situations. Fig 7.03 Illustrates only one example of how the intervention can form around a coastline. These towers can be built in any coastal location that has a gradual land-to-sea decline.

The subsequent pages explore the qualities of this suburbia from three scales and explain how the objectives of the thesis are achieved. First is 'Adaptation', focused at the macro scale, looking at how the towers can cope with extreme climatic conditions. Following this is 'Facilities' at the meso scale, which elucidates on how the towers provide an enduring place to live. Finally is 'Accommodation' which is at the micro scale, explaining how the future of living may evolve.

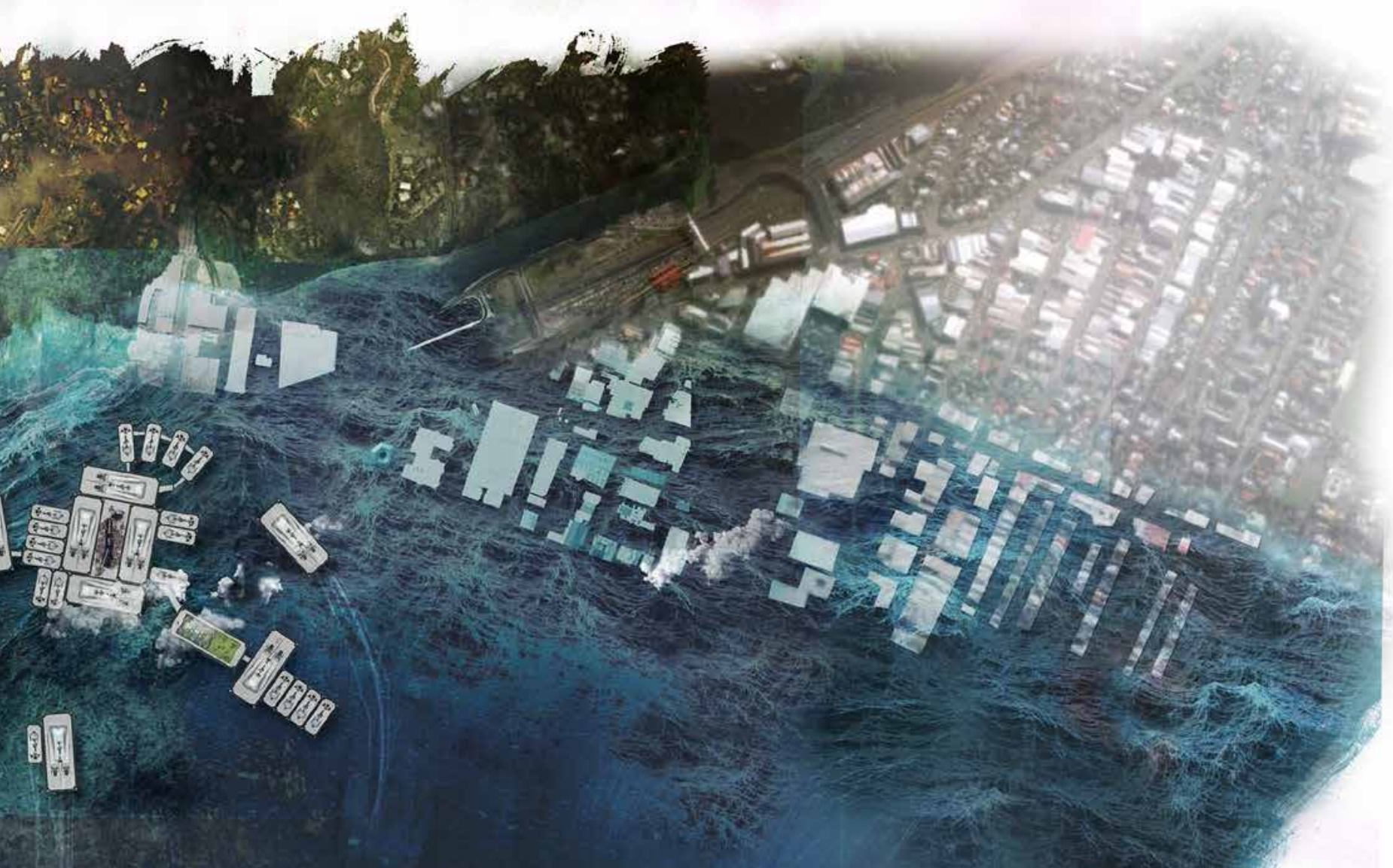

45 

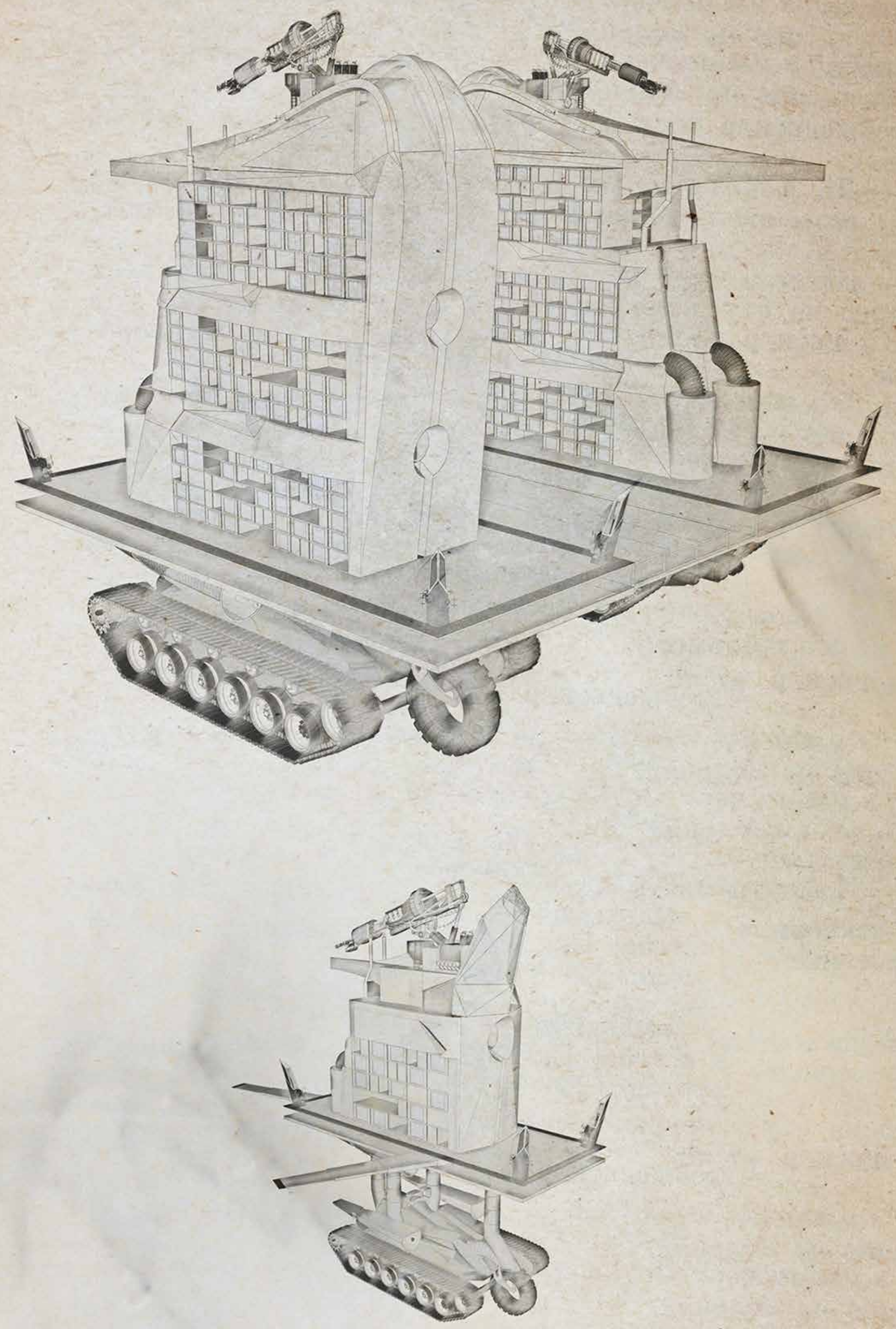


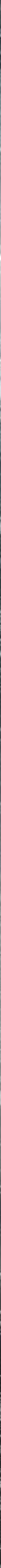


Instance three demonstrates the connectivity and social interaction. It highlights the vivacity of the scheme on the days that the weather is acceptable by the standards of 2100 . It offers the opportunity to socialise in a dynamic network and encourages community events and interaction. The elongated sides of the large towers have extendable platforms that, when encased by all sides, forms a sheltered space for markets, events or leisure activities (see Fig 7.08).

The fair weather will encourage roaming and towers to associate with one another. Smaller towers may have a faster but longer route that covers more area than a larger tower. Occupants are able to see all routes on an digital map and plan to shift their apartment rooms to different towers on different routes as per their fancy (see 'Accommodation', page 96).

In all scenarios there is the option to move closer to the coast in violent weathers to reduce pressure from the waves. This is possible as the vehicles have the capacity to alter wheel heights individually to accommodate any altering terrains. 


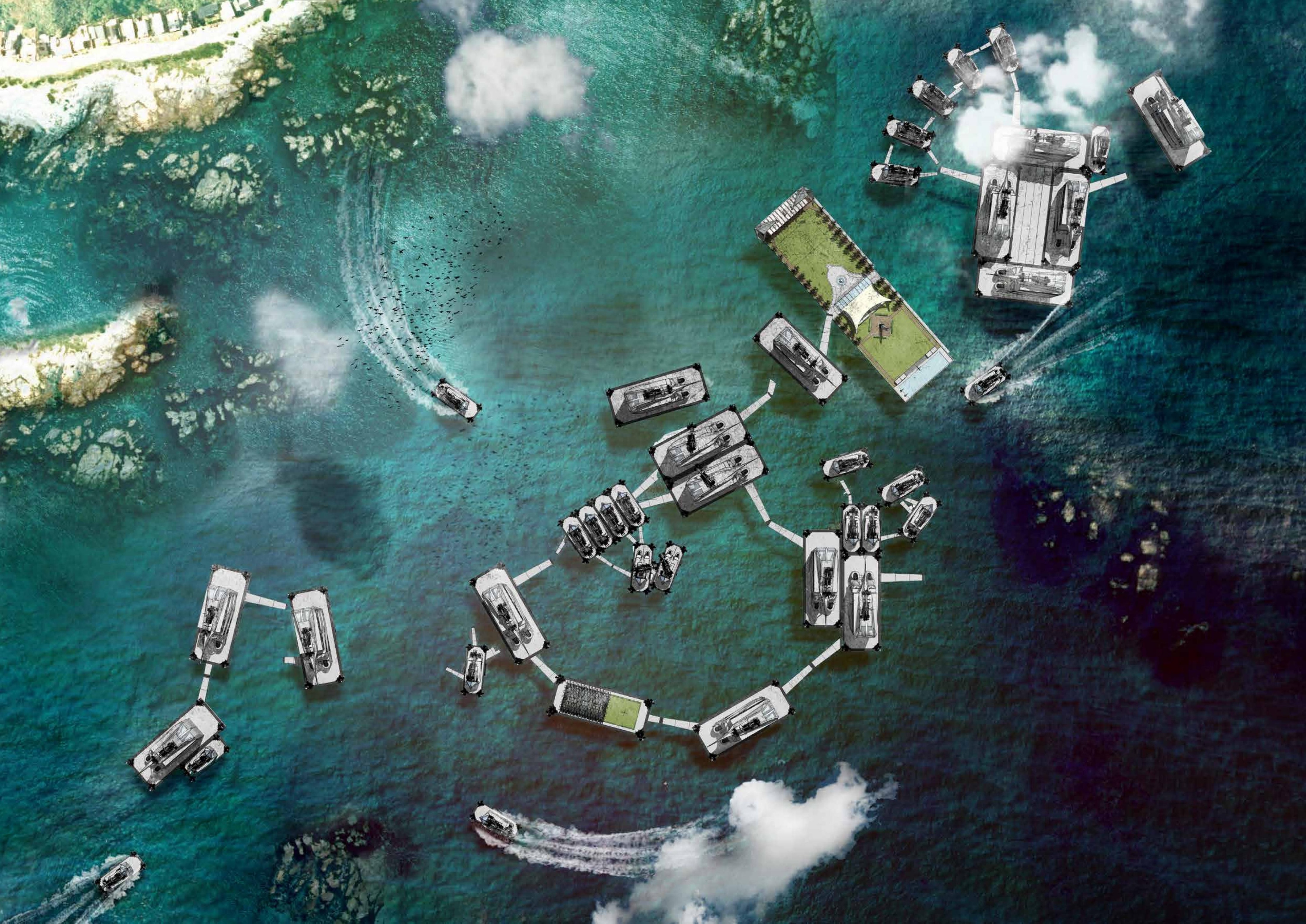


They look as if they are staring us down... but that strong light, it reassures me. Finally our time has come. I'm looking forward to being closer to my friends. They said the top of the towers have an awesome simulation room where all the kids play.

Dad chose a roaming tower because he doesn't like to settle in one place for long. He said he's ordered four rooms, so it looks like ill be sharing with Sis, but that's alright.

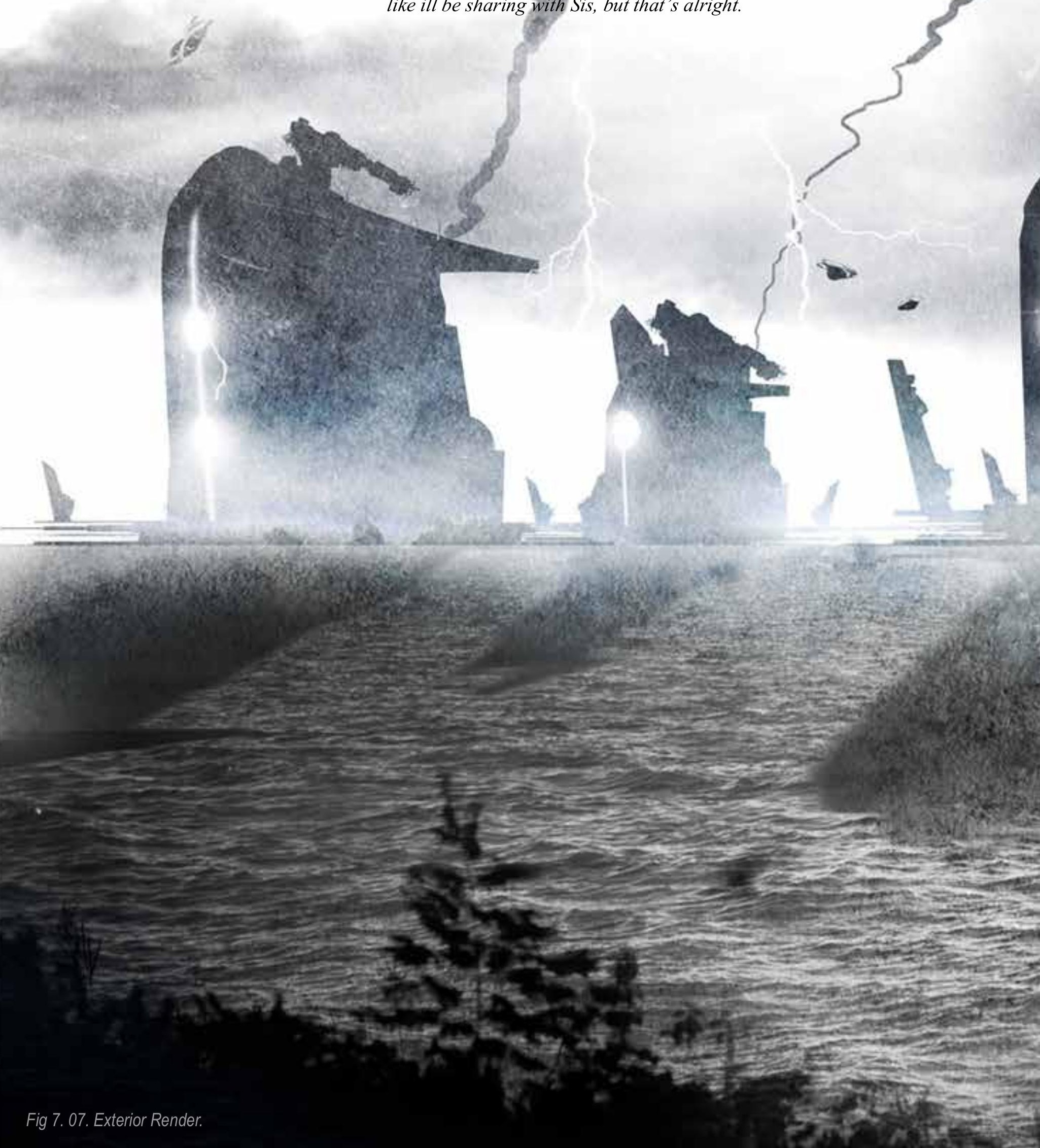




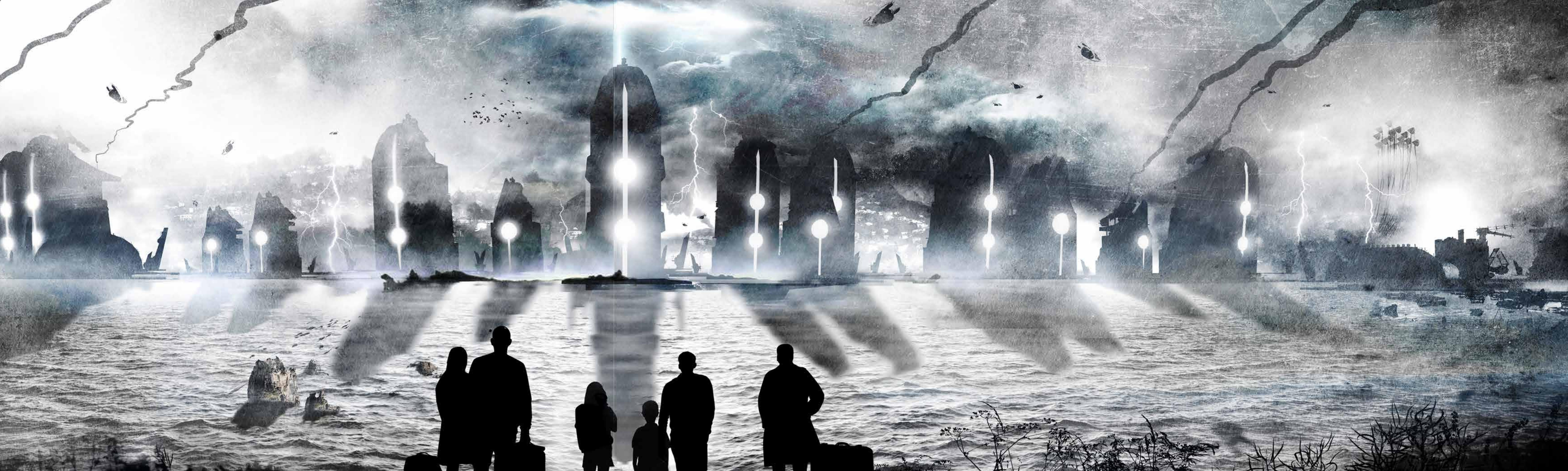


It was cool flying over the neighbourhood. I saw four of the towers in a group and they looked like they were having a market. And the park was huge, I can't wait to go there.

It was quite late by the time we arrived. But I didn't mind because I got to see the cranes shifting people's rooms into place; Grandpa looked a bit frightened by it all, pretty sure his time didn't gravity lasers.

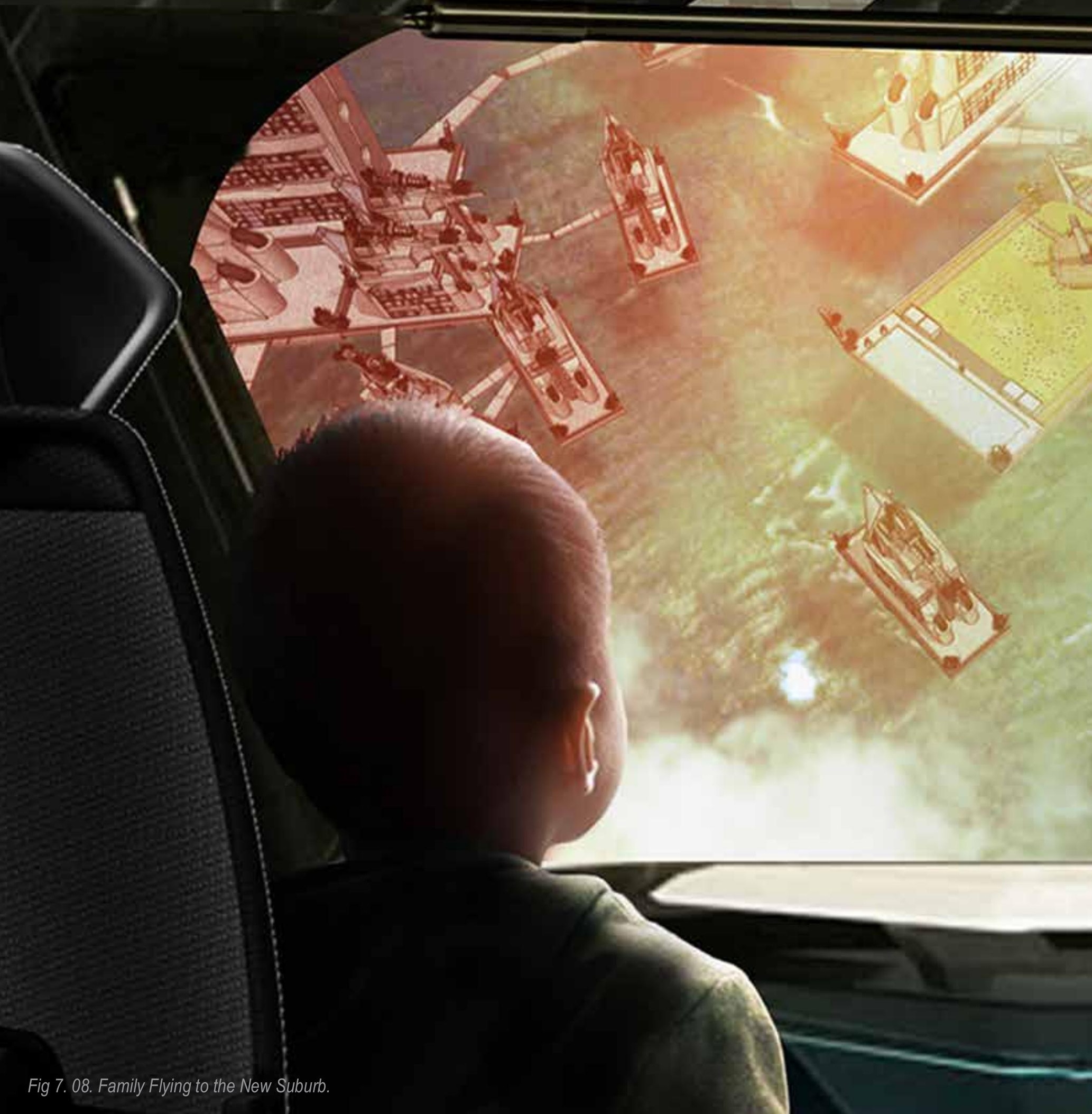




\section{Facilities}

Each tower is equipped with a series of facilities in respect to (primarily) objectives one and three. This section explains how some facilities contribute to an evolution in living and how some aspects of the tower allow it to function as a safe-haven in light of a storm prevailing. Letters reference Fig 7.10.

A: [The subsequent 'Accommodation' section offers a full elucidation] It is proposed that in 2100 you will own a certain amount of rooms instead of land. This feature allows for your prefabricated rooms to be passed from tower to tower via the crane at the top if you want a change in location, move in with someone or wish to downsize/upsize from your current number of rooms into a more suitable tower etc. 3D printable, configurable rooms are believed to a logical progression in the development of fast, inexpensive housing.

B. The gallery space of each tower has a simulation space for the community to enjoy; in particular on the days where the weather does not permit them to access the roaming green spaces. As a simulation space it can project a calming and relaxing environment in dismal weather to provide a sanctuary to escape to. An interior shot can be found on page 95 .

$\mathrm{C}$ : The technology surrounding desalination is believed to be fully resolved before 2100 , where each tower will be equipped with a small desalination plant at the rear. This plant will take water from the immediate environment to provide fresh water for the occupants. Grey water is treated here also and returned back into the environment.

D: Within the towers are flying vehicle storage areas. In the larger towers it is in-between each of the three blocks of five floors of apartments. The entrance to these areas are the holes in the front facade, and exits are out the rear. The smaller towers only have a total of five floors of apartments and the storage space is above this.
E: As aforementioned, power generation for the towers comes from ocean currents and solar gains. The turbines (I) are located at base near the vehicle and remain below the water's surface. Excess power is stored in a giant battery behind the front facade (E). A conveyable example is found in laptops; providing a backup supply in case of emergencies.

F: The four corners of each platform have sensors which produce force fields to prevent people falling into the water. These sensors activate when people come near, developing upon a shockwave attenuation system Boeing patented in 2015 (Atherton). They also serve as a lightning conductors and can be powered by this sporadically absorbed energy.

G: Underneath the base platform is the extendable ground-space for social occasions and the connecting bridges for access between towers. These bridges revolve 180 degrees to stay clear of the structural support (axis of which is shown by red lines) which takes the loads of the towers to the vehicle and into the ground. Each bridge has a magnetic tip that allows it to hone in on the nearest platform (which has an opposing magnetic border) to establish a connection.

$\mathrm{H}$ : The vehicle which allows the towers to move. The tank-inspired wheel system allow it to traverse rugged terrain. 


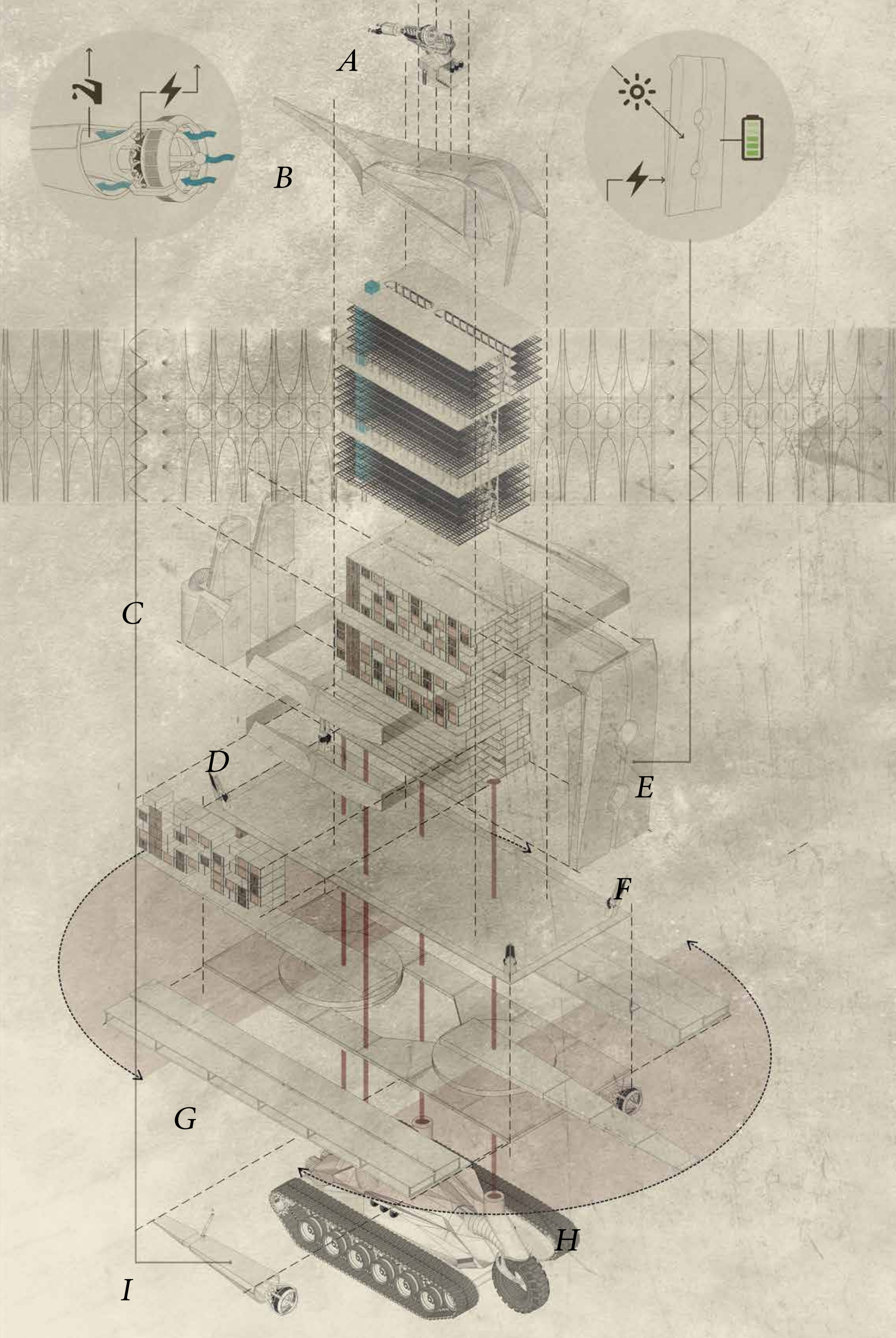


Community spaces are integrated into the intervention to make the sordid setting more convivial and improve upon the facilities on land in a typical suburb. The simulation space (Fig 7.13) was explained on the previous page, leaving the market and green spaces.

The market/social spaces (page 90-91) are made available via the extendable platforms. These areas have the option to be encased on all four sides, providing a space that is more than adequately sheltered. It also establishes events in an optimal visual location to attract community participation.

Green spaces are made accessible for use in acceptable weather. Three prototypes were put forward as seen on page 83. These include a greenhouse, sporting and large-park platforms (Fig 7.11-12); the later being designed in detail to host many different events being $290 \mathrm{~m}$ in length.

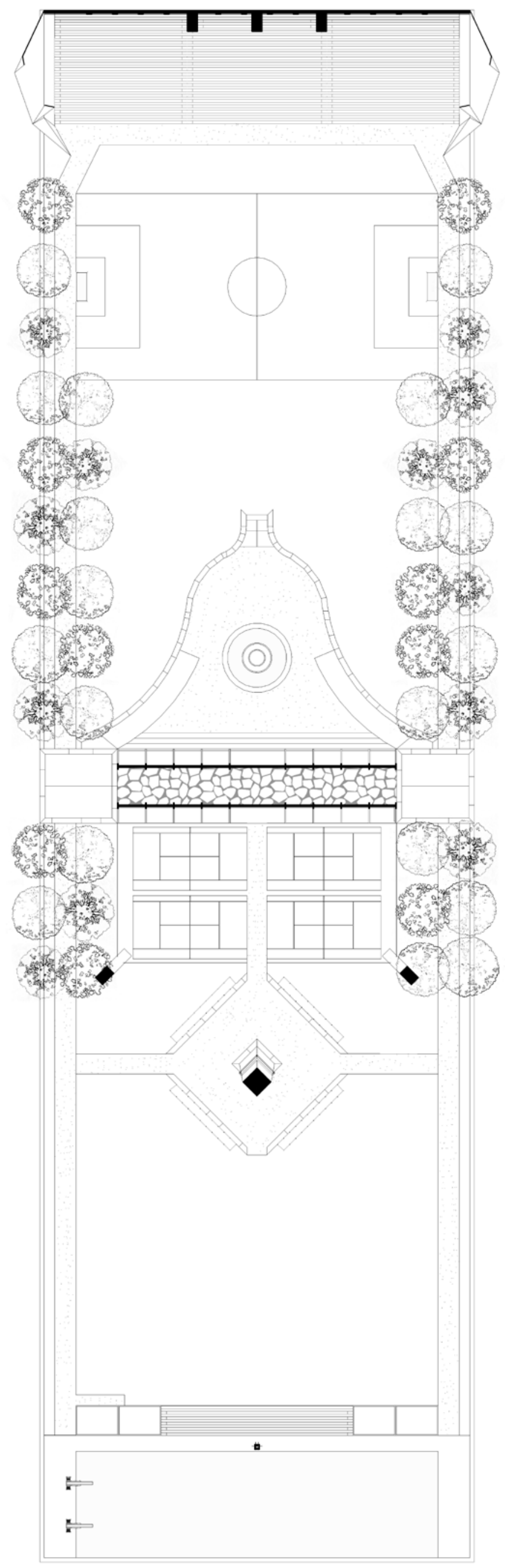


$\Rightarrow \cos ^{2} x^{2}$
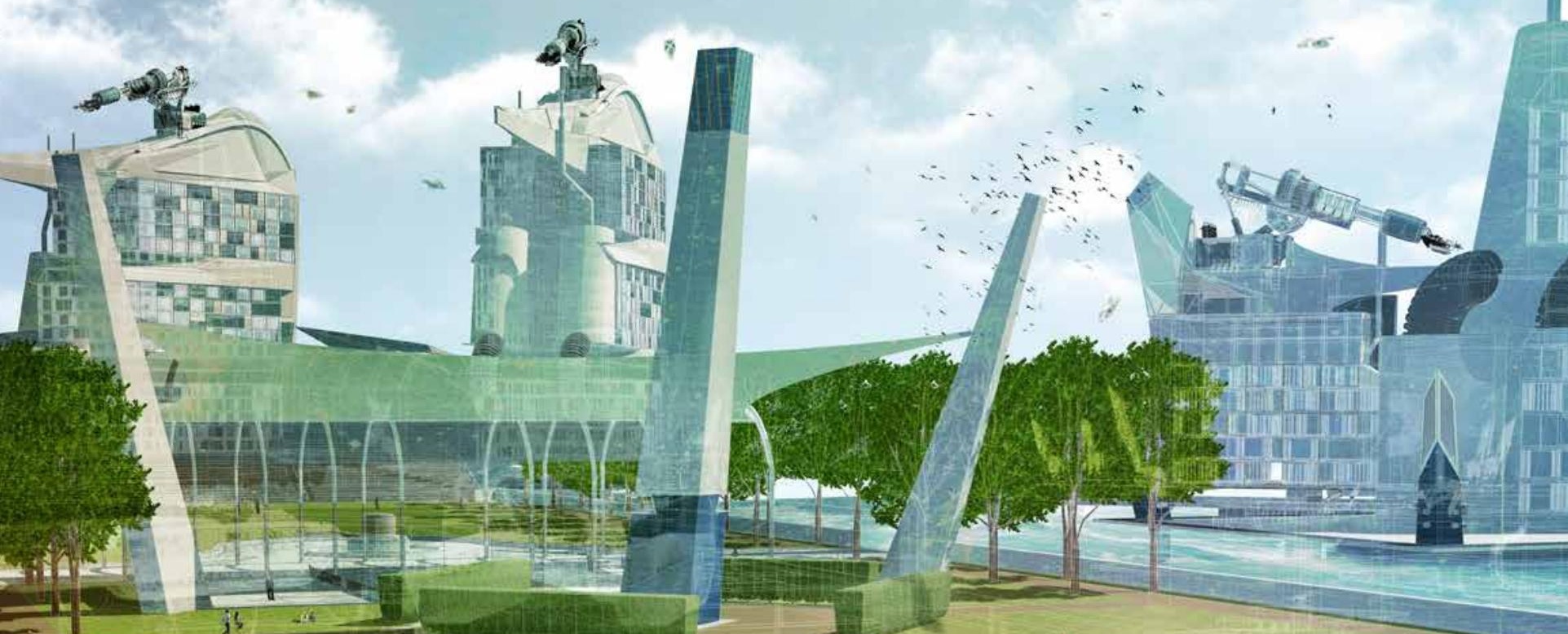

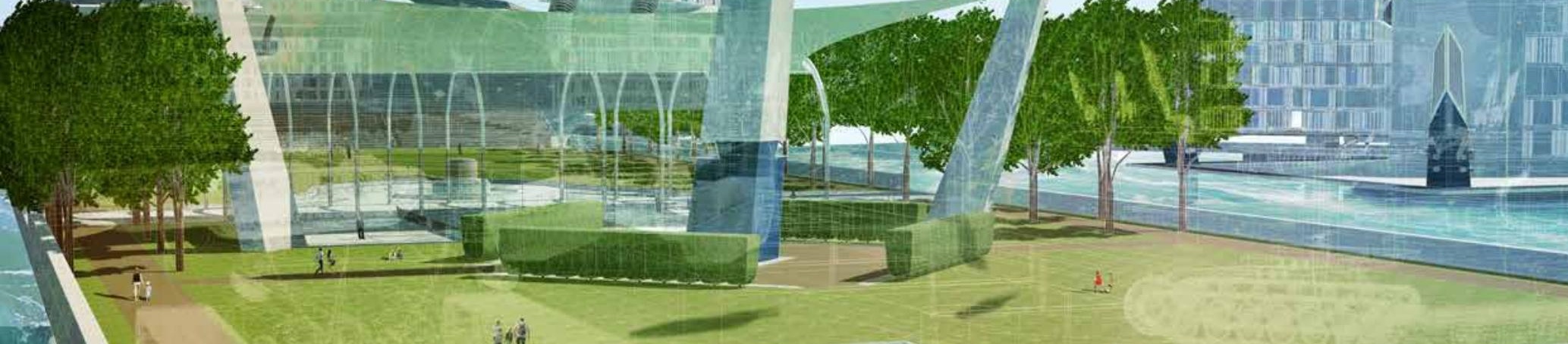

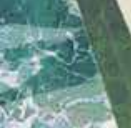
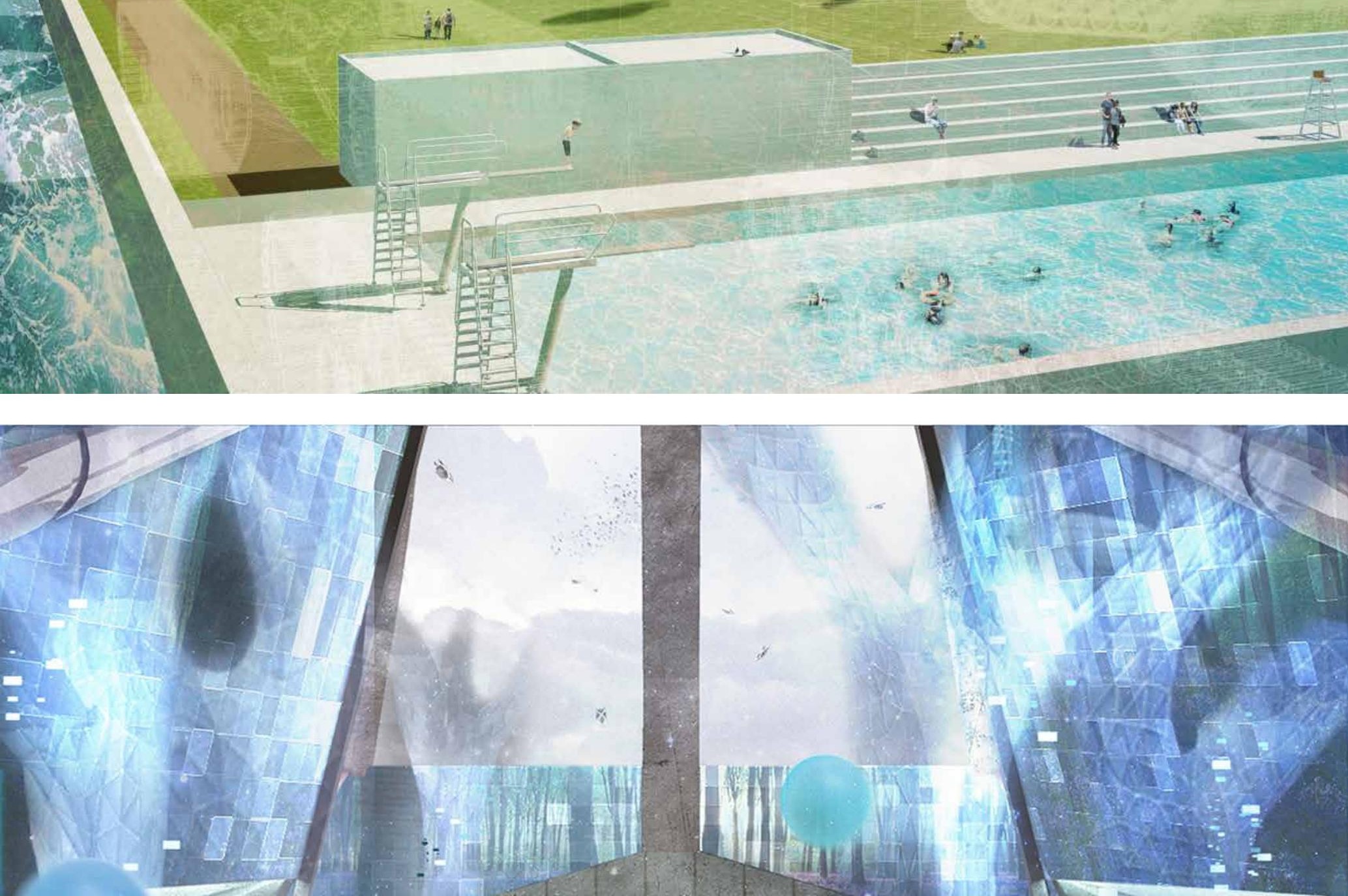

$-2$

is

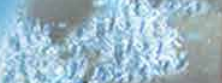

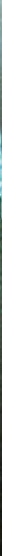




\section{Accommodation}

This section is focused around objective three to provide an understanding of how homes may evolve, and through flexibility, offer a contingency given that social norms vary immensely come 2100.

As touched on, the home of the future is believed to be a series of ordered rooms that will join to form an apartment. Instead of owning land, you will own a certain number of rooms. This way you can take your home with you to new locations as you move within towers or entirely out of the complex; this is advantageous for assimilating with others. By offering endless amounts of locations to settle, and the ability to take your home, it will keep suburbia interesting and never stagnant; people will interact with larger circles and be able to refresh their sense of place with a new location instead of buying a new house.

Being able to take your apartment between towers develops a new level of ownership to the home that is currently not expressed in 2015. The concept for these apartments is similar to portable construction site offices; they can be customised, used for long or short term, used for a variety of functions (from storage to living), moved to new locations and be repurposed.

Conflicts over prime locations will be resolved by instigating time periods for specific lots, allowing the community to share privileges fairly. Positions within towers may change rapidly given the ease at which entire apartments can be relocated. Fig 7.15 illustrates how the rooms are moved. The cranes will fixate to the rooms and be able to transport it to a vacant lot. It is then pushed into place, being able to glide on a series of rollers inbuilt into the structure of the room and of the tower. Kitchens kits are available from within each tower in a compact size that simply joins onto the rooms.

Three room typologies are proposed (Fig 7.14); an internally based living room which accommodates the kitchen add-on, an externally based windowed room (most likely used for bedrooms), and a half-size (usable most likely as bathrooms). This allows for many configurations (see page 99), however it is believed there will be an infinite amount of configurations available when other shapes are included into the scheme; the future will most likely have the capacity to offer more variation than what is proposed.

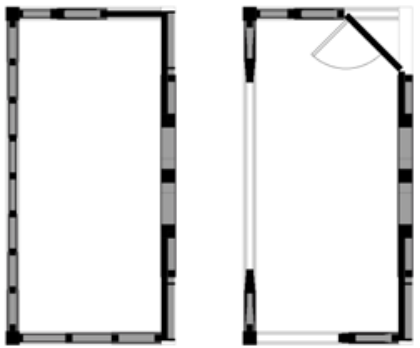

Half-size Room: Ideal for Bathroom, Study, Child's Room.

○
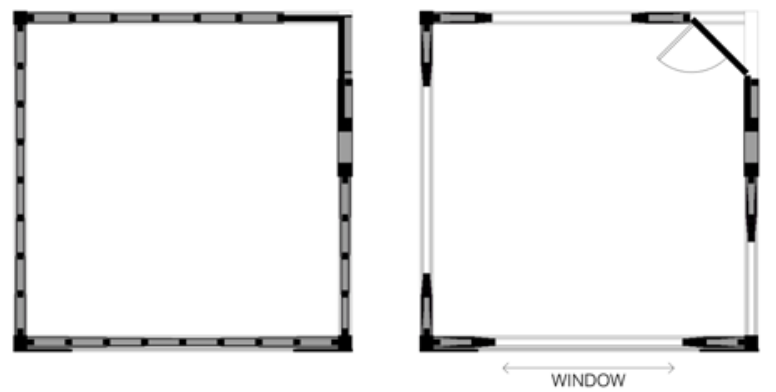

Windowed External Room: For Bedroom or Extended Lounge Spaces.

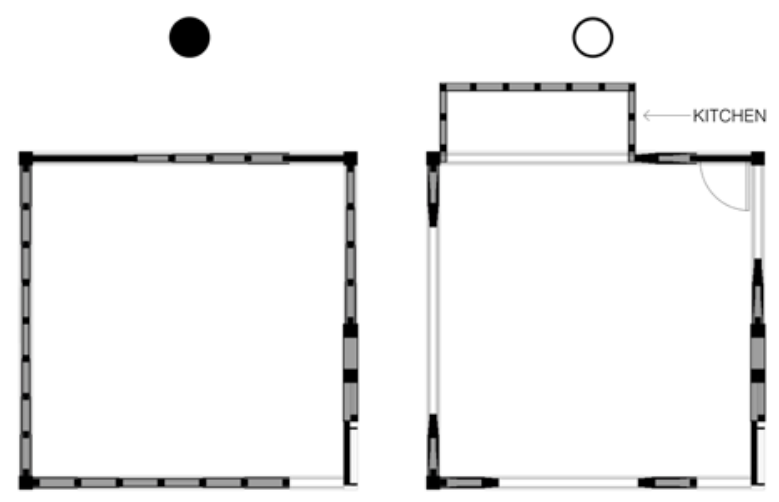

Internal Room: For Lounge and Dining; Kitchen Supplied as an Add-on. 


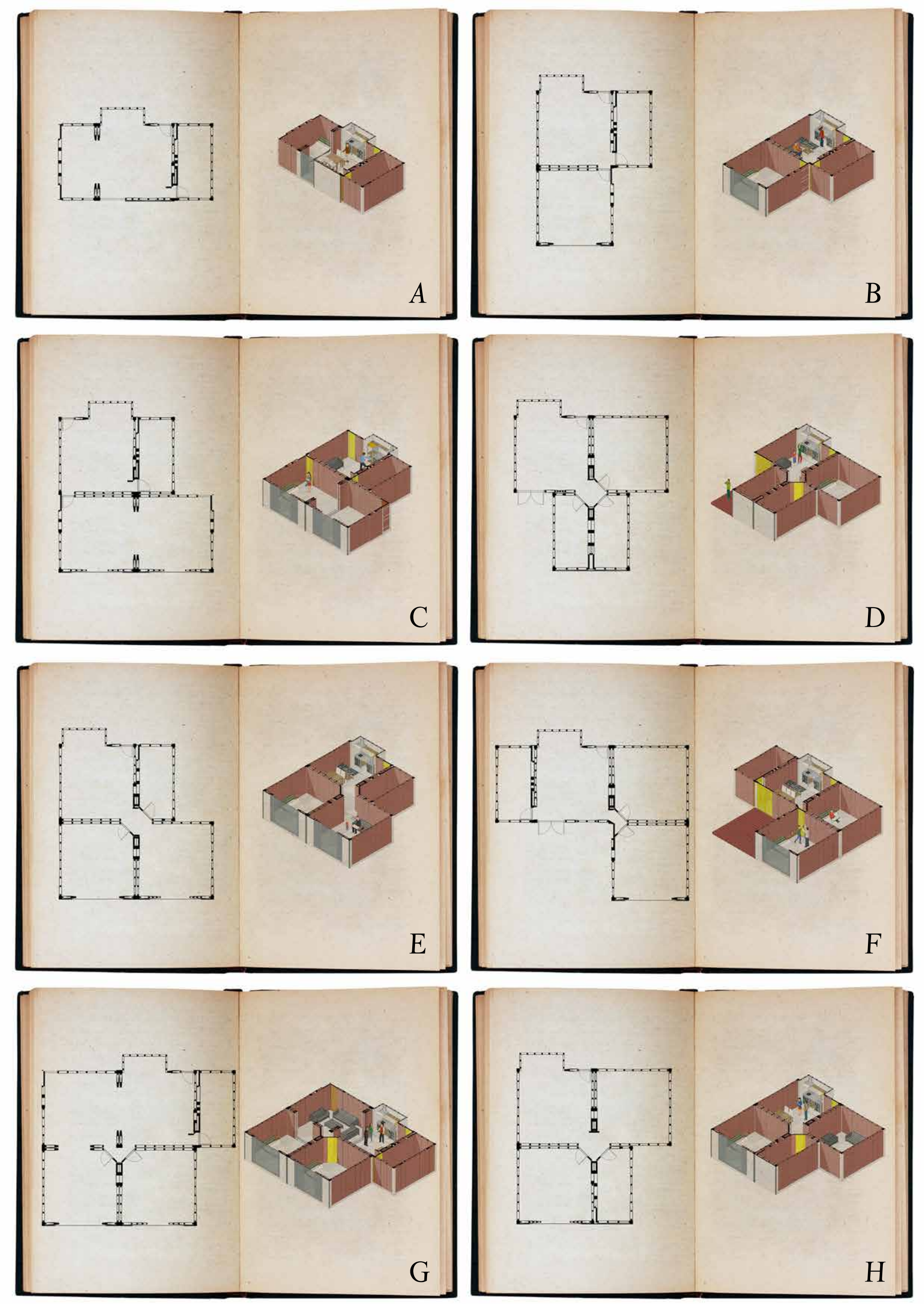


Another feature at the same scale is the housing of the endangered plant species in special containment rooms. These rooms cater for the plant's needs while providing a pleasant scenery for the towers' hallways. These plant rooms are placed in vacant lots until that space is needed, or can be ordered to be placed next to your apartment where walls can be slid open to enjoy these capsules of nature.

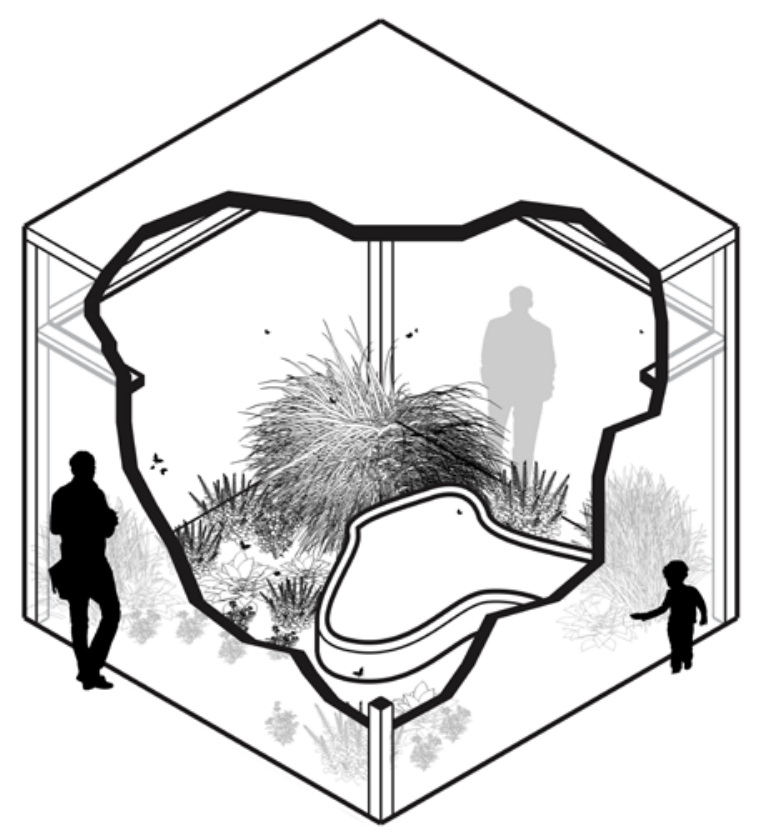

Fig 7. 18-19.

Green Room Diagram (Top). Green Room Render (Bottom). 

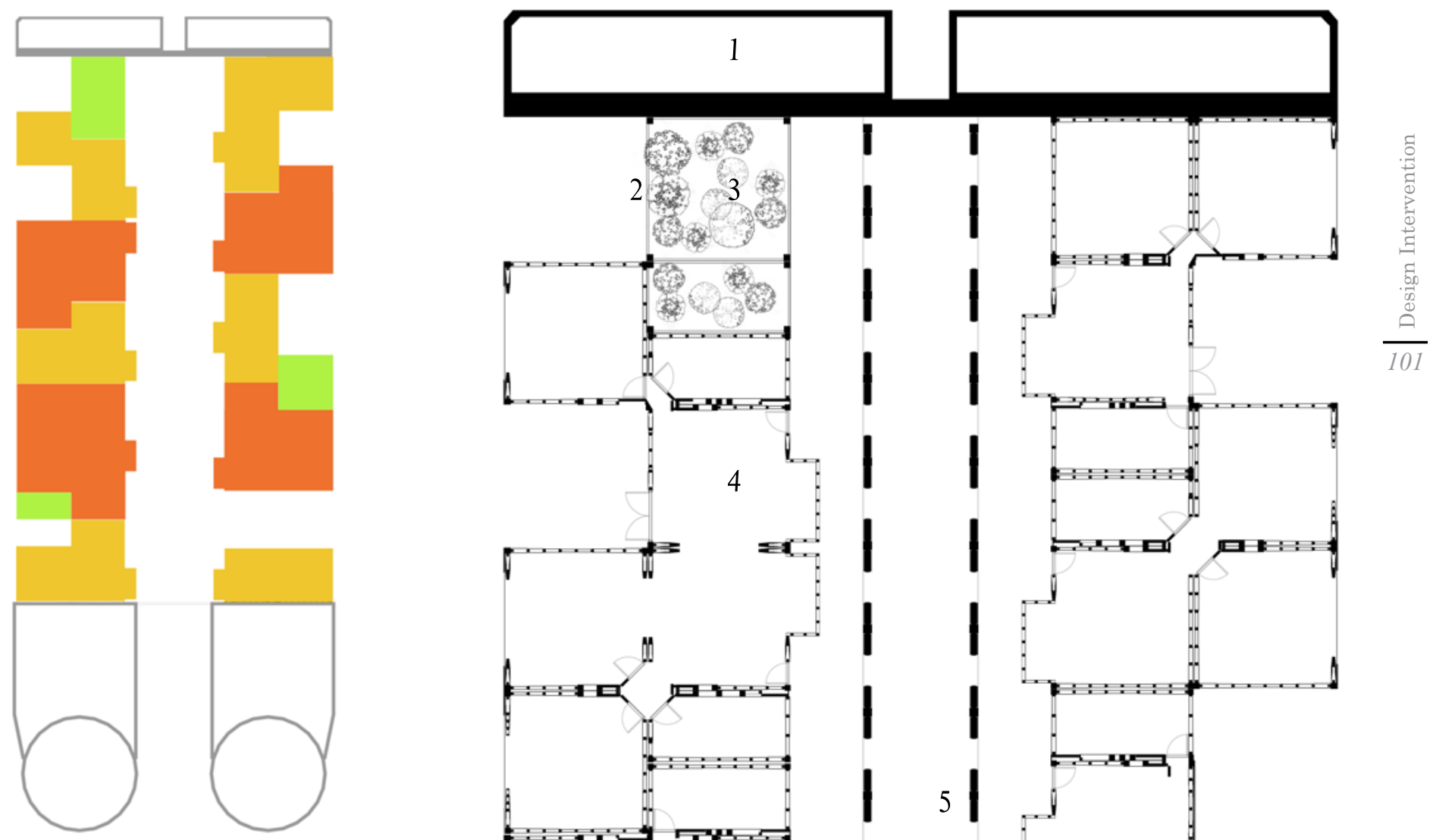

Diagram Key:

General Floor Plan Key:

1 - Stored Power Supply (Battery)

2 - Vacant Lot

3 - Green Rooms

4 - Apartments

5 - Void

6 - Hall Walkway

7 - Elevators

8 - Desalination Plant

9 - Salt-water Collection Tank 
124000

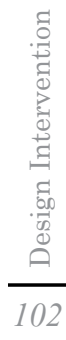

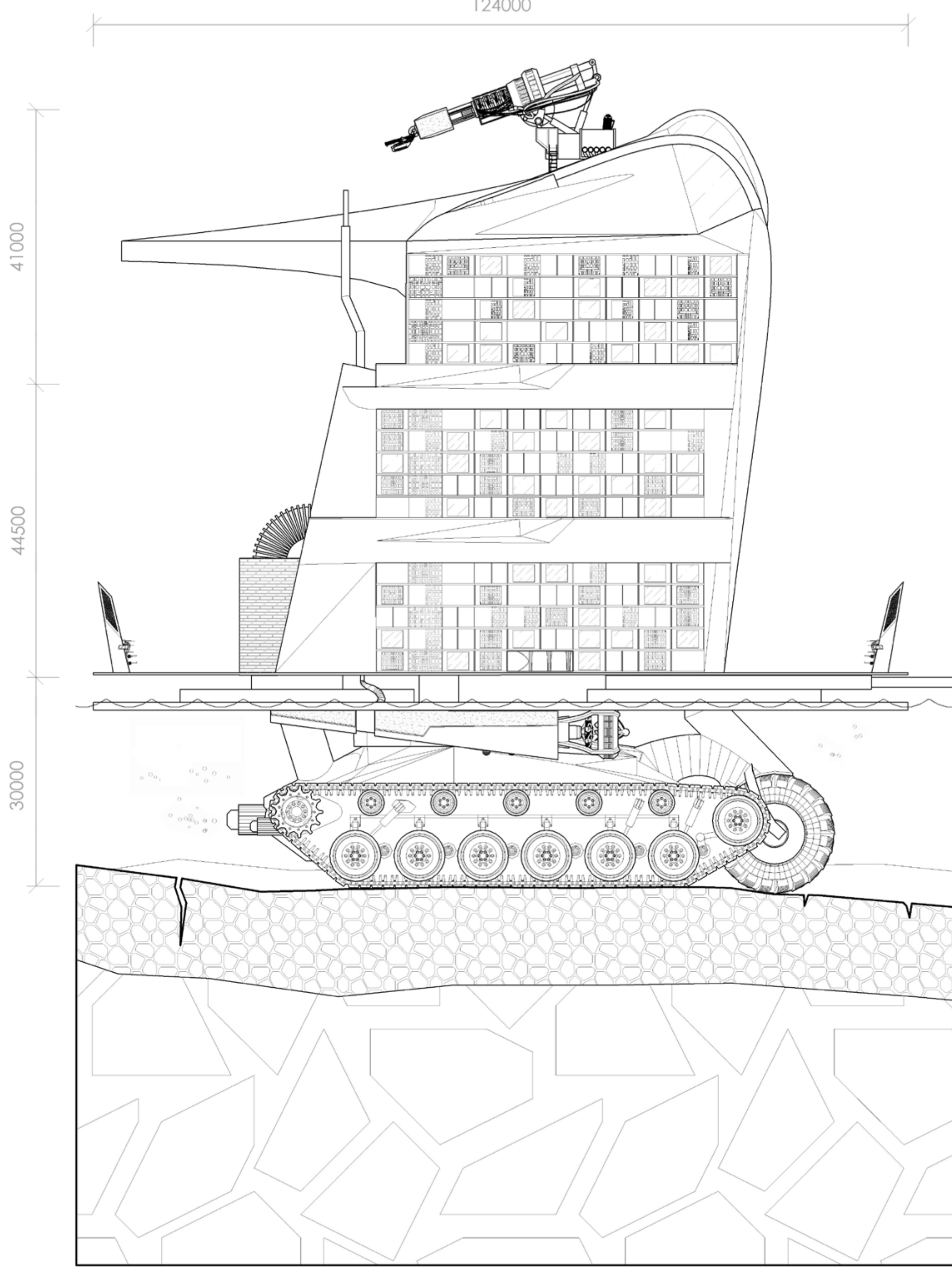




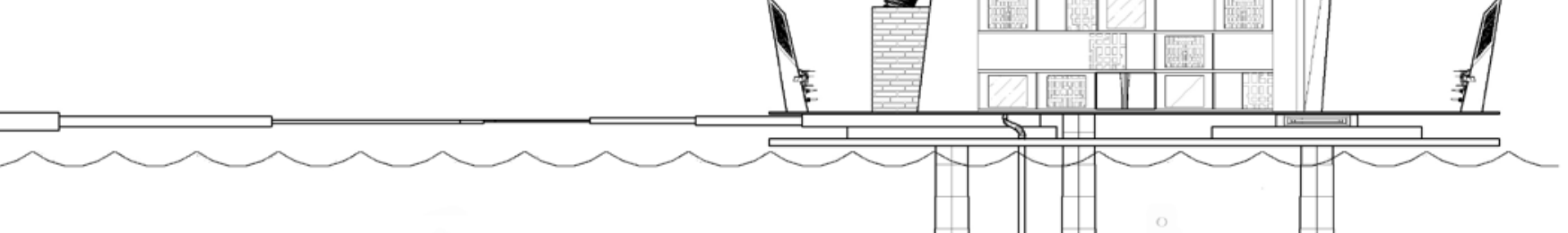




\section{Model}
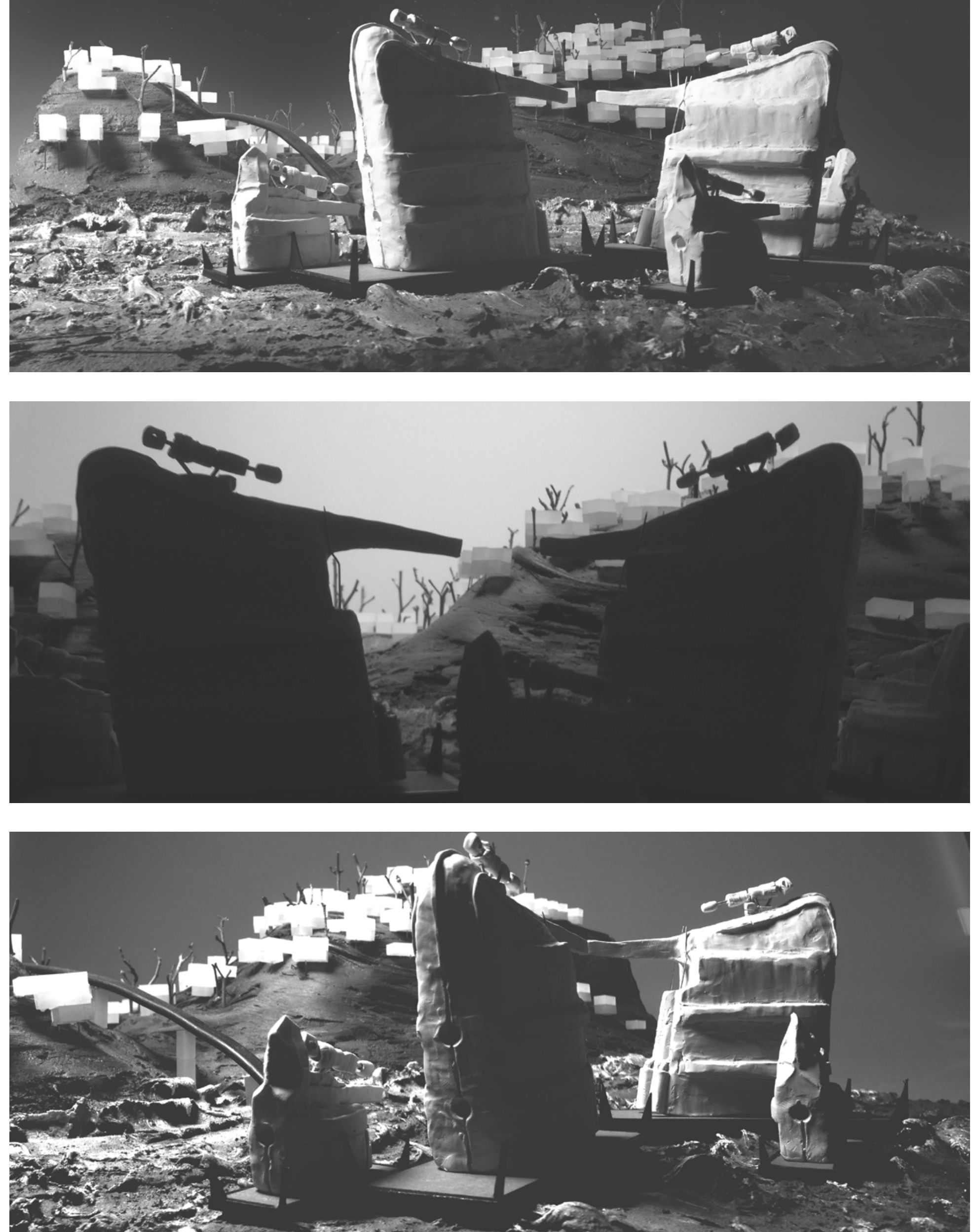


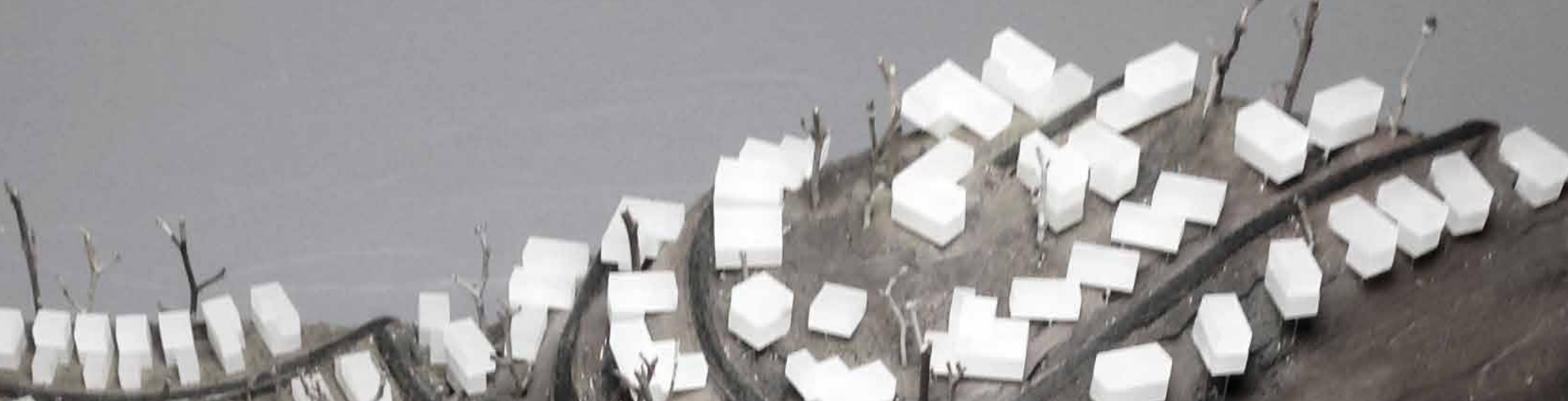

4

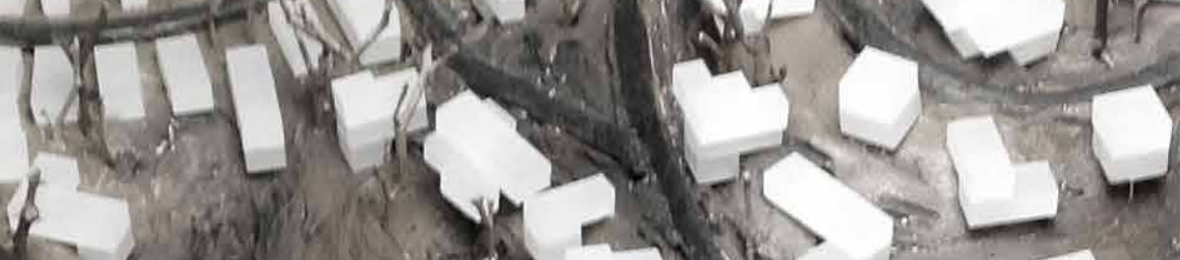

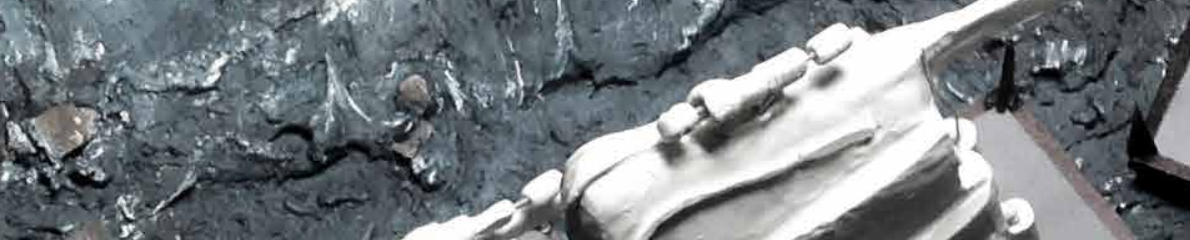
Te: $<$ e $a$ c.

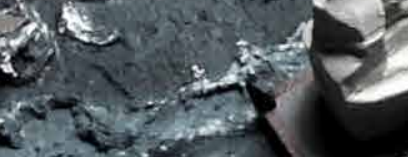
is 3.21

\section{$+y^{2}=$} (I) $4 e^{2}-4$ trente

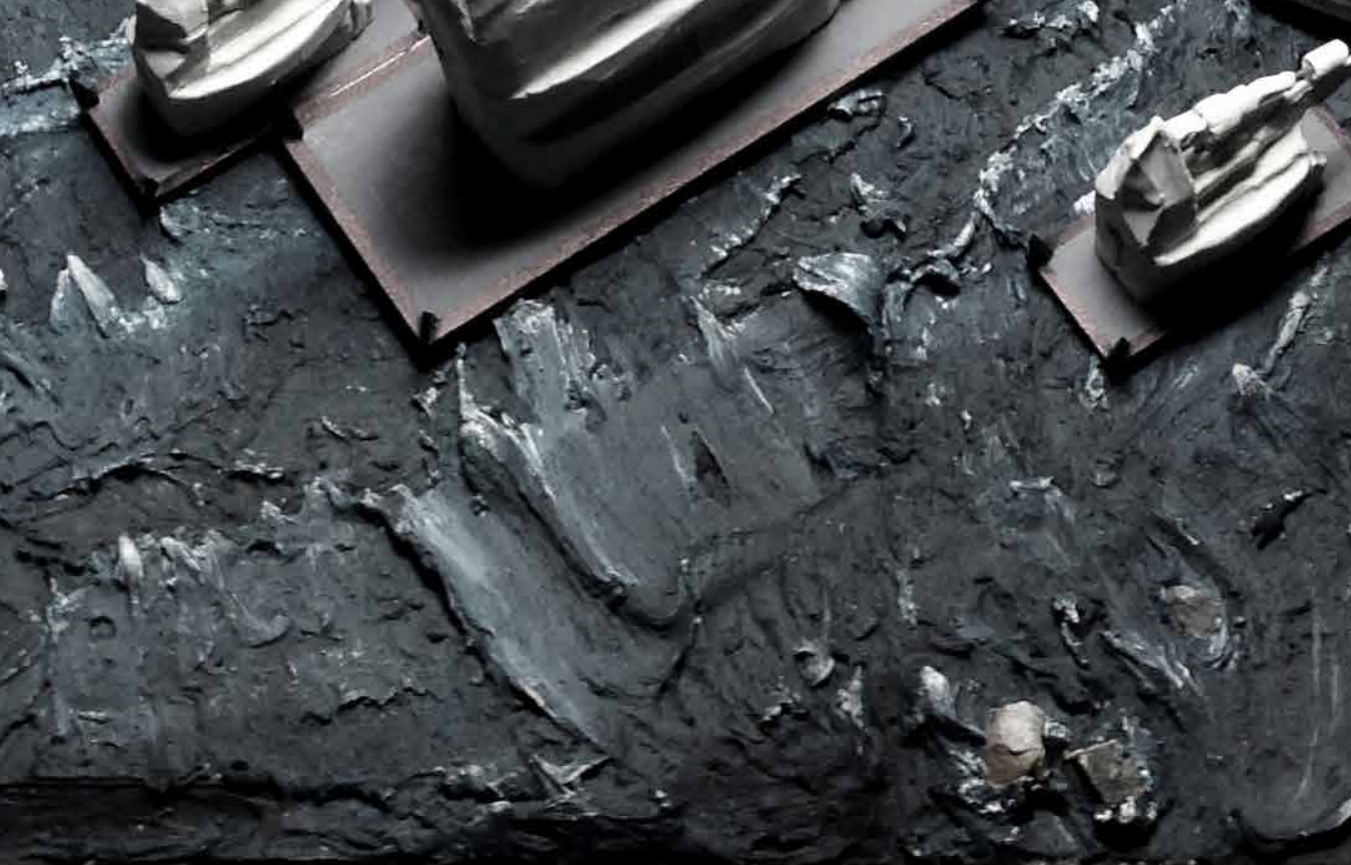

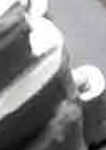

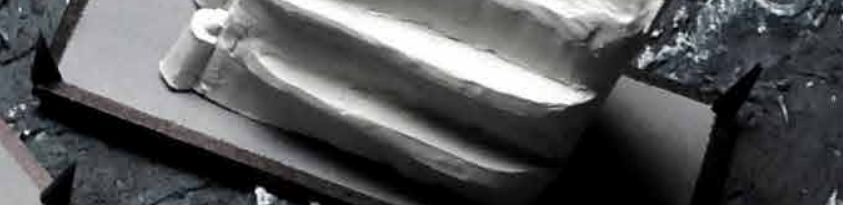

7

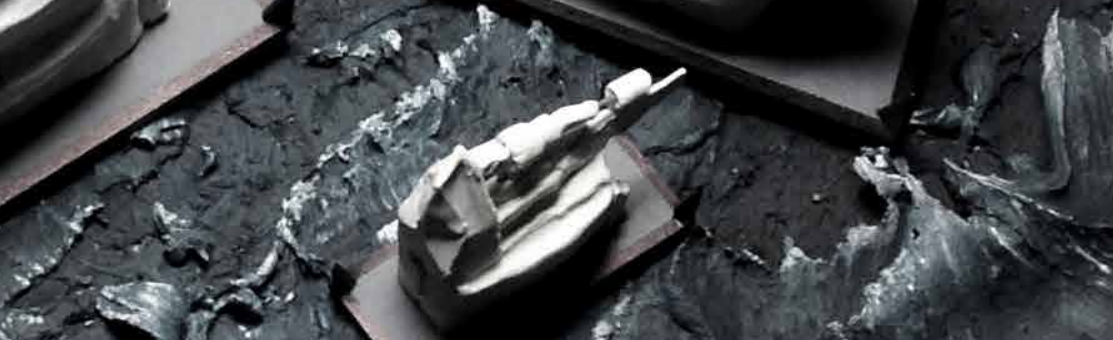





\section{Chapter Eight}

Discussion 


\section{Conclusion}

The design intervention provides a dynamic living situation for residents of 2100 that is both enduring and convivial. The moveable attribute of the towers allows for augmented social interaction than what is seen in current suburbia, and a palpable sense of community when towers congregate together or exchange apartments. Ample spaces for social gatherings adds to this atmosphere and provides opportunities for communities to enliven the dismal setting projected in a worst case scenario for 2100 .

The sea-bound exploration demonstrates a possible future evolution of living that works to provide adaptable architecture with greater safety and concern for its occupants. It offers diverse living locations and caters to both fast-paced lifestyles (those that like to travel) and more reserved lifestyles (those that like to settle). The adaptive design features allows for the impact of the worsening climate to be dampened and endured. Utilising natural energies and local surroundings for water does not exacerbate the climate. Amenities within and around the towers such as the parks, simulation spaces and green rooms adds complexity to the intervention to enrich the living conditions.

In summary, the intervention meets the aims and objectives set for this thesis. It provides a spirited and multifaceted residency within a sordid worst case scenario for 2100 . The kinetic nature of the suburb and its components adds interest within a reinterpreted suburban typology while proving the value that technology can bring to adaptive architecture for a commensal relationship with nature. 


\section{Limitations}

The sublime qualities of technology has meant that the housing aspect of the intervention did circum to some limitations. With the capabilities of technology, an endless string of shapes and sizes will presumably be available for rooms; not being restricted to just the three variations included in this intervention. Varieties of aesthetics would also be made available. For these reasons, the towers and green spaces can be considered prototypes. They stand as an example of what we can build in the sea and as to the benefits it could employ.

On feasibility, it must be noted that technology is not a linear path and new technologies aren't always a success; all technological decisions will be influenced by economical ones. Consequently, this allows the intervention to be achievable under particular circumstances where the funding and resolution of the project is deemed a necessity. 


\section{Further Research}

Even if a worst case scenario never happens, this intervention still offers exploration vantage points for greater research to be developed for human living. There is potential for these towers to roam the land if SLR is found to not be such an issue; connecting cities much like the studied Walking City. The intervention also investigates housing, where the rooms designed could be developed as a part of versatile and interlocking land-based residencies.

Further research pertaining to this thesis' outcome could be exploring the manufacturing process and towers' programmes. As aforementioned, a factory to produce the apartments was considered but unrealised due to time constraints. Investigating how the redundant buildings from SLR could be recycled then $3 \mathrm{D}$ printed as towers and apartments is a logical progression to the intervention. An investigation could also be undertaken to understand the effect on inland living when new programmes like shopping, vacation and work are added to towers. Finding out whether this would enhance cities or cause tension between those on land to those at sea. 


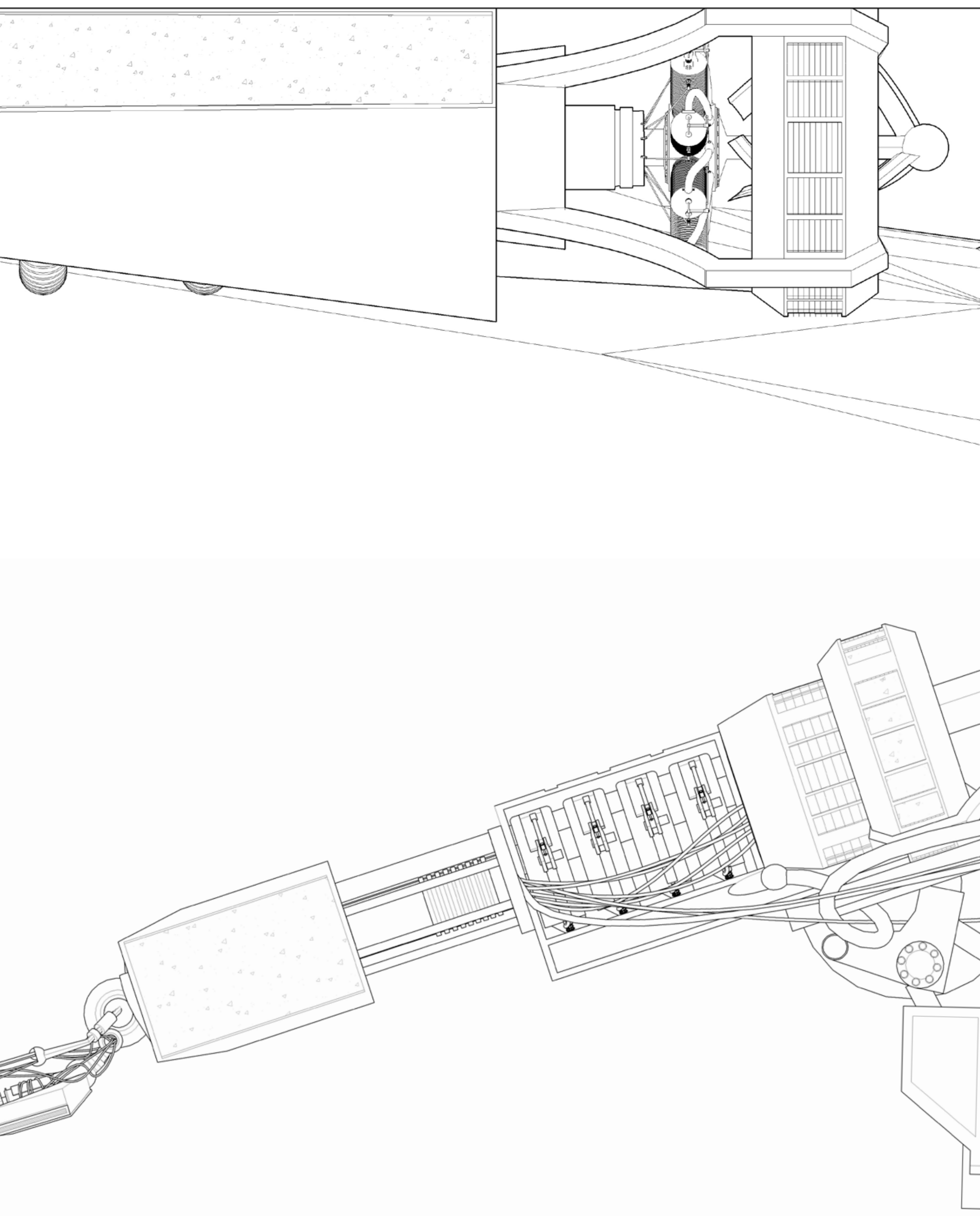




\section{Chapter Nine}

Bibliography 


\section{Works Cited}

Arctic Monitoring and Assessment Program. Arctic Climate Issues 2011: Changes in Arctic Snow, Water, Ice and Permafrost. Norway: Arctic Monitoring and Assessment Programme, 2012. Web. 4 April. 2015. <http://www.amap.no/ documents/doc/arctic-climate-issues-2011-changes-in-arcticsnow-water-ice-and-permafrost/129>.

Atherton, Kelsey. "Boeing Just Patented a Force Field Made of Lasers." Popular Science. Web. 10 May. 2015. <http:// www.popsci.com/boeing-just-patented-force-field-lasers>.

Asselin Stephane. "Water: Urban Landscapes and Water Management" In: Climate Design: Design and Planning for the Age of Climate Change. Berkeley: ORO Editions, 2010. Print.

“BBC Horizon (1964) with Arthur C. Clarke." Youtube. Video, 1964. Web. 10 May. 2015. [Part 1] < https://www.youtube.com/ watch?v=KT_8-pjuctM>, [Part 2] <https://www.youtube. com/watch? $v=$ Xos YXxwFPkg>.

Boullée, Étienne-Louis. "Architecture, essai sur l'art." In: Ms.9153 Bibliothèque Nationale. Ed. Helen Rosenau. Trans. Shelia de Vallée. London: A. Tiranti, 1953. Web. 10 Jan. 2016. $<$ http://monoskop.org/images/b/ba/Boullee_Etienne-Louis_ Architecture_Essay_on_Art.pdf $>$.

Brouwers, Jos. "Road Surface Purifies Air by Removing Nitrogen Oxides (NOx)." University of Technology Netherlands. Web. 10 May. <https://www.tue.nl/en/university/ news-and-press/news/05-07-2010-road-surface-purifies-airby-removing-nitrogen-oxides-nox/>.

Church, John, et al. "Sea Level Change." In: Climate Change 2013: The Physical Science Basis. Cambridge: Cambridge University Press, 2013. Web. 4 April. 2015. <http://www. ipcc.ch/pdf/assessment-report/ar5/wg1/WG1AR5_Chapter13_ FINAL.pdf>.

"Citadel Skyscraper." Evolo. Web. 5 May. 2015. <http://www. evolo.us/competition/citadel-skyscraper/>. 
Construction Specialties Inc. "Adaptive and Dynamic Buildings - The Future of Environmental Design \& Architecture." ArchDaily. Web. 10 May. 2015. <http://www. archdaily.com/71450/adaptive-and-dynamic-buildings$\% 25 e 2 \% 2580 \% 2593$-the-future-of-environmental-designarchitecture/>.

Cook, Peter. Archigram. United States of America: Praeger Publishers, 1973. Print.

De Mul, Jos. The Technological Sublime. 2011. Web. 10 May. 2015. <http://www.nextnature.net/2011/07/the-technologicalsublime/>.

Diamond, Jared. Collapse: How Societies Choose To Fail Or Succeed. United States of America: Penguin Group, 2005. Print.

Dijker, Barb. "What the Heck is this 95th Percentile Number?" Colorado Internet Cooperative Association. Web. 10 Jan. 2016. <http://www2.arnes.si/ gljsentvid10/pct.html>.

Evans, Laura, Taciano Milfont, and Judy Lawrence. Perceptions of Sea-Level Rise in Wellington City and Kapiti Coast Districts. Wellington: Victoria University of Wellington, 2012. Web. 4 April. 2015. <http://www.milfont.com/sealevelreport.pdf $>$.

Furuto, Alison. "Citadel Skyscraper / Victor Kopeikin + Pavlo Zabotin." ArchDaily. Web. 5 May. 2015. <http://www. archdaily.com/221560/citadel-skyscraper-victor-kopeikinpavlo-zabotin/s.

Gilbert-Rolfe, Jeremy. Beauty and the Contemporary Sublime. New York: Allworth Press, 1999. Print.

Garrison, Noah, and Cara Horowitz. How Green Roofs and Cool Roofs Can Reduce Energy Use, Address Climate Change, and Protect Water Resources in Southern California. NRDC, 2012. Web. 10 May. 2015. <http://www.nrdc.org/water/ pollution/files/greenroofsreport.pdf>. 
Kaempffert, Waldemar. "Miracles You'll See In The Next Fifty Years (Feb, 1950)." Modern Mechanix. Web. 10 May. 2015. $<$ http://blog.modernmechanix.com/miracles-youll-see-in-thenext-fifty-years/>.

Kant, Immanuel. Observations on the Feeling of the Beautiful and Sublime. Trans. John Goldthwai. united Steas of America: University of California Press, 1960. Web. 8 June 2014. $<$ http://books.google.co.nz/books?id=K-9G31 HUQEwC\&dq $=$ Observations + on + the + Feeling + of + the + Beautiful + and + Su blime\&source $=$ gbs_navlinks_s $>$.

Kleinfield, N. "A Glimpse Of The Year 2000." The New York Times. Web. 10 May. 2015. <http://www.nytimes. com/1982/01/10/us/a-glimpse-of-the-year-2000.html>.

Lamar, Cyriaque. "Robert Heinlein's predictions for the Year 2000 (from 1952)." io9.gizmodo. Web. 10 May. 2015. <http:// io9.gizmodo.com/5871053/robert-heinleins-predictions-forthe-year-2000-from-1952>.

Lowe, Jason, et al. "UK Climate Projections Science Report: Marine and Coastal Projections." UK Climate Projections. 2009. Web. 4 April. 2015. <http://ukclimateprojections. metoffice.gov.uk/media.jsp? mediaid $=87905 \&>$.

Liu, Chunlei, and Richard Allan. Observed and Simulated Precipitation Responses in Wet and Dry Regions 1850-2100. UnitedKingdom:IOP Publishing,2013.Web.5Jan.2016.<http:// iopscience.iop.org/article/10.1088/1748-9326/8/3/034002/ $p d f>$.

Masters, Jeffrey. "The Effect of Nuclear War on Climate." Weather Underground. Web. 16 April. 2015. <http://www. wunderground.com/resources/climate/nuke.asp $>$.

McGranahan, Gordon, Deborah Balk, and Bridget Anderson. The Rising Tide: Assessing the Risks of Climate Change and Human Settlements in Low Elevation Coastal Zones. United Kingdom: International Institute for Environment and Development, 2007. Web. 20 Dec. 2015. <http://eau.sagepub. com/content/19/1/17.full.pdf + html>. 
Morley, Simon. The Contemporary Sublime. Simonmorley. Web. 10 May. 2015. <http://www.simonmorley.com/biography/ The_Sublime-An_Introduction.pdf $>$.

Neumann, Barbara, Athanasios Vafeidis, Juliane Zimmermann, and Robert Nicholls. "Future Coastal Population Growth and Exposure to Sea-Level Rise and Coastal Flooding - A Global Assessment." PLOSOne.Web. 20 April. 2015. <http://journals. plos.org/plosone/article?id=10.1371/journal.pone.0118571>.

Novak, Matt. "French Prints Show the Year 2000 (1910)." Paleofuture. Web. 10 May. 2015. <http://paleofuture.com/ blog/2007/9/10/french-prints-show-the-year-2000-1910. html>.

Paris, Adam, et al. Global Sea Level Rise Scenarios for the United States National Climate Assessment. United States of America: NOAA, 2012. Web. 4 April. 2015. <http://cpo.noaa. gov/sites/cpo/Reports/2012/NOAA_SLR_r3.pdf $>$.

"Polar Umbrella Buoyant Skyscraper Protects and Regenerates the Polar Ice Caps" Evolo. Web. 5 May. 2015. <http://www. evolo.us/competition/polar-umbrella-buoyant-skyscraperprotects-and-regenerates-the-polar-ice-caps/>.

Quick, Darren. "On the Road to Cleaner Air with Air-Purifying Concrete." Gizmag. Web. 10 May. 2015. <http://www.gizmag. com/air-purifying-roads/15638/>.

Renwick, James, et al. "Four Degrees of Global Warming: Effects on the New Zealand Primary Sector." Ministry for Primary Industries. Web. 5 April. 2015. < http://www.mpi.govt. nz/> Path: Search Query - 'Four Degrees of Global Warming', Link Two "Four Degrees of Global Warming: [PDF, 5 MB]".

Saenz, Aaron. "Retro Futurism - Arthur C. Clarke's Predictions from 1964 (video)." Singularityhub. Web. 10 May. 2015. $<$ http://singularityhub.com/2010/09/01/retro-futurism-arthurc-clarkes-predictions-from-1964-video/>.

Scott Brown, Denise. The Architect Says, Quotes, Quips, and Words of Wisdom. Ed. Dushkes, Laura. New York: Princeton Architectural Press, 2012. Print. 
Sherwood, Mary Martha. The Monk of Cimiés. London: William Darton and Son, 1836. Web. 10 Jan. 2016. <https:// books.google.co.nz/s? id $=d$ HoBAAAAQAAJ\&printsec $=$ frontco ver $\# v=$ onepage $\& q \& f=$ false $>$.

Starr, Steven. "Effects of Nuclear Weapons." Nuclear Darkness, Global Climate Change \& Nuclear Famine. Web. 16 April. 2015. <http://www.nucleardarkness.org/nuclear/ effectsofnuclearweapons $>$.

Stocker, Thomas, et al. "Summary for Policymakers." In: Climate Change 2013: The Physical Science Basis. Cambridge: Cambridge University Press, 2013. Web. 4 April. 2015. <https://www.ipcc.ch/pdf/assessment-report/ar5/wg1/ WG1AR5_SPM_FINAL.pdf>.

Tan, Shaun. Tales from Outer Suburbia. Australia: Allen \& Unwin, 2008. Print.

Tonkin \& Taylor Ltd. Sea Level Rise Options Analysis. Wellington: Wellington City Council, 2013. Web. 5 April. 2015. $<$ http://wellington.govt.nz/ /media/services/environment-andwaste/environment/files/61579-wcc-sea-level-rise-options. $p d f>$.

Turner, John, et al. Antarctic Climate Change and the Environment. Cambridge: Scientific Committee on Antarctic Research, 2009. Web. 4 April. 2015. <http://www.scar.org/ scar_media/documents/publications/ACCE_25_Nov_2009. $p d f>$.

United Nations. "Key Findings and Advance Tables." In: World Population Prospects The 2015 Revision. New York: United Nations, 2015. Web. 11 Jan. 2016. <http://esa.un.org/ unpd/wpp/publications/files/key_findings_wpp_2015.pdf>.

US Army Corps of Engineers. Sea-Level Change Considerations for Civil Works Programs. Washington: 2011. Web. 4 April. 2015. <http://planning.usace.army.mil/toolbox/library/ECs/ EC11652212Nov2011.pdf>. 
Vellinga, Pier, et al. Exploring High-End Climate Change Scenarios for Flood Protection of the Netherlands. Netherlands: Wageningen University and Research Centre \& Alterra and the Royal Netherlands Meteorological Institute, 2008. Web. 16 April. 2015. <http://bibliotheek.knmi.nl/knmipubWR/WR200905.pdf>.

Vinnitskaya, Irina. "Kiefer Technic Showroom / Ernst Giselbrecht + Partner" ArchDaily. Web. 10 May. 2015. $<$ http://www.archdaily.com/89270/kiefer-technic-showroomernst-giselbrecht-partner/>.

Watkins John Elfreth Jr. "What May Happen in the Next Hundred Years." In: The Ladies' Home Journal (1889-1907); Dec 1900; Vol. XVIII, No. 1. Web. 6 May. 2015. <http://www. personal.psu.edu/staff/t/w/twa101/whatmayhappen.pdfs.

"Wellington City Dwellings and Development Map." Forecast. id NZ. Web. 5 April. 2015. <http://forecast.idnz.co.nz/ wellington/dwellings-development-map $>$.

"Wellington City Population and Age Structure Map." Forecast.id NZ. Web. 5 April. 2015. <http://forecast.idnz. co.nz/wellington/population-age-structure-map>.

"Wind Turbines Now Spinning On Bahrain World Trade Center." MetaEfficient. Web. 10 May. 2015. <http://www. metaefficient.com/architecture-and-building/wind-turbinesnow-spinning-on-bahrain-world-trade-center.html>.

Wratt, David and Brett Mullan. "Climate Change Scenarios for New Zealand." The National Institute of Water and Atmospheric Research. Web. 4 April. 2015. <https://www. niwa.co.nz/our-science/climate/information-and-resources/ clivar/scenarios>. 


\section{Figure List}

Title Page: Garage. 105 Hataitai Road, Hataitai, Wellington. Photograph by author.

Fig 0. 01. Grandpa's Story. Drawing Source: Tan, Shaun. Tales from Outer Suburbia. Australia: Allen \& Unwin, 2008. Print.

\section{Chapter One: Design Intent}

Fig 1. 01. From a Spark to a Flame. Photograph by author.

Fig 1. 02. 5th and 95th Percentiles. Graph Source: "Using Anthropometrics In Designing For Enhanced Crew Performance." Ship Journal. Web. 7 Feb. 2016. <http://www. shipjournal.co/index.php/sst/rt/printerFriendly/50/185>.

Fig 1. 03. Deaths from Terrorism, 2000-2004. Graph Source: "Terrorism Deaths In 2014 The Highest On Record: Global Terrorism Index 2015." The Sydney Morning Herald. Web. 8 Dec. 2015. <http://www.smh.com.au/world/terrorism-deathsin-2014-the-highest-on-record-global-terrorism-index-2015finds-20151119-gl2puz.html>.

Fig 1. 04. Wellington Region. Author's own image. Adapted from: Hutt City Council, 'Aerial Maps'. Web. 2 Dec. 2015.

\section{Chapter Two: Setting A Scene And Need For Design}

Fig 2. 01. Llyal Bay Storm. Photograph Source: Neil Rately. Instagram. Web. 7 Feb. 2016. <https://www.instagram.com/ $\mathrm{p} / 35 \mathrm{MAn} 3 v \mathrm{tCd} / \mathrm{s}$.

Fig 2. 02. Diagram of Sea Level Rise Data. Author's own image.

Fig 2. 03. Wellington Sea Level Rise. Author's own image. Adapted from: Tonkin \& Taylor Ltd, 'Sea Level Rise Options Analysis'.

Fig 2. 04. Wellington Region Liquefaction. Author's own image. Data source: Koordinates. Web. 15 April. 2015. 
Fig 2. 05. Wellington Wind Zones. Author's own image. Data source: Koordinates. Web. 15 April. 2015.

Fig 2. 06. Projected World Population. Graph Source: "Global Population Set To Hit 9.7 Billion People By 2050 Despite Fall In Fertility." The Guardian. Web. 8 Dec. 2015. <http://www. theguardian.com/global-development/2015/jul/29/un-worldpopulation-prospects-the-2015-revision-9-7-billion-2050fertility>.

Fig 2. 07. Wellington City Council's 50 Year Growth Plan. Map Source: "Quantifying the Growth Spine." Wellington City Council. Web. 18 April. 2015. <http://wellington.govt.nz/ / media/your-council/projects/files/infill-growthspine.pdf $>$.

Fig 2. 08. Wellington Development Forecast for New Dwellings. Author's own image. Data source: Forecast.id NZ, 'Wellington City Dwellings and Development Map'. Web. 5 April. 2015.

Fig 2. 09. Depiction Map of Newland's Predicted Growth. Author's own image. Adapted from: Hutt City Council, 'Aerial Maps'. Web. 2 Dec. 2015.

Fig 2. 10. Graph of Wellington's Population Growth. Author's own image. Data source (2013-43): Forecast.id NZ, 'Wellington City Population and Age Structure Map'. Web. 5 April. 2015.

Fig 2. 11. Analysis of Wellington's Population Growth and New Dwellings. Author's own image.

Fig 2. 12. Programme Diagram. Author's own image.

\section{Chapter Three: Precedents}

Fig 3. 01. Plug-in City. Drawing Source: "Peter Cook." Hippowallpapers. Web. 7 Feb. 2016. <http://www. hippowallpapers.com/peter-cook>.

Fig 3. 02. Plug-in City. Drawing Source: "Peter Cook." Hippowallpapers. Web. 7 Feb. 2016. <http://www. hippowallpapers.com/peter-cook>. 
Fig 3. 03. Diagram of City's Development and Repurposing Ideology. Author's own image.

Fig 3. 04. Walking City. Drawing Source: "Walking City." Openbuildings. Web. 7 Feb. 2016. <http://openbuildings.com/ buildings/walking-city-profile-39003>.

Fig 3. 05. Diagram of City's Mobility and Flexibility. Author's own image.

Fig 3. 06. Citadel Skyscraper. Image Source: "Citadel Skyscraper." Evolo. Web. 5 May. 2015. <http://www.evolo.us/ competition/citadel-skyscraper/>.

Fig 3. 07. Diagram of Design Features. Author's own image.

Fig 3. 08. Polar Umbrella. Image Source: "Polar Umbrella Buoyant Skyscraper Protects and Regenerates the Polar Ice Caps" Evolo. Web. 5 May. 2015. <http://www.evolo.us/ competition/polar-umbrella-buoyant-skyscraper-protectsand-regenerates-the-polar-ice-caps/>.

Fig 3. 09. Diagram of Design Features. Author's own image.

\section{Chapter Four: Literature Review}

Fig 4. 01. Computer Chip. Image Source: "About Electronics and Communication Engineering." SRI Mittapalli College Of Engineering. Web. 7 Feb. 2016. <http://www.smce.ac.in/ electronics-and-communication-engineering/> .

Fig 4. 02. Newton's Cenotaph. Drawing Source: "AD Classics: Cenotaph for Newton / Etienne-Louis Boullée." Archdaily. Web. 7 Feb. 2016. <http://www.archdaily.com/544946/adclassics-cenotaph-for-newton-etienne-louis-boullee >

Fig 4. 03. Bahrain World Trade Centre. Photograph Source: "The Last WTC Tower's Design Revealed." NeoGAF. Web. 7 Feb. 2016. <http://www.neogaf.com/forum/showthread. php? $t=1059867$ \&page $=3>$. 
Fig 4. 04. Kiefer Technic Showroom. Photograph Source: "Dynamic Facades: The Story." Arch2o. Web. 7 Feb. 2016. $<$ http://www.arch2o.com/dynamic-facades-the-story/>.

Fig 4. 05. Bahrain World Trade Centre Wind Diagram. Video Still Source: "Bahrain World Trade Centre 0/45 deg wind: Flowsquare 4.0." Youtube. Web. 7 Feb. 2016. 0 degree: $<$ https://www.youtube.com/watch? $v=v$ taekm CU8dg>.45 degree: $<$ https://www.youtube.com/watch? $v=$ 4Ml9fZc9N8>.

Fig 4. 06. Design Process Drawings. Author's own image.

Fig 4. 07. Collage Anticipating 2100. Author's own image.

Fig 4. 08. Collage Anticipating 2100. Author's own image.

Fig 4. 09. Design Stage One, Section. Author's own image.

Fig 4. 10. Exploded View and Diagrams. Author's own image.

Fig 4. 11. Design Stage Two, Section. Author's own image.

Fig 4. 12. Hydraulic System. Author's own image.

Fig 4. 13. Design Stage Two, Isometric Drawing of Suburb. Author's own image.

Fig 4. 14. Artist's Visions for the Future. Drawing Source: "French Prints Show the Year 2000 (1910)." Paleofuture. Web. 10 May. 2015. <http://paleofuture.com/blog/2007/9/10/ french-prints-show-the-year-2000-1910.html $>$.

Fig 4. 15. 1950's Prediction of TV Shopping. Drawing Source: "Miracles You'll See In The Next Fifty Years (Feb, 1950)." Modern Mechanix. Web. 10 May. 2015. <http://blog. modernmechanix.com/miracles-youll-see-in-the-next-fiftyyears $>$.

Fig 4. 16. Housing Intervention. Author's own image.

Fig 4. 17. Exterior in Harsh Weather. Author's own image. 


\section{Chapter Five: Prologue}

Fig 5. 01. Site Model. Model by author. Photograph by author.

Fig 5. 02. Horokiwi Context Map. Author's own image.

Fig 5. 03. Horokiwi Progression Diagrams 2010 - 2100. Author's own image.

Fig 5. 04. Horokiwi Progression Maps 2010 - 2100. Author's own images. Aerial Base from: Google Maps. Web. 18 April. 2015 .

\section{Chapter Six: Scenario Development}

Fig 6. 01-07. Illustrations for 'Glasshouse Confessional'. Author's own images.

\section{Chapter Seven: Design Intervention}

Fig 7. 01. Exterior Render. Author's own image.

Fig 7. 02. Exterior Render. Author's own image.

Fig 7. 03. Site Plan. Author's own image. Aerial Base from: Google Maps. Web. 2 Oct. 2015.

Fig 7. 04. Intervention Components. Author's own image.

Fig 7. 05. Aerodynamics Diagram. Author's own image.

Fig 7. 06. Mobility of Design. Author's own image.

Fig 7. 07. Exterior Render. Author's own image.

Fig 7. 08. Family Flying to the New Suburb. Author's own image.

Fig 7. 09. Exterior Render. Author's own image.

Fig 7. 10. Exploded Diagram. Author's own image.

Fig 7. 11. Park Plan. Author's own image. 
Fig 7. 12. Park Render. Author's own image.

Fig 7. 13. Simulation Gallery Render. Author's own image.

Fig 7. 14. Room Variation Diagrams. Author's own image.

Fig 7. 15. Room Placement Diagram. Author's own image.

Fig 7. 16. Two Neighbours Opening Walls To Interact. Author's own image.

Fig 7. 17. Eight Apartment Configurations. Author's own image.

Fig 7. 18. Green Room Diagram. Author's own image.

Fig 7. 19. Green Room Render. Author's own image.

Fig 7. 20. Typical Floor Plan. Author's own image.

Fig 7. 21. Elevations. Author's own image.

Fig 7. 22-25. Model Photos. Model by author. Photographs by author.

\section{Chapter Eight: Discussion}

Fig 8. 01. Exterior Render. Author's own image.

Fig 8. 02. Intervention. Author's own image.

\section{Bibliography/Appendix:}

Fig 9. 01. Elevations. Author's own image.

Fig 10. 01. Initial Concept Model. Author's own image.

Fig 10. 02. Animation Stills for Design Stage Two. Author's own image/video stills.

Fig 10. 03. Design Stage One, Section. Author's own image.

Fig 10. 04-07. Design Stage Three. Author's own image. 

Appendix 


\section{Initial Concept Model}
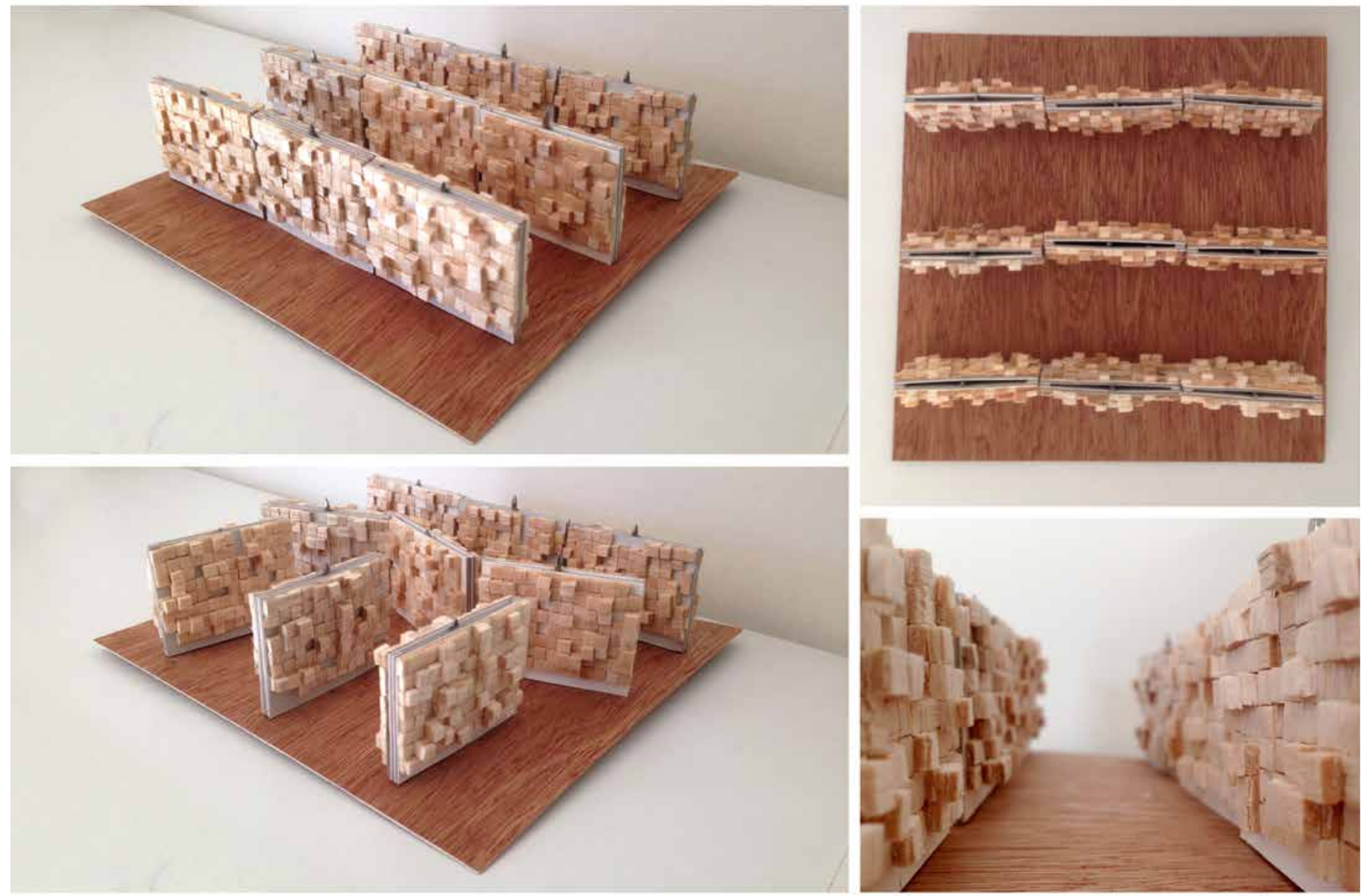

Fig 10. 01. Initial Concept Model: Exploring Moving Buildings and Mass Housing. 


\section{Design Stage Two: \\ Animation}

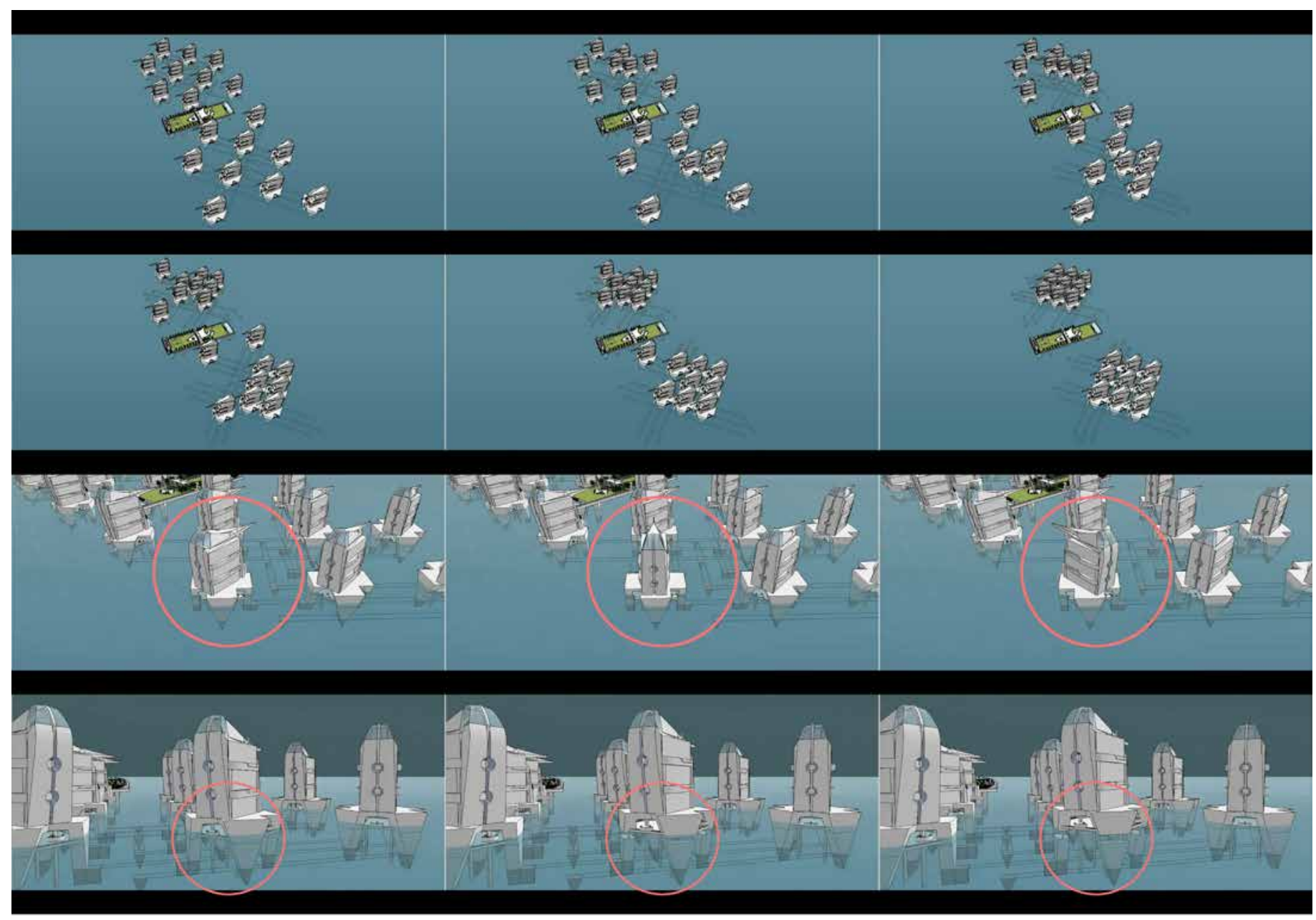

Fig 10. 02. Animation Stills for Design Stage Two: Towers Moving On Rails, Rotating and Moving Vertically on Hydraulic System. 
Supplementary Factory

\section{Concept}

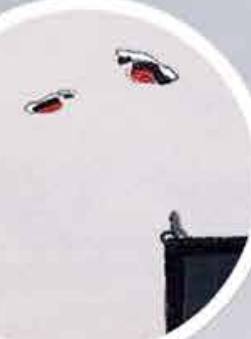

TEMPORARILY

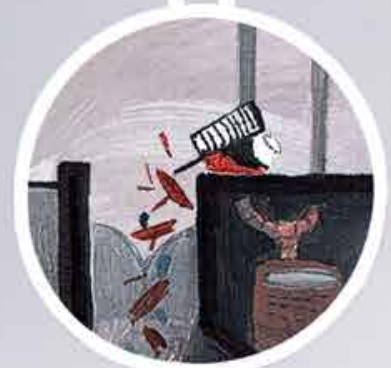

MATERIALS

TRANSPORTED

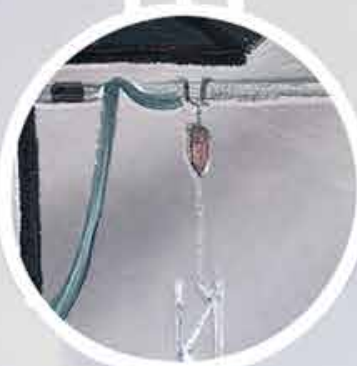

PARTS 3D

PRINTED

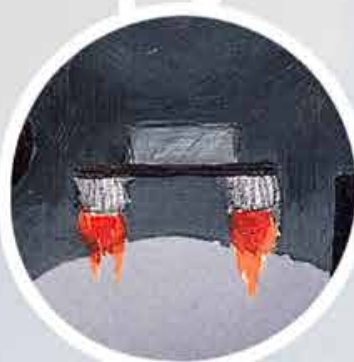

PARTS STORED/ TRANSPORTED

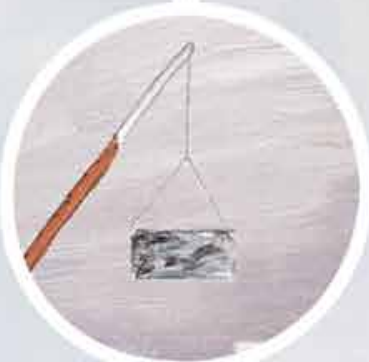

CONSTRUCTION

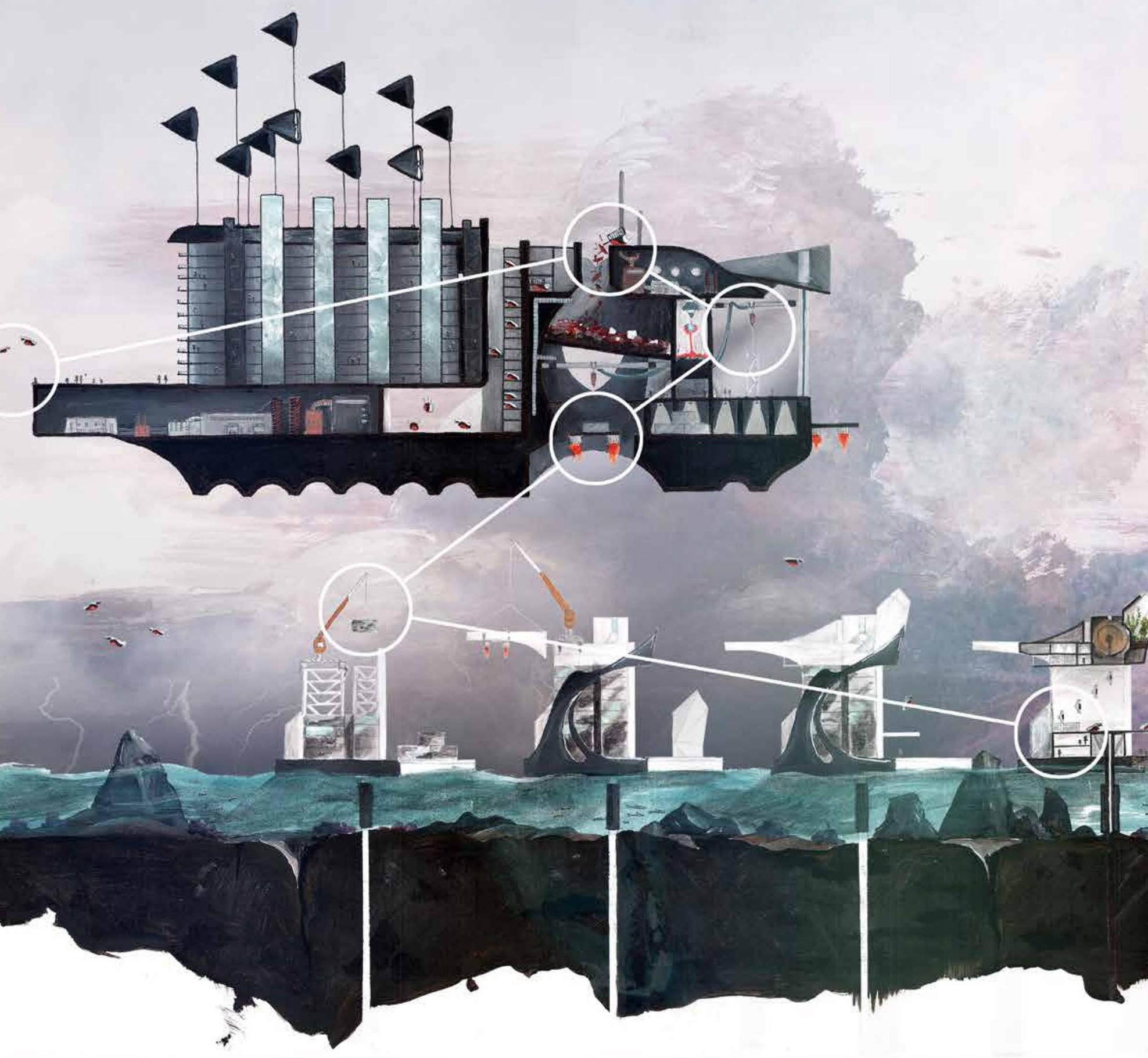




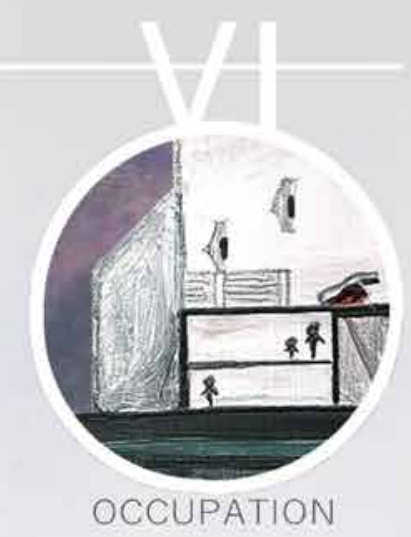




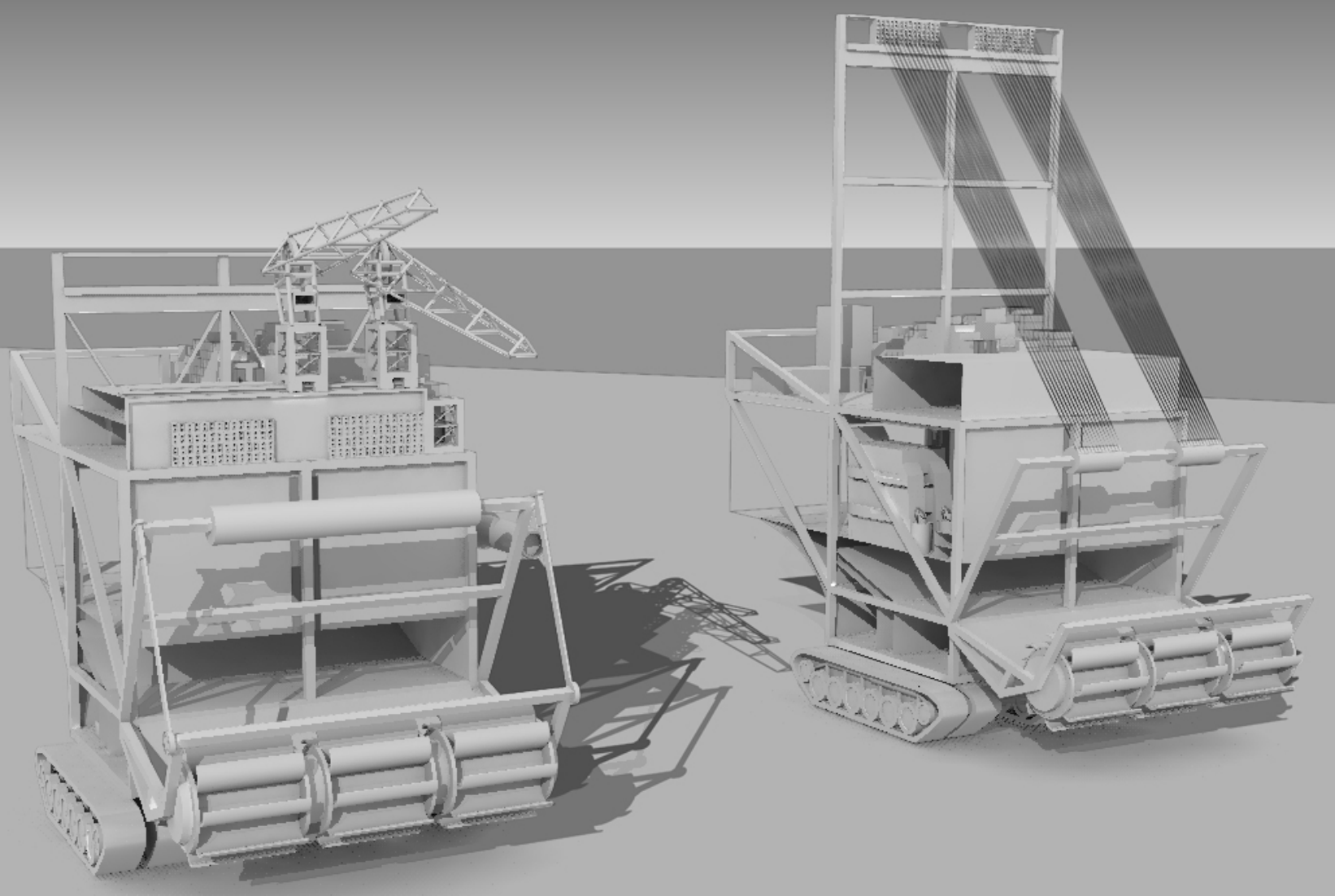

Fig 10. 04-07. Design Stage Three: Grounded Factory Development.

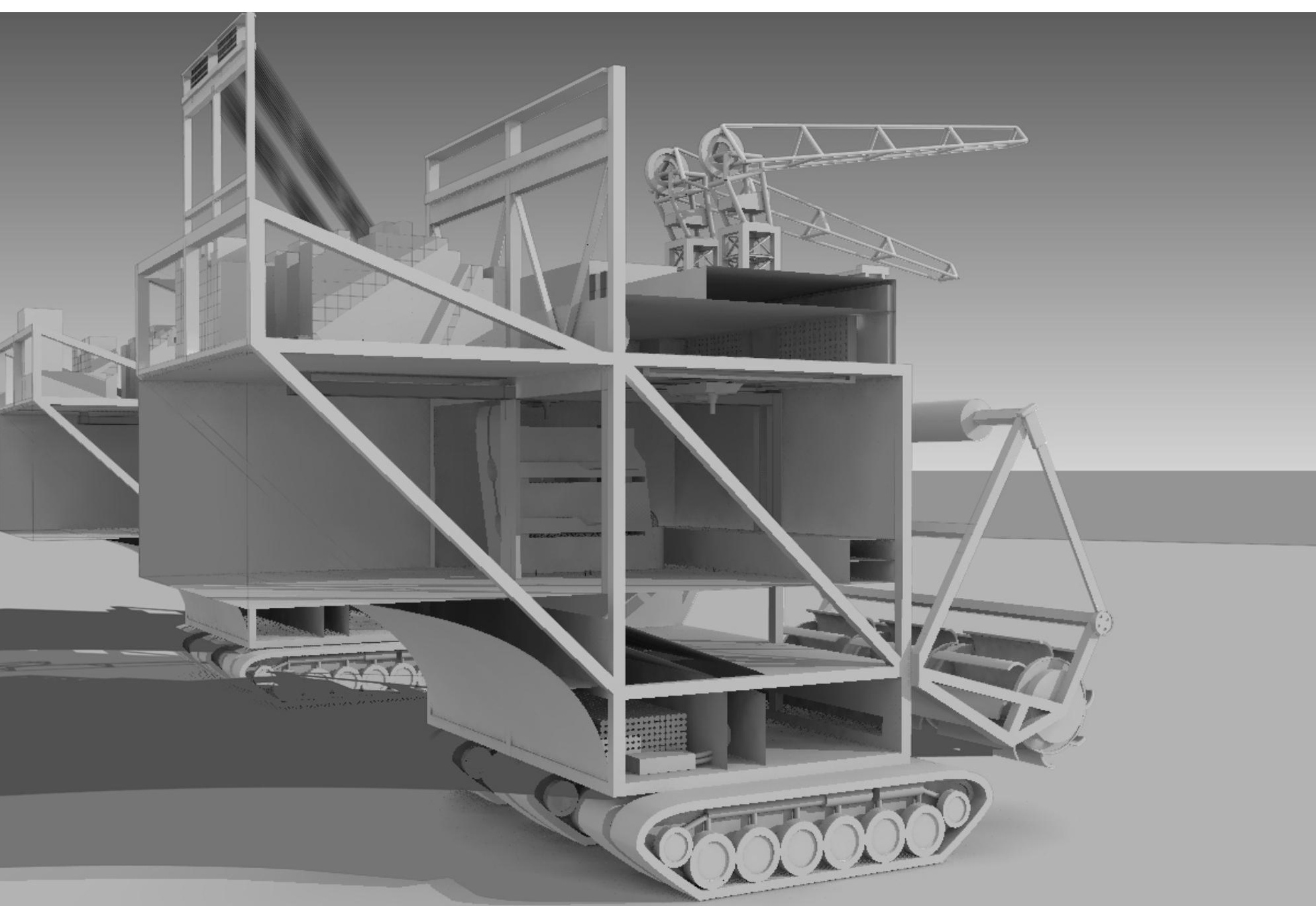



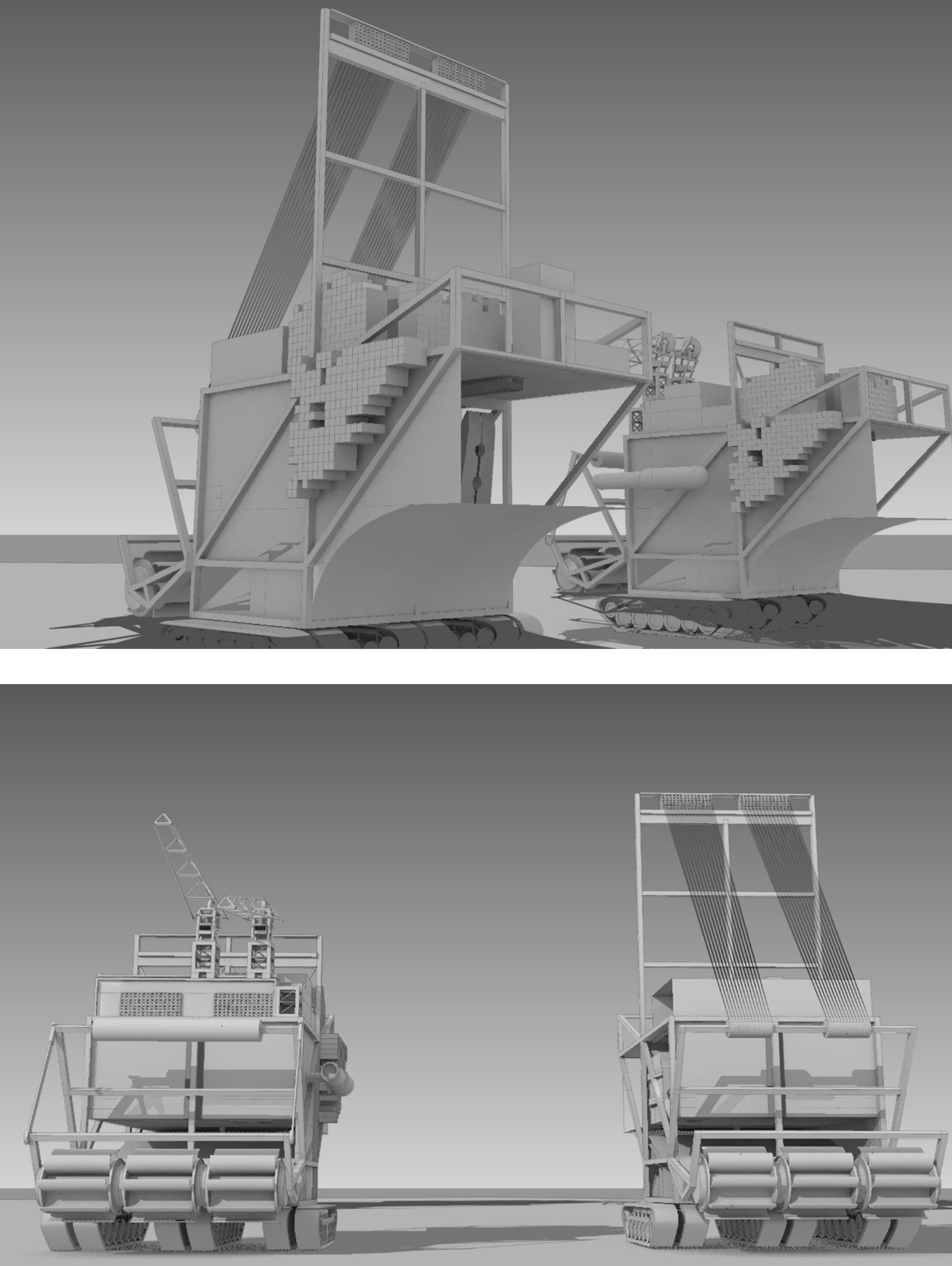

fin 